MARIA FERNANDA TERRA

\title{
O TRATAMENTO DIRETAMENTE SUPERVISIONADO ("DOTS") COMO ESTRATÉGIA PARA A ADESÃO AO TRATAMENTO DA TUBERCULOSE: SIGNIFICADOS SEGUNDO PROFISSIONAIS DE SAÚDE DA SUPERVISÃO TÉCNICA DE SAÚDE DO BUTANTÃ, SÃO PAULO - SP
}

Dissertação apresentada à Escola de Enfermagem da Universidade de São Paulo para a obtenção do título de Mestre em Enfermagem.

Área de concentração:

Enfermagem em Saúde Coletiva

Orientadora:

Prof ${ }^{a}$. Dr ${ }^{\mathrm{a}}$. Maria Rita Bertolozzi 


\section{AUTORIZO A REPRODUÇÃO E DIVULGAÇÃO TOTAL OU PARCIAL DESTE TRABALHO, POR QUALQUER MEIO CONVENCIONAL OU ELETRÔNICO, PARA FINS DE ESTUDO E PESQUISA, DESDE QUE CITADA A FONTE.}

Catalogação na Publicação (CIP)

\section{Biblioteca "Wanda de Aguiar Horta"}

Escola de Enfermagem da Universidade de São Paulo

Terra, Maria Fernanda.

O Tratamento Diretamente Supervisionado (“DOTS") como estratégia para a adesão ao tratamento da tuberculose: significados segundo profissionais de saúde da Supervisão Técnica de Saúde do Butantã, São PauloSP. / Maria Fernanda Terra. - São Paulo, 2007. $168 \mathrm{p}$.

Dissertação (Mestrado) - Escola de Enfermagem da Universidade de São Paulo.

Orientadora: Prof ${ }^{\underline{a}} \mathrm{Dr}^{\mathrm{a}}$ Maria Rita Bertolozzi.

1. Tuberculose (tratamento) 2. Profissionais da saúde (São Paulo) 3. Processo saúde-doença 4. Pesquisa qualitativa (enfermagem).

I. Título. 
"O Homem deve ser o sujeito de sua própría educação".

Paulo Freire 
À Deus

Ao Pablo, minha vida, pelo amor e apoí incondicional

À minha querida mãe Aos meus familiares

Aos meus amigos

À vida, pela oportunidade 


\section{AGRADECIMENTOS}

À professora Doutora Maria Rita Bertolozzi, a quem admiro e respeito pela dedicação, apoío, confiança, valorização $e$ constante incentivo ao orientar-me neste trabalho.

Às professoras Doutoras Margarida María Mattos Brito de Almeida e Renata Ferreira Takahashi pela participação no Exame de Qualificação, contribuindo com valiosas observações.

À Mia Umeda, pelo constante apoío e incentivo durante toda a trajetóría.

ม̇ Ivana Abe, Coordenadora da UBS Jardim São Jorge, pela amizade, apoio e compreensão.

Às colegas de trabalho da equipe verde do PSF Jardim São Jorge, Cynthia, Thais, Elidia, Adriana, Mikaely, Sífvia, Daniela, Elisabete, Ana Maria e Débora pelo carinho e apoio. 
Às enfermeiras do PSF Jardim São Jorge, Daniela, Eluane, Elisabeth, Renata e Líbia, pela amizade, carinho e compreensão.

ม̀ Supervisão Técnica de Saúde do Butantã pela oportunidade oferecida em autorizar a realização deste trabalho, e confiar que o resultado dele será revertído para a melhoria na prátíca diáría do serviço.

Aos profissionais de saúde das Unidades Básicas de Saúde da região da Supervisão Técnica de Saúde do Butantã por participarem deste trabatho e contribuirem para desvendar a realidade de saúde e de vida da regiáo.

À Branca Vaidergorn e Rosa María Cutolo Martins, Coordenadoras do PSF na SUVIS Butantã pelo apoio.

À $\mathcal{N a d i r}$ Aparecida Lopes, bibliotecáría do serviço de Bíblioteca e Documentação da $\mathcal{E}$ EUSP, pela disponibilidade na revisão das referências bibliográficas. 
ג̇ Marine de Souza Pereira, pela revisão do texto deste trabalho.

Ao Pablo Costa e Charlotte Victoria Cowell pelo apoio na tradução do resumo para o inglês.

À Mónica Cecília De-La-Torre-Ugarte-Guanilo pelo apoío na tradução do resumo para o espanhol.

Aos colegas do Grupo de Estudos "Adesão, necessidades e vulnerabilidade em Saúde Coletiva" pelo apoio, incentivo e observações pertinentes para este estudo.

$\mathcal{A}$ todos que não menciono agora, mas cuja presença foi definitiva na construção desta trajetóría. 


\section{RESUMO}

Terra MF. O Tratamento Diretamente Supervisionado (DOTS) como estratégia para a adesão ao tratamento da tuberculose: significados segundo profissionais de saúde da Supervisão Técnica de Saúde do Butantã, São Paulo - SP [dissertação]. São Paulo (SP): Escola de Enfermagem da USP; 2007.

O estudo teve como principal objetivo analisar a adesão ao tratamento da tuberculose a partir da operacionalização da estratégia Tratamento Diretamente Supervisionado (DOTS), sob a perspectiva de profissionais de saúde que atuavam no controle da doença na região da Supervisão Técnica de Saúde do Butantã - SP. Trata-se de pesquisa qualitativa, baseada nos pressupostos da Teoria da Determinação Social do Processo Saúde-Doença e no conceito de Adesão. No período de maio a julho de 2006, foram entrevistados 22 profissionais de saúde das Unidades Básicas de Saúde (UBS) que desenvolviam a estratégia, incluindo os Coordenadores destas UBS. Foram resguardados os procedimentos éticos. Utilizou-se de técnica de análise de discurso apropriada para o tratamento dos depoimentos, que foram decompostos e analisados a partir das categorias analíticas: significados sobre o processo saúde-doença, a forma como se organiza o trabalho na unidade de saúde, os significados sobre a DOTS e sobre a adesão ao tratamento. Os resultados mostram que, de modo geral, os sujeitos do estudo consideram a tuberculose a partir da perspectiva da multicausalidade, ainda que com ênfase nos aspectos sociais. Identificaramse atitudes que revelam estigma, decorrentes da falta de conhecimento a respeito da enfermidade e da forma como relacionar-se com o doente. Evidenciaram-se problemas na organização dos serviços, que se referem à trajetória percorrida pelos pacientes para ter acesso ao diagnóstico da tuberculose, além da ausência da busca de sintomáticos respiratórios. Quanto à DOTS, sua estruturação é diversa entre as UBS, no intuito de considerar as necessidades dos doentes no processo terapêutico, mas também devido à falta de conhecimentos dos profissionais, no que diz respeito à operacionalização da estratégia. A equipe de enfermagem é a que mais intensamente participa da DOTS. Para os profissionais de saúde, a estratégia permite manter atenção junto ao doente evitando o abandono do tratamento. Reitera-se, com algumas ressalvas, que a estratégia apresenta impacto na adesão, uma vez que possibilita a criação de vínculo entre o profissional de saúde e o doente. Além disso, verificou-se a necessidade de ampliar o entendimento a respeito do conceito de adesão, dado que não se restringe a um comportamento pessoal e volitivo.

Palavras-chave: Tuberculose, Adesão, Adesão ao tratamento, DOTS, tratamento supervisionado 


\begin{abstract}
Terra MF. The Directly Observed Treatment (DOTS) as a strategy to improve compliance with tuberculosis treatment: meanings according to Health professionals from the Technical Supervision of Health at Butantã, in the city of São Paulo, Brazil. [Dissertation]. São Paulo (SP): Escola de Enfermagem da USP; 2007.
\end{abstract}

The main goal to this research was to analyze the compliance with tuberculosis therapy by use of the DOTS strategy - (Directly Observed Treatment), under the perspective of health professionals' who carried out the control of tuberculosis in the Supervision of Health region of Butantã in the city of São Paulo, Brazil. This is a qualitative research based on the principles of the Social Determination of the Health-Disease Process Theory and of the concept of compliance. From May to July 2006, 22 Health professionals from the Health Basic Units (HBU), who developed the DOTS strategy, were interviewed, including their unit's coordinators. Ethical procedures were applied to protect them. By using the appropriate speech analysis technique for the handling the collected material, the interviews were fragmented and analyzed according to analytic categories: understanding about the health-disease process, the way that the work is organized within the Health Unit, the meanings about the DOTS and about the compliance with treatment. The results show that, in general, the subjects of this study consider tuberculosis from the perspective of multicausality, even though with emphasis in the social aspects. Attitudes that reveal stigma were identified, derived from the lack of knowledge about the illness and the way of interacting with the patient. Some problems occurred in the organization of the services that refer to the path taken by the patients to having access to the diagnosis of tuberculosis, as well as the lack of search for respiratory symptomatic. With regards to the DOTS, its structure is diverse among the $\mathrm{HBU}$, in the intention of considering the patients' needs in the therapeutic process, but also due to the lack of knowledge of the professionals, when it comes to exercising the strategy. The nursing team is the one which participates most intensely in the DOTS. For the health professionals, the strategy allows them to pay close attention to the patient avoiding any dropping out of the treatment. It is certain, with some exceptions, that the strategy has some impact in its initiation, once it allows for a relationship to be created between the health professional and the patient. It was also verified that there is a need to further unfold the understanding of the concept of initiating this strategy, since it isn't restricted to a personal behavior or to free will.

Key words: Tuberculosis, Compliance, Compliance to treatment, DOTS, supervised treatment 


\section{RESUMEN}

Terra MF. El Tratamiento Acortado Directamente Supervisado (TAES) como estrategia para la adhesión al tratamiento de tuberculosis: significados según los profesionales de salud de la Supervisión Técnica de Salud de Butantã, São Paulo - SP, El Brasil. [tesis de maestría]. São Paulo (SP): Escuela de Enfermería de la USP; 2007.

Este estudio tuvo como principal objetivo analizar la adhesión al tratamiento de tuberculosis, a partir de la operacionalización de la estrategia Tratamiento Acortado Directamente Supervisado (TAES). El análisis estuvo basado en la perspectiva de los profesionales de salud, que participaron en el control de la enfermedad, en la región de la Supervisión Técnica de Salud de Butantã SP, El Brasil. Se realizó una pesquisa cualitativa, basada en los principios de la Teoría de la Determinación Social del Proceso Salud - Enfermedad, y en el concepto de Adhesión. En el periodo de mayo a julio del 2006, fueron entrevistados 22 profesionales de las Unidades Básicas de Salud (UBS) que realizaron la estrategia, así como los Coordinadores de las UBS y del programa en la Supervisión Técnica de Salud de Butantã. Fueron resguardados los procedimientos éticos. Se utilizó la técnica de análisis de discurso, apropiada para el análisis de las declaraciones, las cuales fueron descompuestas y analizadas a partir de las categorías analíticas: significados sobre el proceso salud-enfermedad, la forma como se organiza el trabajo en la unidad de salud, los significados sobre el TAES y sobre la adhesión al tratamiento. Los resultados muestran que, de forma general, los sujetos del estudio consideran la tuberculosis a partir de la perspectiva de la multicausalidad, no obstante, con énfasis en los aspectos sociales. Se identificaron actitudes que revelan estigma, las cuales resultan de la falta de conocimiento al respecto de la enfermedad y de la forma como se relacionan con el enfermo. Se evidenció problemas en la organización de los servicios, referidos a la trayectoria recorrida por los pacientes para tener acceso al diagnóstico de la tuberculosis, además de la falta de búsqueda de los sintomáticos respiratorios. En lo que se refiere a TAES, su estructuración es diversa entre las UBS, debido a la tentativa de considerar las necesidades de los enfermos en el proceso terapéutico, pero también, por la falta de conocimientos de los profesionales, referente a la operacionalización de la estrategia. El equipo de enfermería es el que más intensamente participa del TAES. Para los profesionales de salud, la estrategia permite mantener atención al enfermo evitando el abandono del tratamiento. Se reitera, con alguna reserva, que la estrategia presenta impacto en la adhesión, una vez que posibilita la creación de vínculo entre el profesional de salud y el enfermo. Además, se verificó la necesidad de ampliar el entendimiento, al respecto del concepto de adhesión, debido que no se restringe a un comportamiento personal y volitivo.

Palabras clave: Tuberculosis, Cooperación del paciente, adhesión al tratamiento, TAES, Tratamiento Supervisado 


\section{Sumário}

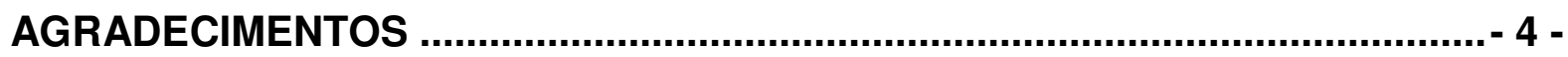

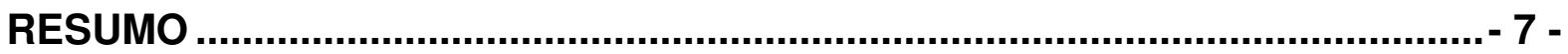

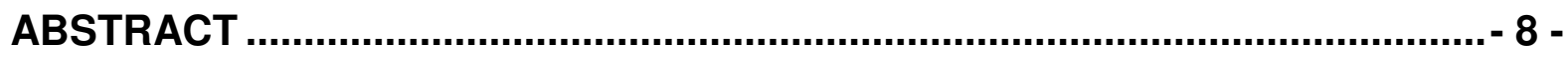

RESUMEN

APRESENTAÇÃO .............................................................................. 15 -

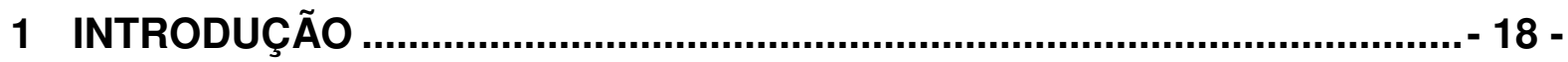

1.1 A CONSTRUÇÃO DO OBJETO DO ESTUDO.......................................................... 19 -

1.1.1 O PERFIL EPIDEMIOLÓGICO DA TUBERCULOSE ........................................ 23 -

1.2 BREVE HISTÓRICO DO CONTROLE DA TUBERCULOSE NO BRASIL.................. 27 -

1.3 O TRATAMENTO DIRETAMENTE SUPERVISIONADO (DOTS) ............................. 31 -

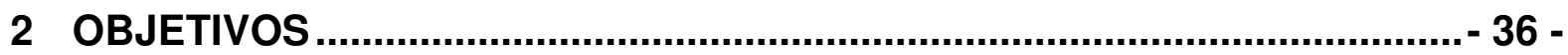

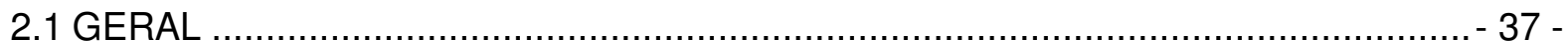

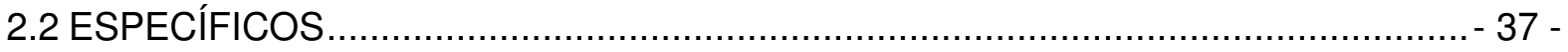

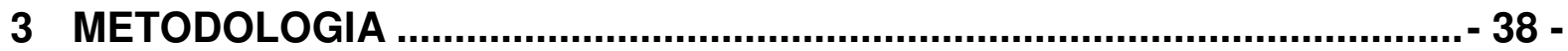

3.1 A OPÇÃO METODOLÓGICA: CONSIDERAÇÕES GERAIS .................................... 39 -

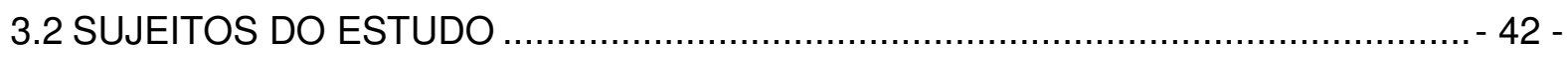

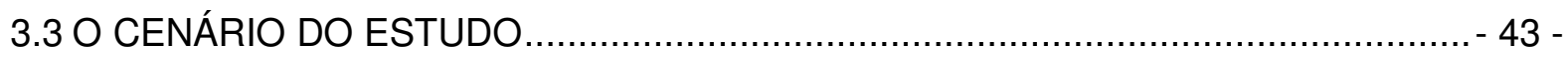

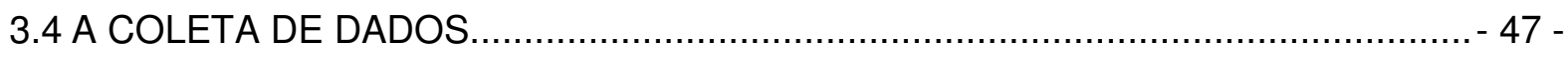


3.5 ETAPAS DO TRABALHO

3.5.1 OS INSTRUMENTOS UTILIZADOS.

3.5.2 TESTE PILOTO $49-$

3.6 PROCEDIMENTOS ÉTICOS $49-$

3.6.1 CATEGORIAS EMPÍRICAS $-50-$

3.6.2 CATEGORIAS ANALÍTICAS 51

3.7 ANÁLISE DOS DEPOIMENTOS $51-$

4 RESULTADOS $-55-$

4.1 OS COORDENADORES DOS SERVIÇOS DE SAÚDE $57-$

4.1.1 OS SIGNIFICADOS SOBRE O PROCESSO SAÚDE-DOENÇA $-58-$

4.1.2 A FORMA COMO SE ORGANIZA O TRABALHO NA UBS. $60-$

4.1.3 OS SIGNIFICADOS SOBRE O TRATAMENTO SUPERVISIONADO (DOTS) $64-$

4.1.4 OS SIGNIFICADOS SOBRE A ADESÃO AO TRATAMENTO. $66-$

4.2 OS PROFISSIONAIS DE SAÚDE QUE PARTICIPAM DA DOTS NO COTIDIANO. 68

4.2.1 OS SIGNIFICADOS SOBRE O PROCESSO SAÚDE-DOENÇA $-69-$

4.2.2 A FORMA COMO SE ORGANIZA O TRABALHO NA UBS. $-71-$

4.2.3 OS SIGNIFICADOS SOBRE O TRATAMENTO SUPERVISIONADO (DOTS) ....... 72 -

4.2.4 OS SIGNIFICADOS SOBRE A ADESÃO AO TRATAMENTO. $-77-$

5 DISCUSSÃo $-80-$ 
5.2 OS SIGNIFICADOS SOBRE O PROCESSO SAÚDE-DOENÇA

5.3 A FORMA COMO SE ORGANIZA O TRABALHO NA UBS

5.4 OS SIGNIFICADOS SOBRE O TRATAMENTO SUPERVISIONADO (DOTS) 101

5.5 OS SIGNIFICADOS SOBRE A ADESÃO AO TRATAMENTO $-111-$

6 CONCLUSÕES E CONSIDERAÇÕES FINAIS $118-$

7 REFERÊNCIAS BIBLIOGRÁFICAS. $127-$ ANEXOS. $137-$ 


\section{LISTA DE TABELAS, FIGURAS E QUADROS}

Tabela 1 - Número de casos notificados, coeficiente de incidência, número de óbitos e coeficiente de mortalidade por ano. Supervisão Técnica de Saúde do Butantã - SP. São Paulo, 2005. $-25-$

Tabela 2 - Cobertura da estratégia DOTS em alguns países das Américas, 2001 $-32-$

Tabela 3 - Pacientes bacilíferos, forma pulmonar de tuberculose, atendidos em TS e cobertura da DOTS no Município de São Paulo - SP. São Paulo, 1998-2000. 34

Tabela 4 - Pacientes bacilíferos, forma pulmonar de tuberculose, atendidos em TS e cobertura DOTS na região da Supervisão Técnica de Saúde do Butantã - SP. São Paulo, 1998 - 2005. -35 -

Figura 1 - Área territorial de abrangência da região da Supervisão Técnica de Saúde do Butantã - SP. - 44 -

Tabela 5 - UBS que integraram o estudo na região da Supervisão Técnica de Saúde do Butantã - SP. São Paulo, 2006. -46 -

Quadro 1 - Características dos sujeitos entrevistados na região da Supervisão Técnica de Saúde do Butantã - SP. São Paulo, 2006.... - 56 -

Quadro 2 - Relação das Unidades Básicas de Saúde, freqüência da DOTS e incentivos oferecidos na região da Supervisão Técnica de Saúde do Butantã - SP. São Paulo, 2006. - 57 - 


\section{LISTA DE ABREVIATURAS E SIGLAS}

ACS

AIDS

BCG

CAPS

CCD

CEME

$\mathrm{Cl}$

$\mathrm{CM}$

CNCT

DAB

DNPS

DNT

DOTS

DST

ESF

HIV

MS

OMS

ONG

OPAS

PAS

PCT

PNCT

PSF

SESP

SNT

SUS

SUVIS

TB

TS

UBS

WHO
Agente Comunitário de Saúde

Acquired Immune Deficiency Syndrome

Bacilo Biliado de Calmette e Guérin

Centro de Atenção Psicossocial

Coordenadoria de Controle de Doenças

Central de Medicamentos

Coeficiente de Incidência

Coeficiente de Mortalidade

Campanha Nacional Contra a Tuberculose

Departamento de Atenção Básica

Divisão Nacional de Pneumologia Sanitária

Divisão Nacional de Tuberculose

Directly Observed Therapy Short Course

Doença Sexualmente Transmissível

Equipe de Saúde da Família

Human Immunodeficiency Virus

Ministério da Saúde

Organização Mundial da Saúde

Organização Não Governamental

Organização Pan-Americana da Saúde

Plano de Atendimento à Saúde

Programa de Controle da Tuberculose

Programa Nacional de Controle da Tuberculose

Programa Saúde da Família

Fundação Serviço Especial de Saúde Pública

Serviço Nacional de Tuberculose

Sistema Único de Saúde

Supervisão Técnica de Saúde

Tuberculose

Tratamento Supervisionado

Unidade Básica de Saúde

World Health Organization 
APRESENTAÇÃO 


\section{APRESENTAÇÃO}

O presente estudo refere-se à implementação da estratégia Directly Observed Therapy Short-Course (DOTS), também conhecido no Brasil por Tratamento Supervisionado (TS), a qual tem sido adotada para o controle da tuberculose em âmbito mundial. Tendo em vista a escassez de estudos que revelem a forma como os profissionais de saúde interpretam a estratégia, especialmente no âmbito do Município de São Paulo, cidade que revela complexidade que a torna particular em termos de organização dos processos de produção e de reprodução social, incluindo a organização da saúde, este estudo teve por objetivo apreender os significados da DOTS para profissionais de saúde. Isso inclui médicos, enfermeiras e auxiliares de enfermagem de Unidades Básicas de Saúde (UBS), além dos coordenadores destas mesmas UBS, além do o profissional responsável pela condução do Programa de Controle da Tuberculose junto à Supervisão Técnica de Saúde do Butantã - São Paulo (SP).

A relevância epidemiológica da tuberculose no Município de São Paulo, mais especificamente na região da Supervisão Técnica de Saúde do Butantã, mostra-se, dentre outros indicadores, pelas elevadas taxas de abandono do tratamento e alto índice de re-tratamento. Nessa região, em $2004,32,1 \%$ dos pacientes foram mantidos sob o Tratamento Supervisionado, taxa que se apresentou pouco abaixo da média do Município de São Paulo, que foi de $33,1 \%$ no mesmo ano. Mas, mesmo assim, valores muito distantes da meta da OMS, que recomenda a adoção 
da DOTS para a totalidade dos doentes em todos os países (São Paulo, 2005a).

Diversamente do que ocorre na literatura internacional, há registros escassos, na literatura científica nacional, de publicações que evidenciam aspectos da implementação da estratégia, principalmente quando se trata de análises qualitativas que retratem os significados concebidos por profissionais de saúde no âmbito do Município de São Paulo. Conforme anteriormente apontado, tais exibem extrema complexidade social e epidemiológica.

Portanto, este estudo teve por finalidade buscar preencher essa lacuna, procurando identificar os limites e as potencialidades dessa estratégia no processo de adesão dos doentes ao tratamento da tuberculose. Com a sua realização, pretendeu-se contribuir para a reorganização da assistência prestada aos portadores da enfermidade e melhorar o desenvolvimento do Programa de Controle da Tuberculose nessa região, o que pode apoiar a implementação da estratégia em outras localidades.

É importante destacar que o estudo foi desdobramento do projeto matriz: "A adesão ao tratamento da tuberculose na perspectiva do Tratamento Diretamente Supervisionado ("DOTS") no Município de São Paulo", que integra uma linha de pesquisa que se refere ao estudo da categoria analítica adesão, desenvolvido no âmbito do Departamento de Enfermagem em Saúde Coletiva da Escola de Enfermagem da Universidade de São Paulo, subvencionado pela FAPESP, CNPq e Programa P1 da PróReitoria de Pesquisa da Universidade de São Paulo. 


\section{INTRODUÇÃO}




\section{INTRODUÇÃO}

\subsection{A construção do objeto do estudo}

A prática profissional fez possível perceber que muitos são os motivos relacionados à manutenção, ou não, do tratamento da tuberculose pelos doentes. A experiência junto ao cotidiano de trabalho revelou elevado número de pacientes em re-tratamento, ainda mantidos sob o esquema auto-administrado, com risco de não manterem a terapia medicamentosa corretamente.

Ao lado da adesão ao tratamento, agregam-se outras questões que tornam complexo o controle da tuberculose, como o estigma da doença ou o efeito de "cura" após o início do tratamento, quando, após o seu início, o doente sente-se recuperado e apto para retornar às atividades da vida e do trabalho, e pode vir a deixar de tomar a medicação. Além disso, outros aspectos são muito relevantes, como as dificuldades no acesso aos serviços de saúde, assim como problemas na sua organização, incluindo a forma como se realizam os processos de trabalho que, via de regra, desconsideram a historicidade do indivíduo e sua inserção social e, portanto, suas necessidades (Bertolozzi, 1998, 2005).

A não adesão mostra-se pelo tratamento irregular, abandono precoce ou tardio, o que pode resultar na forma multirresistente da doença. Via de 
regra, os estudos evidenciam uma série de fatores relacionados ao abandono do tratamento, sem o estabelecimento de peso ou hierarquia entre os mesmos, ressaltando-se determinadas condições, como a co-infecção pelo HIV, a história de tratamento anterior para tuberculose, o hábito de ingerir bebida alcoólica, dentre outros (Dehenzelin et al., 1996; Costa et al., 1998; Albuquerque et al., 2001).

Segundo o Ministério da Saúde, em pacientes sob o tratamento autoadministrado, considera-se alta por abandono quando o doente deixa de comparecer à Unidade Básica de Saúde por 30 dias consecutivos após a data prevista para seu retorno. Para os pacientes sob o Tratamento Supervisionado, o prazo de 30 dias é contado a partir da última tomada da droga (Brasil, 2002b).

Buscando superar as interpretações que multifatorializam o abandono ao tratamento, Bertolozzi $(1991,1998,2005)$, advoga que a adesão ao tratamento transcende a clínica tradicional que, historicamente, propõe alternativas de solução aos problemas na lógica biológica. A autora propõe que o processo de adesão está relacionado à forma como o paciente concebe a doença e como vive a vida. Além disso, propõe que, a depender das condições em que se encontra o momento de vida do paciente, outras questões podem apresentar-se mais relevantes do que a busca por assistência à saúde, como no caso de responder às demandas decorrentes da própria sobrevivência e de sua família, processo que pode fazê-lo deixar em segundo plano o cuidar de si mesmo. 
Costa et al. (1998) ilustram de certo modo essa afirmação, ao apontarem que a procura pelo serviço ocorre, na maior parte das vezes, nos momentos de muita debilidade física, quando o corpo já não consegue cumprir com as tarefas do cotidiano.

Assim, o presente estudo toma a enfermidade como um momento do processo saúde-doença, que está diretamente articulado aos processos que se desenvolvem nas dimensões estrutural, particular e singular (Egry, 1996). A dimensão estrutural compreende os processos de desenvolvimento da capacidade produtiva e das relações de produção, da formação econômica e social e das formas político-ideológicas que legitimam a organização social. A dimensão particular compreende os processos de reprodução social que se manifestam nos perfis epidemiológicos de classe e no perfil saúdedoença. A dimensão singular compreende os processos mais próximos ao indivíduo que, em última instância, levam a adoecer e a morrer (Egry; Fonseca; Bertolozzi, 1994; Egry, 1996).

Assim, é necessário afirmar que o processo saúde-doença de um dado grupo social não pode ser entendido isoladamente, dissociado dos fenômenos que operam na realidade social. Dessa forma, a organização dos serviços também pode condicionar a adesão ao tratamento. Segundo Galesi (1998), que estudou os óbitos por tuberculose como causa básica, no Município de São Paulo, período de 1986 a 1995, as redes de serviços de saúde não têm conseguido garantir, na totalidade dos casos, ações que incluem o diagnóstico em tempo hábil, o tratamento e a consecução da cura, e o que acaba por ocorrer é o abandono do tratamento pelo doente. 
Corroborando essas informações, Campinas (2004), em estudo realizado no Município de São Paulo, no ano de 2003, faz referência ao período de um a seis meses até o diagnóstico definitivo e, dentre os casos estudados, a autora identificou que apenas para $28 \%$ dos pacientes investigados, o diagnóstico foi obtido em menos de trinta dias.

Além da questão relativa à adesão/abandono, outra informação pode ajudar a entender as dificuldades de controle da tuberculose, e se refere ao fato de que, em geral, os trabalhadores desconhecem as necessidades da clientela que atendem. Ora, o desempenho dos profissionais de saúde nos serviços pode potencializar ou limitar o processo da adesão, condicionando o envolvimento do doente em seu processo terapêutico. Neste sentido, todo o complexo que envolve o imaginário do doente portador de tuberculose, a forma como a doença por ele é percebida, assim como os modos de enfrentamento individual do processo saúde-doença podem propiciar certas condições que resultariam na adesão ou no abandono do tratamento (Bertolozzi, 1998, 2005).

Ademais, a compreensão dos profissionais de saúde a respeito do modo como os pacientes entendem o processo saúde-doença também é fundamental, pois, de igual maneira, pode apoiar (ou não) o desenvolvimento do projeto terapêutico. Ainda é importante destacar, conforme anteriormente se apontou muito rapidamente, que a ocorrência da tuberculose está diretamente associada à organização e estruturação da sociedade, que acaba por fortalecer/limitar as condições de vida que podem 
tornar vulneráveis os indivíduos ao desenvolvimento da enfermidade (Costa et al., 1998; Ruffino-Netto; Souza, 1999).

No sentido de se aproximar à magnitude da tuberculose, apresentarse-ão, a seguir, dados epidemiológicos que retratam a sua situação.

\subsubsection{O perfil epidemiológico da tuberculose}

No ano de 1993, a Organização Mundial da Saúde (OMS) declarou a situação da tuberculose em estado de urgência, ocasião em que foi considerada como "calamidade negligenciada", conforme aponta RuffinoNetto (2002). Para ele, a problemática da tuberculose foi deixada de lado pelas autoridades e profissionais de saúde, por ser considerada doença do passado, inclusive para os formadores de profissionais de saúde.

Em 2005, a incidência global da tuberculose foi de cento e trinta e seis casos por cem mil habitantes, sendo que, destes, em sessenta casos por cem mil habitantes foram especificamente casos bacilíferos (World Health Organization, 2007). Segundo a OMS, 2005, dos cento e noventa e nove países que notificavam os casos de tuberculose, vinte e dois foram responsáveis por $80 \%$ dos casos em âmbito mundial, e responsáveis por $25 \%$ das mortes evitáveis, sendo todos estes, países subdesenvolvidos (Ruffino-Netto; Souza, 1999; World Health Organization, 2003; World Health Organization, 2005a). 
Segundo a Organização Pan-Americana da Saúde, no ano de 2005 foram notificados cento e cinqüenta e sete mil novos casos de doentes bacilíferos. Dos casos notificados nas Américas, 50\% concentravam-se no Brasil e no Peru. Atualmente, o Brasil ocupa a quinta posição no "ranking" de casos no continente Americano e a décima no "ranking" mundial (Organización Pan-Americana de la Salud, 2004; World Health Organization, 2005a).

No Brasil, os processos de exclusão social, as debilidades no processo de produção em saúde, as altas taxas de abandono, além da magnitude com que incide a AIDS, determinam que a doença apresente elevadas taxas de morbidade e mortalidade, o que reafirma a necessidade de políticas públicas para o controle da enfermidade, ao lado da transformação das condições sociais (Bertolozzi, 1991; Souza et al., 2005).

É importante destacar que a AIDS piora os indicadores de morbimortalidade em relação à tuberculose, pois a infecção pelo HIV diminui a resposta imunológica. Em geral, os portadores de HIV e tuberculose apresentam maior dificuldade na manutenção da terapia medicamentosa, devido às reações resultantes da interação dos medicamentos utilizados, além do estigma decorrente de ambas (Deheinzelin et al., 1996).

No Estado de São Paulo, dentre os oito mil oitocentos e quatro casos notificados no ano de 2005, 12,9\% apresentaram teste HIV positivo, enquanto $39,7 \%$ não foram submetidos a este teste, tendo sido registrados como "sem informação" no sistema de notificação (São Paulo, 2005b). Testes para a identificação do HIV são recomendados a todos os doentes 
diagnosticados desde o ano de 1998, conforme recomenda a Portaria Conjunta $n^{0} 4$ do Programa de DST/AIDS e de Tuberculose do Estado de São Paulo, de 23/10/1998 (São Paulo, 2006).

O número de co-infectados TB/HIV residentes no Município de São Paulo, em 2004, foi de um mil duzentos e vinte doentes. Destes, $76,4 \%$ foram de casos novos, 10,6\% recidivas e 13,0\% re-tratamentos pósabandono. Nesse mesmo ano, houve redução de 10,0\% de co-infectados em relação a 2003, e queda de $8,0 \%$ em relação a 2002, o que pode indicar uma tendência de queda, sobretudo devido à quimioterapia anti-retroviral.

A região Centro-Oeste apresenta o maior percentual de soropositivos em doentes portadores de tuberculose residentes na área, com 20,4\%; seguida da região Sudeste $(14,8 \%)$, Norte $(13,7 \%)$, Leste $(12,2 \%)$ e Sul (6,1\%) (São Paulo, 2006).

A seguir, apresentam-se os dados relativos à enfermidade na região da Supervisão Técnica de Saúde do Butantã, onde se desenvolveu o presente estudo.

Tabela 1 - Número de casos notificados, coeficiente de incidência, número de óbitos e coeficiente de mortalidade por ano. Supervisão Técnica de Saúde do Butantã - SP. São Paulo, 2005.

\begin{tabular}{ccccrrr}
\hline Anos & $\begin{array}{c}\text { Total de casos novos } \\
\text { (todas as formas) }\end{array}$ & $\mathrm{Cl}$ & $\begin{array}{c}\text { Total de casos novos } \\
\text { (TB pulmonar/ bacilíferos) }\end{array}$ & $\mathrm{Cl}$ & Óbitos & $\mathrm{CM}$ \\
\hline 2000 & 234 & 62,0 & 122 & 32,3 & 12 & 3,2 \\
2001 & 220 & 58,3 & 103 & 27,3 & 8 & 2,1 \\
2002 & 217 & 57,5 & 105 & 27,8 & 16 & 4,2 \\
2003 & 213 & 56,4 & 104 & 27,5 & 2 & 0,5 \\
2004 & 188 & 49,8 & 99 & 26,2 & 3 & 0,8 \\
\hline
\end{tabular}

Fonte: São Paulo, 2005c;d;e; 2006

Cl: Coeficiente de Incidência

CM: Coeficiente de Mortalidade 
A tabela anterior apresenta diminuição importante no coeficiente de mortalidade. Apesar de a restrita série de dados não permitir comentar extensamente o quadro epidemiológico, pode-se conjecturar que tal diminuição esteja associada ao período após o Plano de Atendimento à Saúde $\left(\mathrm{PAS}^{1}\right)$, em que houve importante reestruturação do Sistema de Vigilância Epidemiológica, assim como em decorrência da implantação da DOTS a partir do ano de 2001.

Quanto às taxas de cura e abandono, na mesma localidade, no primeiro trimestre de 2004, considerando-se quarenta e seis casos diagnosticados, vinte e sete doentes (58,7\%) alcançaram a cura, enquanto sete (15,2\%) abandonaram o tratamento (São Paulo, 2006).

As informações apresentadas mostram a relevância epidemiológica da tuberculose nesta região do Município de São Paulo, principalmente tendo em vista o potencial de transmissão dos doentes não tratados, ou daqueles que abandonam o tratamento, pois cada doente bacilífero sem tratamento pode transmitir a doença para outras dez a quinze pessoas no período de um ano (Brasil, 2002a).

Conforme anteriormente mencionado, considera-se, neste estudo, que a situação da enfermidade está diretamente associada à forma como se organizam os processos de produção e de reprodução social, assim como à implementação de políticas de controle da doença. Assim, apresenta-se, a seguir, ainda que de forma bastante sintética, a forma como tem ocorrido esse processo.

1 O PAS, modelo de gerenciamento do sistema de saúde que foi implantado em 1996 no Município de São Paulo. Esteve operante até o ano 2000. 


\subsection{Breve histórico do controle da tuberculose no Brasil}

A tuberculose foi introduzida no Brasil pelos portugueses e jesuítas missionários, a partir de 1500, por ocasião do processo de colonização. Nessa época, as questões de saúde eram tratadas através de intervenções focais, dada a limitação do saber a respeito das enfermidades que acometiam a maior parte da população. Num momento imediatamente seguinte, foram amplamente adotadas as "Campanhas Sanitárias", que tinham por objetivo reter as doenças que ameaçavam a produtividade da população, de forma a garantir a comercialização de alimentos e de outros produtos (Bertolozzi, 1991; Ruffino-Netto, 1999).

No século XIX, o atendimento à saúde era realizado principalmente pelas Santas Casas de Misericórdia, presentes em algumas cidades Brasileiras, e os doentes permaneciam com outros numa mesma enfermaria, sem isolamento (Mendes, 1998; Vendramini, 2001). No atendimento aos enfermos portadores de tuberculose, as Santas Casas foram pioneiras e, no ano de 1899 foi fundada a Liga Brasileira Contra a Tuberculose, entidade filantrópica que defendia a criação de sanatórios para o isolamento dos doentes, além de preconizar a adoção de medidas higiênico-dietéticas (Vendramini, 2001).

Em 1920 foi criado o Departamento Nacional de Saúde Pública, período em que o Estado passou a integrar a luta contra a doença, com a criação da Inspetoria de Profilaxia da Tuberculose (Mendes, 1998). 
No ano de 1941 criou-se o Serviço Nacional de Tuberculose que mantinha ações profiláticas e assistenciais. Cinco anos após, foi instituída a Campanha Nacional Contra a Tuberculose, que assumiu como proposta a expansão da estrutura hospitalar e sanatorial em todo o País. A ampliação da estrutura de serviços trazia a idéia da interiorização e uniformização do atendimento, a normatização das ações de saúde e a formação de recursos humanos, abarcando o pessoal de nível médio e superior. Após dois anos, incluíram-se o exame radiológico periódico obrigatório e a vacinação com o BCG oral como elementos que compuseram as ações de controle da enfermidade (Ruffino-Netto, 2002).

Em 1970, o SNT foi transformado em Divisão Nacional de Tuberculose, iniciando a implementação do Programa Nacional de Controle da Tuberculose. Decorrido um ano, foi criada a Central de Medicamentos, responsável pela aquisição gratuita e distribuição das drogas para todo 0 País (Ruffino-Netto, 2002).

Em 1976 era visível o poder e a autonomia do antigo Departamento Nacional de Tuberculose, devido à organização da Divisão Nacional de Pneumologia Sanitária, que passou a coordenar as ações de controle da enfermidade. Nesse período, tornou-se obrigatória a vacinação com o BCG intradérmico (Ruffino-Netto, 2002).

No ano de 1979 foi introduzido o esquema de tratamento de curta duração, de seis meses, com drogas de uso oral. A maioria dos pacientes realizava o tratamento auto-administrado, recebendo os medicamentos em cotas mensais na unidade de saúde (Vendramini, 2001; Ruffino-Netto, 2002). 
Em 1990 iniciou-se o processo de implementação do Sistema Único de Saúde (SUS). Nesse mesmo ano, em função de ações de controle dos gastos públicos e da descentralização da administração para os estados e municípios, o Programa de Controle da doença foi alvo de intensa desestruturação, tendo sido extinta a Campanha Nacional Contra a Tuberculose. Tal fato levou ao enfraquecimento do processo de supervisão do Programa, o qual anteriormente era continuado, o que determinou repercussões importantes, quase que conduzindo à falência do Programa Nacional de Controle da Tuberculose (Ruffino-Netto; Souza, 1999).

Conforme dito anteriormente, no ano de 1993, a OMS decretou a tuberculose em estado de emergência mundial, mas apenas em 1996 o Brasil implantou o Plano de Ação Emergencial para os Municípios Prioritários, que foram definidos a partir da análise de alguns indicadores, tais como: população acima de cinqüenta mil habitantes, incidência da doença superior à média brasileira (58,4/100.000 hab.), óbitos por tuberculose em casos novos acima de $5 \%$, abandono superior a $10 \%$, alta incidência de AIDS e taxa de cura inferior à $85 \%$. Esse Plano definia o repasse de recursos financeiros aos Municípios (Ruffino-Netto, 2002) e, em 1998, foi ampliado, tendo o Conselho Nacional de Saúde, através da Resolução 284, de 06/08/1998, sugerido o estabelecimento de um novo Plano Nacional de Controle da Tuberculose, com as seguintes metas: diagnosticar, até 2001 , pelo menos $92 \%$ dos casos esperados; tratar $85 \%$ dos casos diagnosticados; até 2007, reduzir a incidência da doença em $50 \%$ e diminuir a mortalidade em dois terços (Brasil, 2000). 
Para atingir as metas propostas, foram definidas as diretrizes e responsabilidades do Ministério da Saúde: estabelecer normas, aquisição e abastecimento de medicamentos; constituir referência laboratorial e de tratamento; coordenar o sistema de informação e apoiar Estados e Municípios através de políticas públicas. Nesse novo Plano, todos os municípios passariam a receber incentivos financeiros por montante de pacientes que obtivessem alta por cura (Brasil, 1999).

Em 2000, elaborou-se novo Plano de Controle da Tuberculose para o período de 2001 a 2005, incorporando as equipes do Programa de Saúde da Família (PSF) e agentes comunitários de saúde. A expectativa era a expansão das ações, com base no estabelecimento de vínculo desses trabalhadores com o doente e sua família, fortalecendo a participação na comunidade, o que poderia colaborar na adesão ao tratamento, e na busca dos sintomáticos respiratórios (Brasil, 2000).

No ano de 2004, o PNCT foi reorganizado, estabelecendo as novas metas para o período de 2004 a 2007 e incluindo a expansão da DOTS aos trezentos e quinze municípios prioritários, responsáveis por $70 \%$ dos casos de tuberculose (World Health Organization, 2005b).

Atualmente, os principais elementos das políticas públicas para 0 controle da tuberculose, no Brasil e no mundo, são: (1) diagnóstico e tratamento precoce, (2) vacinação com BCG em menores de um ano de vida, assim como (3) focalizar o problema nas populações mais vulneráveis, nos municípios com alta endemicidade. Para tanto, as principais diretrizes são: (1) tratamento ambulatorial disponível, em unidades de saúde de baixa 
complexidade, incluindo-se a participação de equipes de saúde da família; (2) atendimento hospitalar, além do (3) acesso aos recursos de imagens, cirúrgicos, laboratoriais e de drogas mais específicas para os casos de multiresistência (Brasil, 2002b).

A implantação da estratégia DOTS emerge de um cenário que evidencia a complexa situação epidemiológica da tuberculose. A proposição desta, em âmbito mundial e nacional, será abordada a seguir.

\subsection{O Tratamento Diretamente Supervisionado (DOTS)}

Antes mesmo de discutir os aspectos mais relevantes a respeito do Tratamento Diretamente Supervisionado, é necessário explicitar que se fará referência à estratégia na designação masculina e feminina, a depender da estrutura da frase apresentada.

A DOTS é considerada um marco para o controle mundial da tuberculose. A estratégia contempla, em sua operacionalização, cinco elementos considerados chave: (1) compromisso governamental em relação à necessidade do controle da enfermidade; (2) diagnóstico através da baciloscopia de escarro; (3) tratamento de curta duração sob supervisão; (4) suprimento ininterrupto das drogas e (5) Sistema de Informação e Registro, que permita acompanhar a evolução dos pacientes, assim como o rendimento geral do Programa. 
A estratégia DOTS tem por objetivo a detecção de $70 \%$ dos casos e alcançar a cura em $85 \%$ dos casos diagnosticados. Tais metas já permitiram o declínio anual de casos no mundo, por meio da diminuição das taxas de incidência em torno de 6 a 7\% ao ano (World Health Organization, 2005b).

No ano de $2000,30 \%$ dos casos mundiais haviam sido descobertos sob a DOTS. Em 2003, cento e oitenta e dois países estavam implantando a DOTS, representando uma cobertura mundial de cerca de $77 \%$ da população. Nesse mesmo ano, 1,8 milhões de pacientes bacilíferos foram notificados sob a DOTS, o que representou $45 \%$ na detecção dos casos (World Health Organization, 2005b).

A implantação da DOTS nos países das Américas teve início em 1996. A Tabela 2 mostra informações sobre a cobertura da estratégia, nessa região, no ano 2000 (Tabela 2).

Tabela 2 - Cobertura da estratégia DOTS em alguns países das Américas, 2001.

\begin{tabular}{ccccc}
\hline$>90 \%$ & $>50 \%<90 \%$ & $>10 \%<50 \%$ & $<10 \%$ & Não DOTS \\
\hline Chile & Bolívia & Argentina & Brasil & Guiana \\
Cuba & Belize & Colômbia & Costa Rica & Suriname \\
Nicarágua & Guatemala & El Salvador & Equador & Países do Caribe \\
Peru & & Honduras & Haiti & Inglês \\
Uruguai & & México & Panamá & \\
Venezuela & & Paraguai & \\
& & República & \\
& & Dominicana & \\
\hline
\end{tabular}

Fonte: Organización Pan-Americana de la Salud, 2004. 
Segundo a Organização Pan-Americana da Saúde (2005), no ano 2003, 75\% da população das Américas estava coberta pela estratégia, com taxa de $81 \%$ de cura.

No Brasil, o Tratamento Supervisionado foi adotado a partir de 1998, nos municípios prioritários; em 2002, a taxa de cura atingiu $75 \%$ dos tratamentos mantidos sob DOTS e a taxa de abandono foi de $18 \%$. Em 2003, a média de cobertura da DOTS era de 34\%. A busca e o diagnóstico de novos casos saltaram de $18 \%$ para $55 \%$, principalmente nos municípios prioritários (World Health Organization, 2005b).

É importante destacar que, em nosso País, a estratégia não se constitui em inovação, pois há registro de que o Tratamento Supervisionado já era realizado por equipes de profissionais de saúde na década de 60 , em unidades de saúde da antiga Fundação Serviço Especial de Saúde Pública SESP- (Ruffino-Netto; Souza, 1999). O tratamento era realizado pela equipe de enfermagem nas Unidades de Saúde, também aos finais de semana. Utilizava-se medicação injetável e, segundo informação de profissional ${ }^{2}$ com ampla experiência na área da tuberculose, a eficácia dessa estratégia era relevante, a ponto de as taxas de abandono atingirem $2 \%$ na zona rural, principalmente em decorrência dos efeitos adversos da medicação.

\footnotetext{
2 A Prof ${ }^{a}$. Dra . Margarida Maria Mattos Brito de Almeida, da Faculdade de Saúde Pública da Universidade de São Paulo, cedeu tais informações durante o Exame de Qualificação da autora do presente estudo.
} 
$\mathrm{Na}$ atualidade, no que diz respeito especificamente ao Estado de São Paulo, a aplicação da DOTS tem sido crescente: no ano de 1998, apenas 2\% dos pacientes estavam sob a estratégia. Em 1999, 7\%; em 2000, 12\%; em 2001, 17\%; e, em 2004, a cobertura com a DOTS atingiu 38\%. (Brasil, 2005a; 2005b). No Município de São Paulo, a cobertura do TS pode ser observada na Tabela a seguir (Tabela 3).

Tabela 3 - Pacientes bacilíferos, forma pulmonar de tuberculose, atendidos em TS e cobertura da DOTS no Município de São Paulo - SP. São Paulo, 1998-2000.

\begin{tabular}{cccc}
\hline Ano & Total de Pacientes & Pacientes em DOTS & Cobertura de DOTS \\
\hline 1998 & 3768 & 23 & 0,61 \\
1999 & 3948 & 188 & 4,76 \\
2000 & 3895 & 281 & 7,21 \\
2001 & 3776 & 411 & 10,88 \\
2004 & 3926 & 1306 & 33,10 \\
$2005^{*}$ & 416 & 36 & 32,69 \\
\hline
\end{tabular}

Fonte: São Paulo, 2006

Esses dados permitem observar que houve um aumento expressivo na cobertura do TS no Município de São Paulo. Mesmo assim, a adesão à estratégia DOTS permanece abaixo da média do País, que é de $35 \%$. Já os dados referentes à região da Supervisão Técnica de Saúde do Butantã podem ser visualizados na Tabela a seguir (Tabela 4). 
Tabela 4 - Pacientes bacilíferos, forma pulmonar de tuberculose, atendidos em TS e cobertura DOTS na região da Supervisão Técnica de Saúde do Butantã - SP. São Paulo, 1998 - 2005.

\begin{tabular}{cccc}
\hline Ano & Total de Pacientes & Pacientes sob DOTS & Cobertura da DOTS \\
\hline 1998 & 78 & 1 & 1,28 \\
1999 & 75 & 7 & 9,33 \\
2000 & 87 & 8 & 9,20 \\
2001 & 76 & 8 & 10,53 \\
2004 & 106 & 34 & 32,08 \\
$2005^{*}$ & 14 & 1 & 7,14 \\
\hline
\end{tabular}

Fonte: São Paulo, 2006

É possível observar um aumento na cobertura do TS na região da Supervisão Técnica de Saúde do Butantã, mas, assim como no Município, a cobertura desta encontra-se abaixo da taxa média do País (35\%).

Assume-se que a tuberculose é um problema de Saúde Coletiva, decorrente, principalmente, das condições sociais. Entende-se também que a DOTS não é suficiente para solucionar o problema, mas admite-se que pode se constituir como estratégia dotada de potencialidade para diminuir a situação epidemiológica da enfermidade. Isto posto, e por não se conhecer como os profissionais de saúde a interpretam no cotidiano da assistência, este estudo teve por finalidade identificar os limites e as potencialidades da estratégia no processo de adesão de doentes ao tratamento da tuberculose, a partir de seus significados para os profissionais de saúde, junto à Supervisão Técnica de Saúde do Butantã. 
OBJETIVOS 


\section{OBJETIVOS}

\section{$2.1 \quad$ Geral}

Analisar a adesão ao tratamento da tuberculose através da operacionalização da DOTS a partir dos seus significados para os profissionais de saúde que atuam no controle da doença na região da Supervisão Técnica de Saúde do Butantã - SP.

\section{$2.2 \quad$ Específicos}

- Identificar os significados a respeito da tuberculose, da adesão ao tratamento e, especificamente, em relação à estratégia DOTS para os profissionais de saúde da região da Supervisão Técnica de Saúde do Butantã.

- Identificar limites e potencialidades da DOTS na adesão ao tratamento.

- Apresentar alternativas para o aperfeiçoamento da implementação da estratégia nessa região. 
METODOLOGIA 


\section{METODOLOGIA}

\subsection{A opção metodológica: considerações gerais}

O presente estudo valeu-se de metodologia qualitativa, tendo os depoimentos dos profissionais de saúde como matéria prima. A pesquisa qualitativa permite incorporar 0 significado e a intencionalidade como inerentes aos atos, às relações, e às estruturas sociais, tomadas como construções humanas significativas (Minayo, 2004).

Segundo Minayo (2004), é possível, por meio da pesquisa qualitativa, adentrar o mundo dos significados das ações e relações humanas para a compreensão de fenômenos específicos e delimitáveis, e acessar questões complexas inerentes ao objeto de estudo e à expressão da subjetividade do pesquisado (Minayo; Sanches, 1993; Martins, 2004).

Segundo Minayo (Minayo, 2004, p.15)

A saúde enquanto questão humana e existencial é uma problemática compartilhada indistintamente por todos os segmentos sociais. Porém as condições de vida e de trabalho qualificam de forma diferenciada a maneira pela qual as classes e seus segmentos pensam, sentem e agem a respeito dela. Isso implica que, para todos os grupos, ainda que de forma específica e peculiar, a saúde e a doença envolvem uma complexa interação entre os aspectos físicos, psicológicos, sociais e ambientais da condição humana e de atribuição de significados. Pois saúde e doença exprimem agora e sempre uma relação que perpassa o corpo individual e social, confrontando com as turbulências do ser humano enquanto ser total. 
A análise do objeto de estudo, que se refere à operacionalização da DOTS e seu impacto no processo de adesão ao tratamento, está pautada no referencial teórico da Teoria da Determinação Social do Processo SaúdeDoença, na medida em que se considera a doença como uma totalidadeparte do processo social. Valeu-se, ainda, como base conceitual para balizar a discussão acerca da adesão ao tratamento, do conceito proposto por Bertolozzi (1998, 2005): “a adesão não se reduz a um ato de violação pessoal. É um processo intimamente associado à vida, que depende de uma série de intermediações que envolvem o cotidiano da pessoa, a organização dos processos de trabalho em saúde e a acessibilidade em sentido amplo que inclui os processos que levam - ou não - ao desenvolvimento da vida com dignidade".

O referencial teórico é a base de sustentação da investigação científica, onde se estabelecem os principais conceitos, categorias e noções com as quais se vai trabalhar. É o "caminho do pensamento" que orienta o trabalho. Assim, utilizou-se referencial teórico pautado no esforço de explicar os problemas de saúde-doença em sua dimensão social. Isto quer dizer que a manifestação do processo saúde-doença é interpretada tendo como pano de fundo o arcabouço estrutural da sociedade, pelo qual a sociedade se organiza para a construção da vida social, o que permite explicar as intermediações entre o desenvolvimento econômico e social e os perfis epidemiológicos.

A Teoria da Determinação Social do Processo Saúde-Doença está assentada nesse pressuposto e coloca a saúde e a doença como momentos 
de um mesmo processo, determinado pela produção e reprodução social (Fonseca; Bertolozzi, 1997).

O processo de reprodução social refere-se à organização da vida social, integrando as formas como se processam o consumo, a consciência, a cultura e as relações sociais. Nessa ótica, os problemas biológicos da saúde são parte do todo da vida social (Fonseca; Egry; Bertolozzi, 2001). Segundo Egry (1996), o processo saúde-doença é “(...) histórico e dinâmico, pois é determinado pela forma como cada indivíduo se insere no modo de produção dominante na estrutura social a que pertence, conferindo a cada indivíduo peculiares condições materiais de existência”.

Nessa estrutura, o ser humano é sujeito participante e construtor da sociedade que não é harmônica e sim histórica, plena de conflitos, tensões e contradições (Bertolozzi; Takahashi, 1990). Decorre daí que o processo saúde-doença integra essa trama, incluindo a problemática que envolve os indivíduos acometidos por tuberculose, devendo ser compreendida e interpretada a partir da inserção social do doente, processo traduzido em potenciais de fortalecimentos e de vulnerabilidades no desenvolvimento da vida. Isto também é válido considerando-se os profissionais de saúde, pois a forma como interpretam e exercem as ações em sua prática profissional está determinada por sua inserção na sociedade. Nessa perspectiva, as ações que podem apoiar (ou não) a adesão ao tratamento também dependem de como concebem a saúde e a doença.

Já em relação ao conceito de adesão ao tratamento, Bertolozzi (1998, 2005) defende que transcende o ato de ingerir o medicamento, e relaciona- 
se diretamente ao lugar ocupado pelo indivíduo no processo de produção e reprodução social, na medida em que deste decorrem condições favoráveis ou limitantes para a efetivação da manutenção da terapêutica. Para a mesma autora, a adesão depende de uma série de intermediações que envolvem o indivíduo, a organização dos processos de trabalho em saúde e a acessibilidade, assim como está intimamente relacionada aos processos que levam (ou não) ao desenvolvimento da vida com dignidade (Bertolozzi, 2005).

Segundo Bertolozzi (2005), a interpretação da categoria de análise adesão deve superar o modelo corrente, e ser interpretada a partir da "identificação de vulnerabilidades e fortalecimentos no contexto da vida cotidiana e nos processos de reprodução social, os quais podem determinar ou não o seguimento do tratamento".

\subsection{Sujeitos do estudo}

Foram entrevistados os coordenadores dos serviços de saúde que desenvolviam o Tratamento Supervisionado, e todos os profissionais de saúde envolvidos na operacionalização da DOTS, perfazendo 22 profissionais de saúde, sendo sete enfermeiras, seis médicos, quatro assistentes sociais e cinco auxiliares de enfermagem. Cabe explicitar que tais coordenadores eram os profissionais que gerenciavam as UBS. Foi 
também entrevistada a Coordenadora do Programa de Controle da Tuberculose e DOTS da SUVIS do Butantã, São Paulo - SP.

\subsection{O cenário do estudo}

O estudo desenvolveu-se nas UBS da Supervisão Técnica de Saúde do Butantã que realizavam o Tratamento Supervisionado, e junto à Coordenação da DOTS que se localiza na SUVIS do Butantã.

A região da Supervisão Técnica de Saúde do Butantã engloba os distritos administrativos de Raposo Tavares, Rio Pequeno, Vila Sônia, Morumbi e Butantã, integrando a região da Coordenadoria de Saúde, que corresponde à divisão Centro-Oeste da Prefeitura do Município de São Paulo. 
Figura 1 - Área territorial de abrangência da região da Supervisão Técnica de Saúde do Butantã - SP.

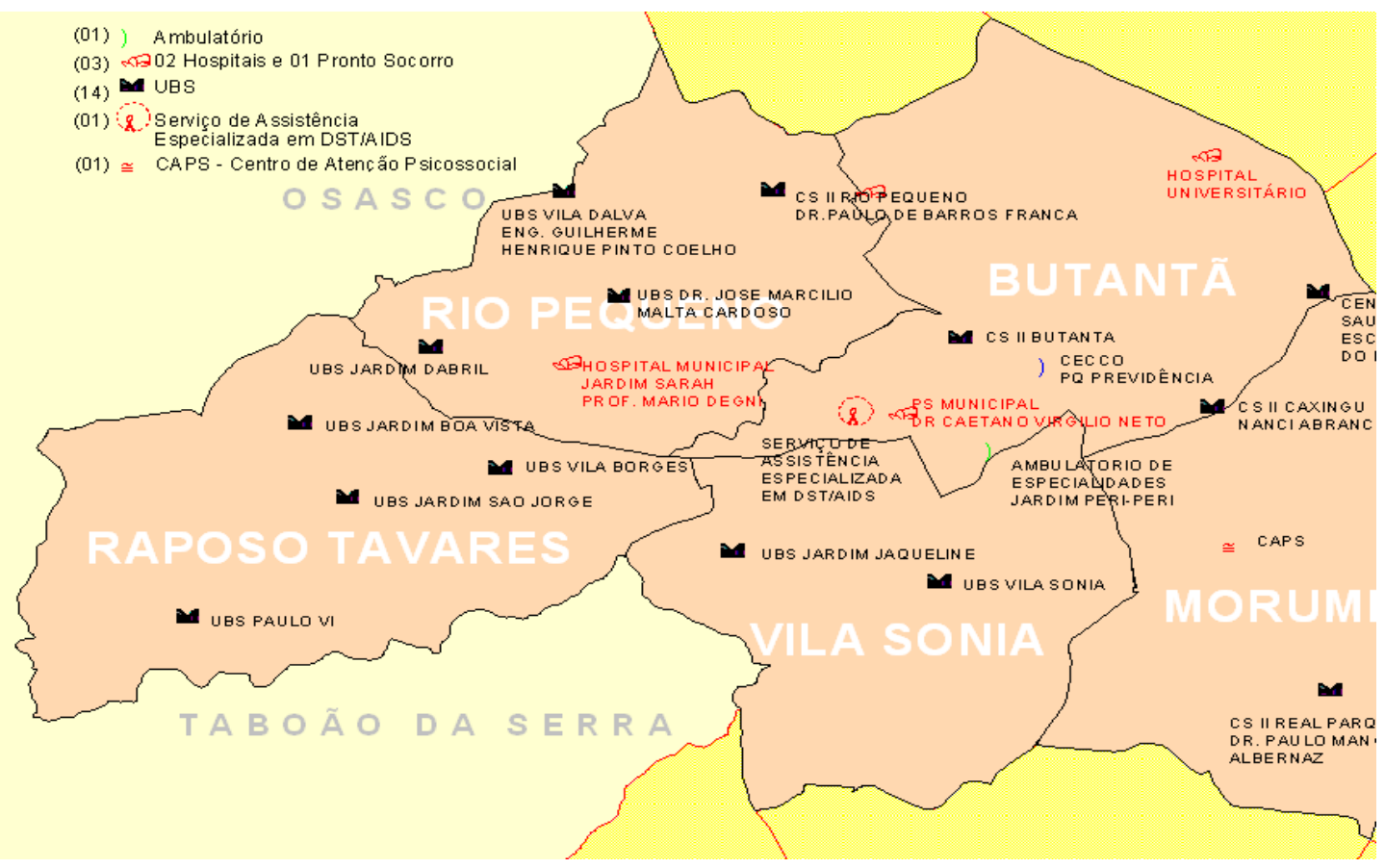

Fonte: (São Paulo, 2004)

Segundo dados da Prefeitura do Município de São Paulo (São Paulo, 2004), a região da SUVIS do Butantã era habitada por cerca de trezentos e setenta e sete mil, duzentos e cinqüenta e sete pessoas, sendo cento e setenta e nove mil, oitocentos e vinte e dois homens e cento e noventa e sete mil, quatrocentas e trinta e cinco mulheres. A população economicamente ativa era estimada em duzentos e sessenta e cinco mil, trezentas e treze pessoas, concentrando a faixa etária de quinze a vinte e quatro anos. Segundo informações da Secretaria de Habitação e Desenvolvimento Urbano (São Paulo, 2004), aproximadamente quarenta e nove mil, quatrocentos e quarenta e oito pessoas moravam em habitações que integram conjuntos sob a forma de favelas, o que equivalia a $13,1 \%$ do 
total de habitantes da localidade. Quanto aos indicadores de saneamento: 99,4\% possuíam água encanada; $92,4 \%$ rede de esgoto e $99,5 \%$ coleta de lixo.

Apesar de esses indicadores se apresentarem favoráveis, há que se ressaltar que a região não é homogênea, apresentando bolsões de pobreza, em regiões não visíveis em mapas geográficos da cidade de São Paulo. Nestes locais, vivenciam-se condições inadequadas de vida, que evidenciam, por exemplo, a necessidade de os moradores deslocarem-se cerca de três a quatro quarteirões para a destinação do lixo. Além disso, o esgoto a céu aberto é comum nas "vielas" das favelas, além das "corredeiras de água" advindas das residências; em muitos casos, a energia elétrica não é regulamentada, facilitando a ocorrência de acidentes, cuja gravidade é muito importante, quando se verifica o material com o qual são construídas as moradias.

No que diz respeito aos equipamentos de saúde, havia quatorze Unidades Básicas de Saúde. Deste total, onze desenvolviam o sistema tradicional de atenção à saúde, contando suas equipes com médicos (clínicos, pediatras e ginecologistas-obstetras), enfermeiros, odontólogos, auxiliares de enfermagem e pessoal para apoio técnico. Duas UBS eram consideradas Unidades Mistas, pois desenvolviam o sistema tradicional de atenção à saúde e o Programa Saúde da Família (PSF). Este contava com Equipes de Saúde da Família (ESF) em conformidade às normas do Ministério da Saúde, ou seja, compostas por um médico, um enfermeiro, um a dois auxiliares de enfermagem e cinco a seis agentes comunitários de 
saúde, obedecendo ao preceito da delimitação da área de abrangência com adscrição da clientela. Apenas uma Unidade Básica de Saúde restringia-se ao Programa de Saúde da Família.

A região também possuía um ambulatório de Especialidades, um Centro de Atenção Psicossocial (CAPS), um Serviço de Atendimento Especializado em DST/AIDS, um Pronto Socorro Municipal, dois hospitais, o Hospital e Maternidade Municipal e o Hospital Universitário da USP.

Tabela 5 - UBS que integraram o estudo na região da Supervisão Técnica de Saúde do Butantã - SP. São Paulo, 2006.

\begin{tabular}{ll}
\hline Unidades Básicas de Saúde & Modelo de atenção à saúde \\
\hline B & Programa Saúde da Família \\
C, D & Mista (PSF e modelo tradicional) \\
E,F,G,H,I & Tradicional \\
\hline
\end{tabular}

Cabe ressaltar que aqui encontraram-se apresentadas oito UBS, dado que só nestas a DOTS era operacionalizada. Nenhuma das UBS da Região Administrativa do Morumbi participou do estudo, pois não desenvolviam o Tratamento Supervisionado na época em que foram coletados os depoimentos dos profissionais de saúde. 


\subsection{A coleta de dados}

As entrevistas foram realizadas pela própria pesquisadora, no período de maio a julho de 2006. Para a sua realização, respeitou-se a data, o horário e o local definidos pelo entrevistado, conforme a sua disponibilidade. Para tanto, em alguns serviços de saúde, a pesquisadora retornou mais de uma vez para conseguir realizar as entrevistas devido a imprevistos advindos da dinamicidade do próprio serviço de saúde, além de ter feito uso de transporte próprio para a coleta dos dados.

\subsection{Etapas do Trabalho}

Tendo em vista que o presente estudo integrou o projeto matriz que tem a finalidade de mapear a situação da DOTS no Município de São Paulo (Bertolozzi, 2005), a aprovação por parte do Comitê de Ética em Pesquisa (CEP) da Secretaria da Saúde do Município de São Paulo já havia sido obtida (Anexo I). O projeto foi apresentado a todos os coordenadores das UBS e à Coordenadora da região da SUVIS Butantã, em reunião que ocorria mensalmente, denominada "Reunião de Chefia". Nesta, foram discutidos os objetivos e a forma como seria realizada a coleta de dados, confirmando-se 
a disponibilidade da pesquisadora na apresentação dos resultados por ocasião da conclusão do estudo.

Após essa aproximação, a pesquisadora entrou em contato com a Coordenadora do PCT e da DOTS na SUVIS, e foi informada sobre as UBS que desenvolviam a DOTS na região.

A seguir, foi necessário entrar em contato por telefone com os coordenadores dessas UBS, momento em que a pesquisadora já era informada a respeito dos profissionais de saúde que, de alguma forma, participavam da DOTS na UBS. O passo seguinte foi entrar em contato com estes, para agendar a data, o horário e local para a entrevista.

Todos os sujeitos do estudo optaram por participar da entrevista nos locais de trabalho, em ambiente que resguardava a liberdade de expressão e privacidade. As entrevistas foram gravadas e tiveram a duração média de 20 minutos.

\subsubsection{Os instrumentos utilizados}

As entrevistas foram orientadas por roteiro semi-estruturado, contendo questões abertas e fechadas. As questões fechadas focalizavam dados de caracterização geral dos entrevistados. Utilizou-se um roteiro para a entrevista destinado aos profissionais de saúde (Anexo II) e um roteiro aos coordenadores dos serviços de saúde (Anexo III) que desenvolviam o 
Tratamento Supervisionado, tendo em vista a especificidade do trabalho de cada um desses protagonistas. Esse mesmo roteiro foi utilizado na entrevista com a Coordenadora do PCT e DOTS na SUVIS Butantã. Durante a entrevista, a pesquisadora interferiu o mínimo possível, limitando-se a esclarecer questões que suscitavam dúvidas.

\subsubsection{Teste Piloto}

Anteriormente à coleta de dados, em maio de 2006, a pesquisadora realizou entrevista piloto com profissionais de saúde com a finalidade de proceder aos ajustes nos instrumentos que orientaram a realização das entrevistas. Os resultados do teste piloto não foram incluídos no estudo.

\subsection{Procedimentos éticos}

No momento da entrevista, em respeito à Resolução 196/1996 do Conselho Nacional de Saúde, apresentou-se o Termo de Consentimento Livre e Esclarecido aos profissionais de saúde (Anexo IV). Uma cópia foi entregue ao profissional de saúde e a outra ficou sob a guarda da 
pesquisadora. É importante salientar que não houve recusa de nenhum profissional de saúde em relação à participação no estudo. Os depoimentos foram transcritos na íntegra pela própria pesquisadora.

\subsubsection{Categorias empíricas}

- Idade;

- Sexo;

- Categoria profissional;

- Função desenvolvida no serviço;

- Treinamento para desenvolver a DOTS;

- Freqüência da DOTS na UBS;

- Profissional que se ocupa da operacionalização da DOTS na UBS;

- Tipo de incentivos oferecidos com a DOTS;

- Aspectos positivos da DOTS;

- Aspectos negativos da DOTS; 


\subsubsection{Categorias Analíticas}

Tendo em vista que o conceito de adesão está intimamente relacionado à forma como se interpreta o processo saúde-doença e à forma como se organiza o trabalho na unidade de saúde, foram adotadas como categorias analíticas no presente estudo: os significados do processo saúdedoença, a forma como se organiza o trabalho na UBS, os significados sobre o Tratamento Supervisionado (DOTS) e os significados sobre a adesão ao tratamento.

\subsection{Análise dos Depoimentos}

No que diz respeito ao tratamento dos depoimentos, foi utilizada a técnica de análise de discurso proposta por Fiorin (1989). Essa técnica foi inicialmente empregada na França, pelo filósofo Michel Pêcheux, no final da década de 60, com a proposta de substituir a Análise de Conteúdo tradicional. Para Michel Pêcheux, o discurso sempre foi o objeto de uma busca infinita que, sem cessar, "Ihe escapa". É no discurso, precisamente, que se concentram, se intrincam e se confundem, como um verdadeiro nó, as questões relativas à língua, à história e ao sujeito (Ferreira, 2005).

É importante apontar que a análise de discurso não tem a pretensão de esgotar as possibilidades de interpretação. O que distingue e identifica a 
Análise do Discurso é a sua forma peculiar de trabalhar com a linguagem numa relação estreita e indissociável com a ideologia (Fiorin, 1990).

Portanto, a utilização da Técnica de Análise do Discurso, para compreender os significados sobre a adesão ao tratamento a partir da DOTS para os profissionais de saúde, nas UBS da região da SUVIS Butantã, fundamentou-se no entendimento de que a linguagem mantém relação com a ideologia, mas não se reduz a esta.

Segundo Fiorin (1990), a ideologia corresponde ao conjunto de idéias e representações que servem para justificar e explicar a ordem social, as condições de vida dos seres humanos e as relações que mantém entre si.

Ainda para Fiorin (1990), as visões de mundo não se desvinculam da linguagem, porque a ideologia é imanente à realidade, é indissociável da linguagem, entendida em seu sentido amplo de instrumento de comunicação verbal ou não-verbal. As idéias e, por conseguinte, os discursos, são expressões da vida real e a realidade se expressa por meio dos discursos (Fiorin, 1990).

O mesmo autor aponta que o discurso é mais o lugar da reprodução do que o lugar da criação e que as visões de mundo correspondem a uma formação discursiva constituída por um conjunto de temas e figuras. Para ele, o discurso não é um amontoado de frases, mas combina elementos lingüísticos (frases ou conjuntos constituídos de muitas frases), utilizados com o propósito de exprimir pensamentos, de falar do mundo exterior ou do mundo interior. 
Segundo Minayo (2004), a Análise de Discurso visa compreender o modo de funcionamento, os princípios de organização e as formas de produção social da fala/ discurso/ depoimento.

Na Análise de Discurso, busca-se captar as visões de mundo do enunciador, o que permite reconhecer, interpretar e reinterpretar as concepções sobre determinado objeto que, no presente estudo, refere-se à adesão ao tratamento da tuberculose a partir da operacionalização do Tratamento Supervisionado (DOTS), na perspectiva dos profissionais de saúde.

Seguindo as etapas percorridas por Bertolozzi (1998), o material empírico foi decodificado através da técnica proposta por Fiorin (1989), a qual está fundamentada na Teoria de Greimás ou Teoria da Geração de Sentido do Texto, que permite depreender frases temáticas. Tal análise é realizada buscando-se os temas (elementos abstratos) e as figuras (elementos concretos) presentes nas falas. Segundo Fiorin (1990), "Tema é o elemento semântico que designa um elemento não-presente no mundo material, mas exerce o papel de categoria ordenadora dos fatos observáveis. São temas, por exemplo, amor, paixão, lealdade, alegria”. Por sua vez, “(...) figura é o elemento semântico que remete a um elemento do mundo natural: casa, mesa, mulher, rosa, etc.".

Reafirmando a posição de Bertolozzi (1998), que também fez uso dessa técnica, a análise dos depoimentos foi feita não na pretensão de colocar em cheque a veracidade das informações dadas pelos entrevistados, mas de buscar entender sua visão de mundo. Tratou-se, portanto, de buscar 
conhecer, interpretar e reinterpretar as concepções dos entrevistados sobre a saúde-doença, a organização do trabalho, e a adesão dos pacientes ao tratamento a partir da operacionalização do Tratamento Supervisionado. Os depoimentos foram decodificados e sintetizados em frases temáticas (Anexo V), que se encontram agrupadas e serviram para orientar o processo de apresentação e de discussão dos resultados.

É importante ressaltar que nem todas as frases temáticas foram utilizadas, tendo sido privilegiadas as que mais se relacionavam ao objeto de estudo.

Da mesma forma que Bertolozzi $(1998,2005)$, cada sujeito da pesquisa recebeu uma letra de identificação e um número de ordem, assim como cada frase temática, um número, de forma a possibilitar a sua visualização no conjunto de frases. O Coordenador do Programa de Controle da Tuberculose e Tratamento Supervisionado na Supervisão Técnica de Saúde do Butantã é identificado como "COO". Os coordenadores das UBS são identificados como "GER" e os profissionais das UBS são identificados conforme a categoria profissional: as enfermeiras como "ENF", os médicos como "MED" e os auxiliares de enfermagem como "AE". 
RESULTADOS 


\section{RESULTADOS}

Antes de apresentar os resultados que dizem respeito às categorias analíticas, vejam-se os dados que caracterizam os profissionais entrevistados.

Quadro 1 - Características dos sujeitos entrevistados na região da Supervisão Técnica de Saúde do Butantã - SP. São Paulo, 2006.

\begin{tabular}{|c|c|c|c|c|c|}
\hline UBS & Profissional & Função & Idade & Sexo & Qualificação \\
\hline & Assistente social & Coordenador do PCT & 47 & $\mathrm{~F}$ & $\operatorname{sim}$ \\
\hline B & $\begin{array}{c}\text { Médico } \\
\text { Enfermeira } \\
\text { Auxiliar de enfermagem }\end{array}$ & $\begin{array}{c}\text { Coordenador de UBS } \\
\text { ESF } \\
\text { ESF }\end{array}$ & $\begin{array}{l}36 \\
29 \\
54\end{array}$ & $\begin{array}{l}M \\
F \\
F\end{array}$ & $\begin{array}{l}\text { não } \\
\text { não } \\
\text { não }\end{array}$ \\
\hline C & Médico & Coordenador de UBS & 53 & $\mathrm{~F}$ & $\operatorname{sim}$ \\
\hline D & $\begin{array}{c}\text { Enfermeira } \\
\text { Auxiliar de enfermagem } \\
\text { Enfermeira }\end{array}$ & $\begin{array}{c}\text { Coordenador de UBS } \\
\text { ESF } \\
\text { ESF }\end{array}$ & $\begin{array}{l}43 \\
34 \\
32\end{array}$ & $\begin{array}{l}F \\
M \\
F\end{array}$ & $\begin{array}{l}\text { sim } \\
\text { não } \\
\text { não }\end{array}$ \\
\hline$E$ & $\begin{array}{l}\text { Enfermeira } \\
\text { Enfermeiro }\end{array}$ & $\begin{array}{c}\text { Coordenador de UBS } \\
\text { UBS }\end{array}$ & $\begin{array}{l}46 \\
40\end{array}$ & $\begin{array}{l}\mathrm{F} \\
\mathrm{M}\end{array}$ & $\begin{array}{l}\text { sim } \\
\text { não }\end{array}$ \\
\hline $\mathrm{F}$ & $\begin{array}{l}\text { Assistente social } \\
\text { Médica }\end{array}$ & $\begin{array}{c}\text { Coordenador de UBS } \\
\text { Sanitarista }\end{array}$ & $\begin{array}{l}51 \\
52\end{array}$ & $\begin{array}{l}F \\
F\end{array}$ & $\begin{array}{l}\operatorname{sim} \\
\operatorname{sim}\end{array}$ \\
\hline G & $\begin{array}{c}\text { Assistente social } \\
\text { Auxiliar de enfermagem } \\
\text { Auxiliar de enfermagem } \\
\text { Enfermeira } \\
\text { Médica }\end{array}$ & $\begin{array}{c}\text { Coordenador de UBS } \\
\text { UBS } \\
\text { UBS } \\
\text { UBS } \\
\text { Sanitarista }\end{array}$ & $\begin{array}{l}40 \\
24 \\
64 \\
53 \\
62\end{array}$ & $\begin{array}{l}F \\
M \\
F \\
F \\
F\end{array}$ & $\begin{array}{l}\text { não } \\
\text { não } \\
\text { não } \\
\text { sim } \\
\text { sim }\end{array}$ \\
\hline $\mathrm{H}$ & $\begin{array}{l}\text { Médica } \\
\text { Médica }\end{array}$ & $\begin{array}{c}\text { Coordenador de UBS } \\
\text { Sanitarista }\end{array}$ & $\begin{array}{l}41 \\
51\end{array}$ & $\begin{array}{l}F \\
F\end{array}$ & $\begin{array}{l}\text { não } \\
\text { sim }\end{array}$ \\
\hline 1 & $\begin{array}{c}\text { Assistente social } \\
\text { Auxiliar de enfermagem } \\
\text { Enfermeira }\end{array}$ & $\begin{array}{c}\text { Coordenador de UBS } \\
\text { UBS } \\
\text { UBS }\end{array}$ & $\begin{array}{l}51 \\
50 \\
59\end{array}$ & $\begin{array}{l}F \\
F \\
F\end{array}$ & $\begin{array}{l}\text { não } \\
\text { não } \\
\text { não }\end{array}$ \\
\hline
\end{tabular}


Quadro 2 - Relação das Unidades Básicas de Saúde, freqüência da DOTS e incentivos oferecidos na região da Supervisão Técnica de Saúde do Butantã - SP. São Paulo, 2006.

\begin{tabular}{|ccc|}
\hline UBS & DOTS & Incentivos \\
\hline B, E, G & diário & Cesta básica; cereal; achocolatado \\
C, F & semanal & Cesta básica; cereal; achocolatado \\
I & semanal & Vale transporte; cesta básica \\
D & $3 \times /$ semana & Cesta básica; cereal; achocolatado \\
H & mensal & Cesta básica \\
\hline
\end{tabular}

As frases extraídas dos depoimentos dos sujeitos pesquisados revelam diferentes dimensões de cada uma das categorias analíticas que, evidentemente, guardam entre si articulação e dependência, conforme também mencionado por Bertolozzi (2005).

Entretanto, serão apresentadas separadamente para melhor clareza. Conforme anteriormente apontado, os resultados são apresentados segundo a especificidade do sujeito emissor, respeitando-se cada um dos temas que perfazem as categorias analíticas.

\subsection{Os coordenadores dos serviços de saúde}

Foi entrevistada a totalidade dos coordenadores das UBS que desenvolviam a DOTS, assim como a Coordenadora do Programa de 
Controle da Tuberculose e DOTS da SUVIS do Butantã, totalizando nove profissionais.

Quanto ao sexo, predominaram os coordenadores do sexo feminino, totalizando oito pessoas. No que se refere à idade, somente um profissional tinha menos do que 40 anos, sendo que a mais ampla parcela encontrava-se na faixa etária de 40 a 50 anos. Não houve diferença importante em relação àqueles que tinham sido capacitados através de treinamento, ainda que isto tenha ocorrido em relação à maior parcela dos coordenadores de saúde.

\subsubsection{Os significados sobre o processo saúde-doença}

Para os coordenadores, a tuberculose incide nas pessoas "difíceis" (Ger.A1.31), nos alcoolistas (COO.I1.17) e, naqueles que sofrem abandono da família (Ger.A1.19). A esse respeito, um dos profissionais mencionou que uma adolescente sentia-se tão abandonada, que pediu para ser adotada pelo profissional que realizava o TS (Ger.A1.37).

Segundo os entrevistados, as pessoas acometidas pela tuberculose geralmente são trabalhadores que não possuem registro em carteira e que, portanto, não dispõem de benefícios quaisquer, como o auxílio-doença, que os permitiria realizar o tratamento sem a necessidade premente de trabalhar (Ger.H3.18). São, em geral, pacientes que a equipe de saúde necessita 
acompanhar de maneira próxima, "ficar em cima" (Ger.D1.16), mostrando-se disposta a "adotar o paciente durante o tratamento" (Ger.D1.20; Ger.D1.27).

Dentre os depoimentos, mencionou-se a existência de preconceito, advindo do medo que os profissionais de saúde têm de adquirir a doença dentro da unidade de saúde no momento em que o doente realiza o TS (Ger.F2.34). Alguns coordenadores referiram que tais profissionais expressam medo contrair a tuberculose (Ger.F2.35), apesar das constantes orientações oferecidas na UBS de que esse sentimento deveria advir de situações que envolvem casos ainda não diagnosticados e tratados inadequadamente (Ger.F2.36).

Ainda a respeito do estigma, alguns coordenadores mencionaram que os doentes verbalizam situações de preconceito sofrido nos serviços de saúde e em seu ambiente de trabalho (Ger.F2.37). Em alguns depoimentos, houve alusão de que o doente tem medo de ser reconhecido no serviço de saúde por vizinhos ou outros membros da comunidade. Desse modo, alguns pacientes procuram atendimento em serviços de saúde distantes de seu domicílio (COO.I1.6). Os doentes também se afastam do serviço de saúde por medo de receber o diagnóstico, tornando-se necessária a busca do paciente pela equipe de saúde, seja no domicílio ou no trabalho, com a finalidade de resgatá-lo para o tratamento (COO.I1.6; COO.I1.30).

Os médicos, enfermeiros e agentes comunitários de saúde foram citados como os profissionais mais sensibilizados sobre a questão da tuberculose (Ger.F2.23). Mesmo assim, num depoimento revelou-se que, dentre estes profissionais, nem todos tinham conhecimento da gravidade da 
doença, do modo de transmissão, e da importância do tratamento correto (Ger.H2.13). Dessa forma, não se dá a devida relevância aos cuidados a serem mantidos perante a doença (Ger.F2.38).

\subsubsection{A forma como se organiza o trabalho na UBS}

$\mathrm{Na}$ grande maioria dos depoimentos, verificou-se menção de que o Programa de Controle da Tuberculose teve um declínio no período em que o modelo do PAS esteve operando no Município. Os depoimentos apontam que, nessa época, os serviços de saúde estavam "desorganizados, desmantelados", e todos os equipamentos da unidade de saúde encontravam-se "sucateados" (Ger.A1.2).

Em decorrência, os doentes que apresentavam tuberculose não foram devidamente acompanhados, chegando-se a mencionar que foram "abandonados" pelos profissionais de saúde (Ger.A1.16; Ger.D1.14). Ademais, não havia registro de informações dos casos na região (COO.I1.19; Ger.D1.3).

Mencionou-se que o processo de reorganização da atenção básica teve início com a troca da gestão municipal, o que proporcionou mudanças significativas para o sistema de saúde, ainda que tal momento tenha sido marcado por "confusão" (Ger.A1.3). A equipe da vigilância epidemiológica vivenciou momentos difíceis, tendo sido necessário buscar os doentes 
"abandonados" e "ficar em cima" para incentivar a retomada do tratamento (Ger.D1.4).

Para os coordenadores, o objetivo principal da unidade de saúde é diminuir a disseminação da tuberculose, controlar os bacilíferos (Ger.G1.11) e promover a ausência do abandono do tratamento (Ger.D1.36). A unidade de saúde é considerada a porta de entrada para os casos (Ger.F2.11) e os doentes são acompanhados a partir das planilhas do PCT (COO.I1.28). Por meio destas, é possível saber onde moram e trabalham os doentes, o que facilita ir ao seu encontro, quando necessário (COO.I1.30).

Em algumas UBS, o atendimento aos doentes era centralizado no médico sanitarista do serviço (Ger.A1.15; Ger.G1.5), profissional considerado essencial para o acompanhamento dos casos, além de realizar o diagnóstico e o tratamento (Ger.A1.30; Ger.E1.8). Em outros serviços, era centralizado no enfermeiro. Mas, em relação à realização da DOTS, em todas as unidades de saúde, segundo os depoimentos, era centralizado na equipe de enfermagem (Ger.C4.22).

Os depoimentos evidenciam que os enfermeiros "têm conhecimento de todos os pacientes" (Ger.C4.11), e são os responsáveis por (1) atender o doente em consulta de enfermagem, (2) realizar as visitas domiciliárias, (3) controlar os faltosos, (4) elaborar os relatórios e (5) solicitar a medicação (Ger.C4.24; Ger.G2.17). Mas, os depoimentos mostram, também, que os enfermeiros têm sua atuação prejudicada em razão do acúmulo de funções burocráticas que acaba por tomar grande parte de seu tempo no serviço (Ger.D1.17; Ger.F2.16). 
Quanto aos auxiliares de enfermagem, realizam a supervisão da ingesta da medicação pelo doente (Ger.F2.18).

Apesar de o trabalho ser distribuído entre os sujeitos que operam o processo de produção de serviços, os depoimentos revelam a necessidade de se dispor de uma equipe para atender aos doentes e organizar os serviços de vigilância epidemiológica (Ger.D1.31; Ger.F2.14), o que pode contribuir para a organização do fluxo interno da unidade de saúde (Ger.F2.9; 10) e para compartilhar o processo de tratamento (Ger.D1.32). Tal equipe deve ser composta por profissionais dotados de perfil para atuar nessa "modalidade de tratamento" (COO.I1.31; Ger.A1.36): devem ter sensibilidade (COO.I1.23), pois o Tratamento Supervisionado exige maior envolvimento do profissional com o doente (COO.I1.35).

Considera-se que a rede de saúde possui os elementos necessários para diminuir o número de doentes: aparelho de raio $\mathrm{X}$, medicação e exame baciloscópico de escarro, o que permite agilizar o diagnóstico da tuberculose (Ger.A1.17; Ger.F2.8).

Disse-se que o atendimento da farmácia está orientado a não entregar medicação antituberculostática às pessoas que recorrem à unidade de saúde com prescrição externa, para impedir a perda de casos. Quando ocorre tal situação, o funcionário encaminha a pessoa ao enfermeiro do serviço (Ger.D1.13).

Falou-se que algumas UBS realizavam constante mobilização junto aos trabalhadores em relação à tuberculose (Ger.A1.39), para que mostrassem prontidão na busca dos sintomáticos respiratórios (Ger.A1.40). 
Mas, apesar dos esforços, o serviço ainda não está plenamente sensibilizado para tal (Ger.F2.21; Ger.F2.24), nem mesmo durante a consulta médica (Ger.C4.24).

Os depoimentos evidenciam que a organização do serviço, assim como o acompanhamento dos doentes, apresentam falhas por falta de recursos humanos (Ger.C4.5), pois os profissionais de saúde que se aposentam não estão sendo repostos (Ger.G1.9), e os profissionais qualificados são "subutilizados", uma vez que desenvolvem muitas atividades burocráticas (Ger.C4.26).

Quanto à operacionalização da DOTS, alguns depoimentos mostram que não repercute negativamente na rotina do serviço (COO.I1.25; Ger.C4.17; Ger.H3.5). Assim, foi considerada atividade "tranqüila" (Ger.A1.29; Ger.C4.21), "muito rápida" (Ger.C4.27), que não obstrui o fluxo de atendimento (Ger.D1.16).

Por outro lado, outros depoimentos apontaram que o TS é trabalhoso (Ger.D1.34), e sobrecarrega a equipe responsável (Ger.D1.21; Ger.D1.28), principalmente devido às atividades burocráticas (Ger.C4.25). E também que não é uma atividade "tranqüila" (Ger.F2.27), trazendo impactos na rotina de serviços da UBS e repercutindo na sua dinâmica (COO.I1.39; COO.I1.40; Ger.B1.8). Por fim, que exige espaço físico para o atendimento da demanda e para realizar a supervisão da ingesta do medicamento (Ger.D1.25). E que as UBS não dispõem de tal espaço (Ger.A1.5; Ger.F2.20; Ger.G1.10). 


\subsubsection{Os significados sobre o Tratamento Supervisionado (DOTS)}

Os depoimentos apontam que o TS foi iniciado nas unidades de saúde por volta do ano 2001, quando estas passaram a receber os incentivos da Secretaria Municipal de Saúde para que o TS fosse desenvolvido (COO.I1.20; Ger.E1.7).

Para alguns coordenadores, o Tratamento Supervisionado é considerado como "proposta interessante" para controlar as dificuldades da baixa adesão ao tratamento da tuberculose (Ger.B1.3). Outros depoimentos fazem referência de que é uma estratégia eficiente, um "investimento", que permite o aumento nas taxas de cura e diminuição nas taxas de abandono de tratamento (Ger.H3.7).

Quanto ao significado da DOTS, houve menção de que significa (1) "pegar no pé" (Ger.E1.5); (2) ficar "mais em cima" (Ger.D1.10); (3) "ver" (COO.I1.4); (4) controlar e observar a ingestão da medicação (Ger.A1.4; Ger.D1.8; Ger.G1.3); (5) observar e garantir a adesão ao tratamento (Ger.D1.9; Ger.E1.4; Ger.G1.3; GerH3.3; Ger.H3.4); (6) "segurar" o doente até o final do tratamento (Ger.F2.29); (7) quebrar a cadeia de transmissão da tuberculose (Ger.F2.2; Ger.F2.7); (8) alcançar a cura (Ger.D1.22; Ger.H3.3); (9) evitar o acúmulo de medicação no domicílio do paciente (Ger.D1.11); (10) evitar "conseqüências" do tratamento incorreto (Ger.D1.23); acompanhar os comunicantes (Ger.H3.9); (12) permite abordar as dificuldades no tratamento (Ger.H3.10); (13) diminuir a resistência aos 
medicamentos, (14) organizar o serviço de saúde, e (15) permitir que todos "falem a mesma língua" (COO.I1.22; COO.I1.36). Dessa forma, o TS melhora o serviço de saúde (COO.I1.21) e facilita o atendimento do doente na UBS (COO.11.36).

Quanto à indicação do tratamento supervisionado, mencionou-se que o profissional de saúde é quem define os doentes a serem mantidos sob a estratégia (Ger.B1.9) mas que, geralmente, é indicado aos pacientes que apresentam recidiva da doença ou para aqueles que haviam abandonado o tratamento anteriormente (Ger.C4.7), além dos pacientes "que dão trabalho" (Ger.H3.15). Entretanto, encontraram-se depoimentos que apontam que o TS deve ser oferecido a todos os doentes (COO.I1.10), e que se deve possibilitar ao doente que "decida" como o tratamento pode ser realizado (COO.I1.11).

Alguns consideram que o TS não permite a autonomia do paciente (Ger.B1.10). Entretanto, devido à situação atual da tuberculose, deve ser "obrigatório" (Ger.B1.11; Ger.D1.33) e "prioritário" na UBS (Ger.F2.25).

Quanto à freqüência do TS, alguns depoimentos fizeram menção de que é realizado diariamente, principalmente no caso de doentes que requerem a supervisão constante por parte da equipe de saúde (Ger.A1.21; Ger.A1.23; Ger.D1.19). Encontraram-se depoimentos que apontam que o TS assume características de "policialesco" quando realizado diariamente, afetando a privacidade do doente (Ger.A1.33). Assim, advoga-se que deveria ser realizado uma vez na semana (Ger.A1.10), ou a cada dois ou três dias (Ger.D1.12; Ger.E1.6; Ger.F2.19). Mas, quando o profissional de 
saúde percebe dificuldades na adesão, a freqüência dos retornos pode ser modificada (Ger.B1.6; Ger.D1.18).

Apontou-se que o final de semana é um problema na dinâmica do TS, no caso dos doentes que não têm família ou residência, como os moradores de rua. Nesse caso, não ocorre a supervisão (Ger.D1.34; Ger.E1.11).

\subsubsection{Os significados sobre a adesão ao tratamento}

Para alcançar o objetivo de encerrar o tratamento do doente, houve referência à importância da criação de vínculo entre o doente e o profissional de saúde (Ger.A1.20; Ger.D1.24). O vínculo decorre do acolhimento oferecido ao doente (Ger.A1.11), e se estabelece na orientações fornecidas por ocasião da pós-consulta (Ger.A1.31), durante a participação dos doentes nas atividades do serviço (Ger.H3.8). E, principalmente, por ter um profissional de saúde responsável pelo acompanhamento diário do doente, permitindo que o doente tenha alguém como referência na unidade de saúde (Ger.A1.27; Ger.F2.3).

O vínculo foi citado como fundamental para o acompanhamento do doente, pois através deste, o doente sente-se mais próximo da equipe de saúde (Ger.C4.30). O comprometimento da equipe de saúde com o doente, no processo terapêutico, permite que este tenha espaço para retornar à UBS, quando não sentir-se bem, ou caso tenha dúvidas sobre seu tratamento 
(Ger.A1.18; Ger.A1.22). Além disso, faz com que alguns doentes procurem com maior freqüência os profissionais para falar de seus sintomas, mesmo após o término do tratamento (Ger.A1.26).

Os depoimentos apontam que, a partir da criação do vínculo, o profissional de saúde flexibiliza a freqüência do tratamento supervisionado, conforme as necessidades do doente, de modo a permitir que a pessoa sinta-se responsável em seu processo terapêutico (Ger.E1.20). Tal flexibilidade é admitida como questão de cidadania, pois possibilita a "liberdade" ao doente durante o tratamento (Ger.D1.12).

Os depoimentos revelam, ainda, que há algumas circunstâncias especiais, que exigem maior flexibilidade no tratamento supervisionado, entre as quais doentes acamados ou sob esquema diferenciado de tratamento, que requerem o acompanhamento da equipe por meio de visitas domiciliárias (COO.I1.6).

Quanto aos incentivos oferecidos, são apontados como positivos na adesão a cesta básica mensal (COO.I1.45), assim como os achocolatados e cereais (Ger.A1.13; Ger.C4.9).

Dentre as questões citadas nos depoimentos que interferem negativamente na adesão ao tratamento, destacam-se a quantidade de medicamentos utilizados no tratamento e seus efeitos colaterais (Ger.B1.5), além das más condições de alimentação e a falta de estímulo familiar aos doentes alcoolistas (COO.I1.17).

Ainda que a cesta básica tenha sido apontada como positiva na adesão, alguns profissionais consideram que a sua distribuição irregular 
repercute de forma negativa, deixando a equipe de saúde, por vezes, constrangida perante o doente e seus familiares (Ger.C4.13; Ger.C4.15). Muitas vezes, o paciente passa a receber as cestas quando já encerrou 0 tratamento (Ger.C4.13). Num dos depoimentos houve referência de que tal irregularidade na entrega das cestas básicas decorre da dificuldade de os entregadores "entrarem com o caminhão na favela", ou por não encontrarem o endereço de moradia do paciente (COO.I1.42). Uma maneira para contornar esse problema seria o doente fazer uso de alternativa para a retirada da cesta nos locais de distribuição. Mas, na maioria das vezes, os profissionais de saúde não oferecem essa possibilidade, pois sabem que o doente não dispõe de transporte. Ou, ainda, por desconhecimento desta alternativa (COO.I1.43).

\subsection{Os profissionais de saúde que participam da DOTS no cotidiano}

Foi entrevistada a totalidade dos profissionais que realizavam a DOTS nos serviços de saúde da região da SUVIS do Butantã, perfazendo treze profissionais, sendo dez do sexo feminino. Quanto à área de formação, eram cinco enfermeiras, três médicos e cinco auxiliares de enfermagem. Todos apresentavam tempo de formação superior a cinco anos.

No que diz respeito ao treinamento junto ao PCT, a totalidade dos médicos referiu tê-lo recebido. Dentre os enfermeiros, apenas uma referiu ter 
experiência e formação em saúde pública, enquanto os outros revelaram que o aprendizado foi resultado da prática diária no serviço, ou por orientações prestadas pela SUVIS via telefone. Todos os auxiliares de enfermagem negaram ter recebido treinamento para a operacionalização da DOTS.

\subsubsection{Os significados sobre o processo saúde-doença}

Os depoimentos dos profissionais de saúde revelam que a tuberculose é doença social (Enf.B2.11), acometendo principalmente os alcoolistas (Enf.C1.30), as pessoas "carentes" (Méd.G2.12), os mais "pobres" (Enf.H2.9), os desempregados (Med.A2.9) e os que moram sob precárias condições (Méd.G2.41).

Os depoimentos evidenciam que os doentes, ao receberem o diagnóstico da tuberculose, sentem-se mal, "sujos", pois consideram que a doença atinge pessoas que apresentam condutas não aceitas na sociedade (Enf.C1.14). O trabalhador de saúde considera que o recebimento do diagnóstico produz efeito negativo ao doente, pois a enfermidade compromete o bem estar geral, "abate o corpo" (Enf.H2.8).

Os depoimentos também revelam que os doentes sentem-se excluídos de seu convívio familiar e do círculo de amigos (AE.F1.26). De igual maneira, isso ocorre no âmbito dos serviços de saúde, pois os 
profissionais de saúde têm medo da tuberculose, das doenças infectocontagiosas (AE.F1.15; Enf.H2.7): têm medo de "contaminar-se" (Enf.H2.10). Em decorrência desse sentimento, o atendimento é rápido para que, da mesma forma, o doente seja dispensado "rapidamente" (Enf.C1.48).

Entretanto, em um dos depoimentos houve referência ao fato de que o entendimento sobre a tuberculose se modificou com o tempo, e que não há mais estigma (AE.B2.33), pois a enfermidade é divulgada na televisão (AE.B3.23), e é doença que pode acometer a qualquer indivíduo (Enf.C1.63).

Em alguns dos depoimentos mencionou-se que os serviços de saúde "subestimam" a tuberculose (Méd.G2.23), pois não fazem o diagnóstico rapidamente (Med.G2.24), principalmente nas unidades de saúde (Méd.A2.13). Apontou-se que nem todos os profissionais que estão "na porta de entrada do serviço" estão conscientes em relação ao problema (Méd.G2.26).

Disse-se ainda que os pacientes percebem-se "doentes", mas desanimam em buscar atendimento, por não sentirem confiança na resolubilidade dos serviços de saúde (Med.G2.22). Nos depoimentos, este problema é colocado como um dos responsáveis pelos quadros de tuberculose multiresistente e pela grande quantidade de casos. Apontou-se que o doente chega em estado grave à UBS, com chance de já ter contaminado muitas pessoas (Méd.G2.40), dificultando as ações de prevenção e "controle" da doença (Méd.G2.42).

Apontou-se que a tuberculose deve ser considerada caso de "emergência" nas UBS (Enf.C1.14) e o tratamento considerado prioridade 
(AE.C2.14; Enf.C1.17; Enf.H1.34), pois constitui problema que não se restringe ao indivíduo, mas à população em geral (Enf.C1.62).

\subsubsection{A forma como se organiza o trabalho na UBS}

Os depoimentos dos profissionais de saúde afirmam que a prioridade da unidade de saúde é controlar a tuberculose (Enf.C1.7). Entretanto, houve referência de que há muita dificuldade em realizar constantemente a busca ativa dos sintomáticos respiratórios (Enf.E2.30) e que a unidade de saúde deveria ser a porta de entrada para os casos de tuberculose. Mas os casos graves não são detectados na UBS (Med.G2.20; Méd.G2.21), e sim durante a internação hospitalar (Med.G2.27).

Dentre as atividades do PCT/ DOTS citadas nos depoimentos, estão (1) a abertura da ficha de notificação da tuberculose; (2) atendimento ao doente (Enf.H2.6); (3) informar as modalidades de tratamento disponíveis (que são o tratamento auto-administrado ou o tratamento supervisionado); (4) acompanhar os comunicantes, além de (5) realizar visitas domiciliárias (Méd.C5.2).

Quanto aos profissionais envolvidos na DOTS, a maioria dos depoimentos referiram que a equipe de enfermagem é a principal no acompanhamento dos doentes (AE.C3.3; AE.F1.5; Méd.C3.5), mas os depoimentos apontam a necessidade de se dispor de equipe preparada para 
cuidar dos doentes, que deveria ser formada por enfermeiro, auxiliares de enfermagem e médico (AE.B3.28; AE.C2.5; Enf.B2.5; Enf.H1.2).

Os depoimentos revelam que as atividades desenvolvidas pelos enfermeiros são: (1) elaborar relatórios mensais; (2) preparar a equipe de enfermagem para atuar junto dos doentes na DOTS; (3) fazer consulta de enfermagem; (4) acompanhar os comunicantes; (5) realizar as visitas domiciliárias (Enf.B2.5; Enf.C1.5); (6) solicitar os exames e (7) fazer anotações em prontuário (Enf.E2.3).

Os auxiliares de enfermagem são responsáveis pela supervisão da ingesta do medicamento pelo doente (AE.B3.2; AE.F1.18; AE.H2.3; Enf.B2.16; Enf.C1.16; Enf.H1.11).

Apontou-se que, nas unidades de saúde, constantemente ocorrem mudanças de gestão administrativa, o que impede que os profissionais de saúde dêem continuidade às atividades já iniciadas no serviço (Méd.A2.3), fato que gera desinteresse do trabalhador para envolver-se com os “assuntos da UBS” (Méd.A2.4).

\subsubsection{Os significados sobre o Tratamento Supervisionado (DOTS)}

Os depoimentos revelam que a DOTS significa (1) "ver" a ingesta da medicação (AE.H2.5); (2) "pegar no pé" (AE.F1.17); (3) "cobrar" (Enf.H1.9); (4) controlar os doentes (Enf.C1.56; Méd.C5.10); (5) "olhar" de maneira 
próxima o doente (Enf.H1.16); (6) "ter visão" sobre a evolução do doente no tratamento (Enf.E2.20); (7) garantir a adesão (AE.F1.22; AE.F1.23); (8) evitar o abandono (Enf.C1.32; Med.G2.34); (9) garantir a cura (Enf.F3.11); (10) controlar a transmissão da tuberculose (AE.C2.10; AE.C3.4; Enf.H1.23) e é (11) momento para criar o vínculo (AE.F1.31; Enf.B2.31; Enf.C1.15; Enf.F3.9; Enf.F3.10; Med.A2.21).

Quanto à indicação da DOTS, os depoimentos fazem referência ao fato de que os doentes deveriam ser "forçados" a aceitá-la (Enf.C1.55). Outros profissionais mencionam que a DOTS não deve ser indicada a todos os pacientes (AE.B3.15), apenas para os "rebeldes" (Enf.B2.7), os "complicados" (Enf.H1.5; Enf.H1.6), os "complexos" (Enf.H1.4), os "sem consciência" da doença (AE.H2.19) para aqueles que não aderem ao tratamento (Méd.G2.4), além dos doentes resistentes aos medicamentos (Enf.F3.14; Med.G2.9).

Alguns depoimentos apontam que o TS deveria ser "obrigatório" a todos os doentes (AE.B3.21; Enf.C1.13; Enf.C1.15; Méd.C5.22), independentemente da condição da família ou do paciente (Enf.B2.17). Outros mencionaram que o TS deveria ser realizado apenas nos dois primeiros meses de tratamento, seguindo o protocolo do Ministério da Saúde (Méd.C5.18).

Os depoimentos apontam que operacionalizar a DOTS envolve orientar o doente sobre o tratamento (AE.C2.6) e sobre a gravidade da doença (AE.B3.24), mostrando o contrato de adesão ao TS, para que este o assine (AE.F1.9). Neste contrato, o doente assume o compromisso de tomar 
a medicação sob a supervisão de um profissional de saúde (Med.C5.5) e define-se o local (Enf.C1.20; Enf.F3.17) e a freqüência do TS junto com o doente (Enf.F3.16), considerando suas necessidades (Méd.A2.19). Depois de preenchido, o "contrato" é encaminhado para a SUVIS, para que o doente seja cadastrado para receber a cesta básica (Enf.B2.18). Alguns depoimentos evidenciam que, além de supervisionar a ingesta da medicação, a equipe de saúde deve sempre manter a atenção na recuperação do paciente (Enf.E2.33), permitindo que este se sinta acolhido (Enf.E2.22).

Quanto ao local a ser realizado o TS, houve alusão de que pode ocorrer na UBS ou no domicílio (Enf.H1.7) mas, grande parte dos profissionais citam que a UBS é o local apropriado, por dispor de bom espaço físico (Enf.E2.28). Alguns depoimentos revelam que o TS no domicílio seria possível se a UBS dispusesse de Agente Comunitário de Saúde para realizá-lo (Enf.C1.35; Méd.G2.7). Outros profissionais mencionam que o TS realizado no domicílio contribui para "esconder" o doente, colaborando na perpetuação do estigma da tuberculose (Enf.E2.29).

Quanto à periodicidade do TS, mencionou-se que, em alguns casos, ocorre diariamente, preferencialmente no período da manhã e na UBS (AE.C2.8; Enf.E2.2; Enf.E3.7; Méd.C4.5; Méd.C5.6). Em outras unidades de saúde, o TS é realizado três vezes por semana, também no interior da própria unidade (AE.F1.10).

Conforme os depoimentos, cada unidade de saúde apresenta uma maneira diferente para desenvolver o TS. Em uma das UBS, o doente permanece com o medicamento, levando-o ao serviço de saúde nos dias 
combinados para o TS (AE.F1.24). Em outro serviço, o TS é realizado três vezes na semana no final da tarde. Nesse caso, o doente, pela manhã, em jejum, toma a primeira medicação e, à tarde, vai à UBS para que o profissional de saúde supervisione a ingesta da segunda medicação do dia, a pirazinamida (Enf.H1.8). Outro depoimento aponta que, quando o doente rejeita tomar o lanche na UBS, é impedido de tomar a segunda medicação, que deve ser ingerida após o desjejum. Nesta circunstância, a equipe de saúde orienta o doente a retornar ao seu domicílio, alimentar-se e voltar à UBS para tomar a segunda medicação (AE.B3.10).

Referiu-se que os doentes se "engajam" muito bem na DOTS (Enf.C1.11) e, quando possível, a equipe de saúde procura envolver membros da família nesse processo (Enf.B2.24), deixando-os responsáveis por supervisionar a ingesta da medicação nos finais de semana (Enf.B2.22).

Nessa perspectiva, o trabalho do ACS é citado como "super importante", pois conhece o doente e pode acompanhar todo o tratamento (Enf.B2.8), tendo sido citado como essencial no funcionamento do PCT (Med.G2.31).

Mencionou-se que quando o doente não comparece ao TS, a equipe de saúde entra em contato com ele ou com a família (AE.B3.19; Enf.H1.18), via telefone (Enf.H2.17), ou por visita domiciliária do ACS (AE.F1.27), ou pela equipe de enfermagem, que faz "visita rápida" (Enf.B2.21; Enf.C1.40). Considera-se necessário saber o motivo da falta do doente (AE.F1.12; AE.H2.7), mesmo sob o TS (AE.B3.8). 
O doente sob TS, geralmente, reside próximo à UBS e não trabalha (Med.A2.9; Méd.A2.11; Méd.C5.23). Quando trabalha em local muito distante de seu domicílio, há possibilidade de a equipe de saúde solicitar o TS para a UBS mais próxima ao trabalho do paciente (Enf.C1.58).

Os incentivos citados nos depoimentos foram: a cesta básica, que o doente começa a receber após o primeiro mês de tratamento; o lanche, que inclui o achocolatado e o cereal (AE.F1.14; AE.F1.25; Enf.F2.19; Méd.A2.10); além do passe de ônibus, entregue quando necessário aos doentes (Enf.H2.22). Citou-se que o lanche não é adequado aos pacientes que apresentam restrições, como os hipertensos ou diabéticos (Enf.C1.44). Aludiu-se que os "pacientes diferenciados", ou seja, aqueles que apresentam "melhor condição sócio-econômica", não recebem a cesta básica (Méd.G2.13).

Outros depoimentos revelam que o trabalho no TS é gratificante ao profissional (AE.C2.12), pois o doente agradece a atenção dispensada (AE.C2.11).

Quanto às limitações na operacionalização da DOTS, apontou-se que é burocrático (Enf.F3.18), que não é oferecido pela totalidade dos profissionais de saúde que atendem os doentes de tuberculose (Enf.C1.12; Enf.C1.54) e que a maioria dos profissionais não têm consciência sobre a importância da estratégia (Enf.C1.60). Apontou-se, ainda, que a entrega dos incentivos é irregular (Méd.C5.20) e que as cestas básicas são entregues com muito tempo de atraso (Enf.H1.21), criando problemas na rotina da UBS 
(Méd.C5.19). Apontou-se que o paciente "cobra" da equipe que o atende o recebimento da cesta básica (Méd.C5.8).

Apontou-se que o TS não possibilita que o doente se responsabilize pelo seu tratamento (Enf.B2.13), ficando esse encargo com a equipe de saúde, que, portanto,"carrega” o doente (Enf.B2.30).

\subsubsection{Os significados sobre a adesão ao tratamento}

A adesão ao tratamento da tuberculose é tida como "complicada" (AE.F1.19) e decorre do vínculo entre o profissional de saúde e o doente (AE.F1.32; Enf.C1.33; Enf.H2.13). Este ocorre quando o paciente sente-se acolhido pelo profissional que o atende, ao poder se expressar sobre as dificuldades do tratamento, isto é, quando pode "desabafar" (AE.C2.13; AE.H2.6; AE.H2.22; Enf.E2.12; Enf.E2.22). Para que o doente sinta-se acolhido perante os profissionais que o atendem, é necessário que estes estejam integrados às rotinas do TS (AE.F1.15; Enf.H2.23; Med.C5.11).

O oferecimento dos incentivos colabora na criação do vínculo (Enf.C1.23) e na adesão ao tratamento (Enf.B2.12; Enf.H1.28; Méd.A2.17; Méd.G2.35). Mencionou-se que, “(...) no Brasil, o PCT não funciona sem a cesta básica" (Méd.G2.37), pois as pessoas são "necessitadas" (Enf.C1.25) e "carentes" (Méd.G2.12). 
Outras questões que apóiam positivamente a adesão ao tratamento referem-se ao seu monitoramento por familiares (Enf.C1.46; Méd.G2.14), à realização de visita domiciliária e contato por telefone - quando o doente falta à consulta de rotina (Enf.H2.18, Méd.A2.16) - além do controle na entrega da medicação (Enf.C1.37). No caso dos pacientes alcoolistas e tabagistas, solicita-se que diminuam o consumo, sem cessá-lo totalmente, de forma a evitar prejuízos na terapêutica (Enf.C1.38).

Em alguns depoimentos verificou-se a importância dos agentes comunitários de saúde no processo da adesão ao tratamento, pois estes profissionais conhecem a família e atuam como elo de informação entre a equipe de saúde e o doente (AE.B3.27; Enf.B2.9). Segundo menção, os agentes comunitários lidam com questões que vão além da doença, o que permite avaliar outras necessidades que podem afetar 0 tratamento (Enf.B2.19).

Por outro lado, verificaram-se algumas citações de questões que interferem negativamente no processo de adesão ao tratamento da tuberculose, como: (1) o medo da doença após sua descoberta (AE.H2.14; Enf.E2.32); (2) a rejeição; (3) o isolamento; (4) a falta de apoio de familiares (AE.F1.28; Enf.H1.24); (5) a falta de apoio e de acolhimento no serviço (Enf.H1.24; Enf.H2.14), que deixa o paciente "nervoso" e sem paciência na UBS (AE.C3.17) para aguardar o atendimento (AE.F1.33); (6) a dificuldade no acesso às UBS (Enf.B2.28; Méd.G2.28); (7) a prorrogação do tratamento do doente, quando necessária (AE.C3.20); além (8) dos efeitos colaterais dos medicamentos, principalmente no início do tratamento (Enf.H2.21). 
Apesar de os incentivos colaborarem na adesão, alguns depoimentos revelam que sua distribuição é irregular e que ocorrem atrasos. Ainda que o conteúdo da cesta básica é "pobre" (Méd.C5.14), gerando, entretanto, expectativas aos doentes e familiares (Méd.C5.16). Enquanto que, para a equipe, isto se constitui em "pesadelo" (Enf.C1.22), com riscos de comprometer o vínculo com o doente e a equipe (Enf.C1.24).

A seguir, apresenta-se a discussão dos resultados com base na literatura científica. 
DISCUSSÃO 


\section{DISCUSSÃO}

\subsection{Características dos profissionais das UBS}

Dentre a totalidade dos profissionais de saúde, que atuavam diretamente na operacionalização da DOTS, dois estavam na faixa etária de 21 a 30 anos, cinco entre 31 e 40, 5 entre 41 e 50, oito entre 51 e 60 e dois acima dos 61 anos. Destaca-se o fato de que entre os coordenadores entrevistados, um tinha menos do que 40 anos.

O número de mulheres atuantes no serviço de saúde foi expressivo. A esse respeito, quando se verifica a forma como interpretam a questão relativa à saúde-doença, assim como procedem no cotidiano da assistência, ainda que não tenha sido objeto de estudo, verifica-se que há um importante componente, nas atitudes presentes e que pode relacionar-se à perspectiva de gênero, não se resumindo à variável sexo.

Segundo Fonseca (1998), a incorporação da categoria gênero permite diferenciar mulheres e homens não apenas biologicamente, mas socialmente. Isto permite refletir sobre a natureza do trabalho, particularmente desenvolvido pelas mulheres, o que pode dar um contorno distinto à gênese de organização dos processos de produção em saúde. Isto porque se verificou, conforme pode ser constatado na apresentação dos 
resultados que emanaram da decodificação dos depoimentos, que a atitude de acolhimento e prontidão para o estabelecimento de vínculo com as pessoas enfermas estiveram presentes.

Quanto à formação, sete eram enfermeiros, seis médicos, quatro assistentes sociais e cinco auxiliares de enfermagem, cuja graduação havia ocorrido há pelo menos cinco anos.

Quanto à experiência anterior na área de Tisiologia e Vigilância Epidemiológica, dentre os coordenadores de UBS, três disseram não tê-la e os demais referiram experiência de três anos no mínimo e quinze anos no máximo. Dois coordenadores de UBS eram responsáveis por realizar assistência e organizar a DOTS aos portadores de tuberculose. Dentre os profissionais de saúde que atuavam na assistência, nove disseram não ter tido experiência ou treinamento em Vigilância epidemiológica e Tisiologia, e os outros quatro mostraram que sua formação estava centrada na área de Saúde Pública, tendo experiência mínima de dez anos.

Destaca-se que a maior parte dos profissionais de saúde mencionou aprender a realizar ações de vigilância no cotidiano da assistência, assim como na própria operacionalização da DOTS. Os profissionais de nível superior mencionaram recorrer aos manuais técnicos para o esclarecimento de eventuais dúvidas, assim como por meio de contato telefônico com a SUVIS. Já os auxiliares de enfermagem dependiam da supervisão das enfermeiras.

Ainda que se considere persistente 0 aprendizado a partir das experiências concretas, provenientes da realidade, há que se ter em mente 
que é necessário um permanente processo de captação e reflexão acerca das questões de saúde, buscando nas vertentes teóricas o contraponto para explicar a realidade. E esta é uma das propostas dos Pólos de Educação Permanente, instituídos particularmente nos últimos cinco anos, de forma integrada à Atenção Básica. A proposição da Educação Permanente busca acoplar o processo de produção de serviços de saúde com a academia, de forma a tornar mais fisiológica a relação entre essas instituições. Nesse sentido, os trabalhadores de saúde poderiam valer-se de processos mais continuados de qualificação, tirando o caráter emergencial que, em geral, pouco apresenta significado no cotidiano de trabalho dos profissionais da saúde.

\subsection{Os significados sobre o processo saúde-doença}

De modo geral, encontrou-se similaridade na percepção dos gerentes das Unidades Básicas de Saúde e dos demais profissionais de saúde, em afirmar que a tuberculose é doença relacionada às condições sociais. Admite-se que grande parte dos indivíduos acometidos pela doença morava sob precárias condições de vida, trabalhava sob condições desfavoráveis, não sendo assegurados por leis trabalhistas. Sabe-se que há um número muito expressivo dos pacientes em trabalho informal e que apresentam baixo grau de escolaridade. Apontou-se que muitos doentes são 
considerados carentes por falta de suporte emocional e familiar e, na maioria dos casos, são alcoolistas.

A literatura corrobora esses achados. Ainda que em contexto social bastante distinto da sociedade brasileira, serão também utilizadas referências bibliográficas de âmbito internacional que podem apoiar a discussão dos dados.

Nessa perspectiva, Edginton, Sekate e Goldstein (2002), ao estudarem os conhecimentos sobre a tuberculose junto aos doentes e membros da comunidade, na África do Sul, em 1999, mostraram que $70 \%$ dos doentes nunca tiveram trabalho formal, e cerca de $44 \%$ estudaram menos de quatro anos. No Brasil, Bertolozzi (1991), ao traçar o perfil de doentes que recorriam à unidades de saúde do Município de Taboão da Serra - SP, refere que $66,7 \%$ dos doentes encontravam-se desempregados. Vendramini (2001), ao avaliar a DOTS junto aos doentes em uma Unidade Distrital de Saúde do Município de Ribeirão Preto-SP, referiu que metade dos pacientes sob tratamento trabalhava como autônomo e que, durante o tratamento, permaneciam desempregados.

Conforme se verificou nos resultados apresentados, há um estereótipo a respeito das pessoas que apresentam tuberculose. Veja-se que, por exemplo, os gerentes referem-se aos pacientes, de modo geral, como pessoas "difíceis", "complicadas". Os profissionais interpretam que os pacientes recebem o diagnóstico de tuberculose e sentem-se "mal, sujos, e que apresentam comportamentos não aceitos pela sociedade". Tal 
estereótipo ajudaria a levar o indivíduo a apresentar medo em receber o diagnóstico, dado que a enfermidade carreia o preconceito.

Vários autores, em contextos distintos, confirmam esses resultados, como Kelly (1999), ao analisar o entendimento dos doentes sobre a tuberculose em Chicago, no período de novembro de 1994 a abril de 1995. Da mesma forma, Edginton, Sekate e Goldstein (2002), ao estudarem os conhecimentos sobre a tuberculose junto aos doentes e membros da comunidade, na África do Sul, em 1999. Ou Meulemans et al. (2002), ao investigarem os conhecimentos em relação à enfermidade, no Paquistão, entre 1997 e 1998. E mesmo Eastwood e Hill (2004), ao estudarem as diferenças na busca por tratamento e conhecimentos sobre a tuberculose junto aos doentes em Gâmbia, 2002.

De modo geral há menção de que a tuberculose é doença "suja", e que as pessoas acometidas são pobres, com comportamentos que violam as regras de normalidade da sociedade. Inclusive, associando-a à prostituição, o que suscita sentimento de temor tanto aos doentes como em relação aos membros da comunidade onde o indivíduo vive, ou no grupo familiar ou em pessoas que integram seu grupo social. Segundo Bertolozzi (2005), para os profissionais de saúde, a tuberculose incide indiscriminadamente nas pessoas, sem voltar os olhos para as determinações do processo de vida dos indivíduos.

Numa outra perspectiva de abordagem, mas de igual maneira, revelando o preconceito em relação à enfermidade e especificamente envolvendo uma situação de gênero, Long et al. (2001), ao estudarem as 
conseqüências sócio-econômicas do estigma da tuberculose sob uma perspectiva de gênero, no Vietnã, 2000, mostraram que as mulheres, em geral, não possuíam oportunidades de estudos, e tinham acesso restrito à informação e aos serviços de saúde. Tais mulheres, ao receberem o diagnóstico de tuberculose, eram afastadas da rotina de atividades da família e da comunidade, prática que se perpetuava mesmo após o término do tratamento. Bertolozzi (2005) esclarece que os doentes acreditam desenvolver a tuberculose como uma forma de castigo.

Segundo os resultados do presente estudo, os profissionais de saúde acreditam que o recebimento do diagnóstico da tuberculose é pesaroso ao doente, por medo do isolamento familiar, da possibilidade de ter que se afastar do trabalho durante o período do tratamento, e pelo fato de sentir-se como um "peso" nas finanças da família.

Bertazone (2003), em estudo realizado em unidade de internação para doentes de tuberculose, em Ribeirão Preto-SP, refere que os doentes, por medo de ausentarem-se do trabalho, negligenciam os cuidados com sua saúde. Tal situação necessita que os profissionais de saúde, trabalhem de maneira a oferecer assistência reflexiva e de qualidade ao doente e sua família, considerando suas crenças, valores e princípios colaborando para solucionar ou minimizar o sofrimento do paciente.

Yamada et al. (1999), ao buscarem os conhecimentos de imigrantes filipinos a respeito da tuberculose, nos Estados Unidos, em 1994, e Long et al. (2001), ao estudarem as conseqüências sócio-econômicas do estigma da tuberculose sob uma perspectiva de gênero, no Vietnã, em 2000. Debateram 
essa questão, afirmando a presença do estigma no convívio familiar, pode fazer com que o recebimento do diagnóstico seja apreendido como sentença de morte ao doente, dado que o excluirá do cotidiano e de possibilidades de apoio para o enfrentamento da enfermidade.

Encontrou Bertolozzi (2005), ao entrevistar os trabalhadores da saúde a respeito da DOTS, na região central do Município de São Paulo, apresentou que estes acreditam que os doentes que apresentam maiores possibilidades de acesso ao consumo teriam maior dificuldade em lidar com a doença no cotidiano, fato que se origina de contradição inerente à própria inserção de classe.

Rajeswari et al. (2005), ao estudarem os doentes que receberam o diagnóstico da tuberculose na Índia, 2000, citam que, por medo, muitos doentes (67\%) informavam incorretamente o próprio nome e/ou o endereço de moradia para evitar serem encontrados e terem que vivenciar situações constrangedoras. No presente estudo, os depoimentos apontam outra faceta: que os doentes, principalmente os que apresentam HIV + , procuravam atendimento em unidades de saúde distantes de sua moradia. Destaca-se que tais estudos apontam que os doentes, por conta das condições econômicas da família, não deixaram de trabalhar para realizar o tratamento, necessitando do empenho dos profissionais para adequar o modo de tratamento, considerando suas necessidades.

Outro resultado do presente estudo refere-se ao fato de que a doença acarreta mudanças na rotina diária, dentre as quais aquelas que se relacionam diretamente ao estigma causado pela enfermidade. Tais como 
não compartilhar dos utensílios domésticos e não compartilhar do momento das refeições, assim como processos que incidem no interior da relação entre parceiros, podendo resultar em desarmonia conjugal; além das rupturas ou modificações importantes no cotidiano da produção e reprodução social do indivíduo. Nessa linha, Bertolozzi (2005) vai além, ao mencionar que o recebimento do diagnóstico “(...) causa impacto importante na vida do paciente, devido ao estigma que subjaz à enfermidade; à necessidade de cumprir o esquema terapêutico, o que acaba por trazer mudanças em sua vida; à chance de morte e faz emergir sentimentos de receio em relação à possibilidade de transmissão, principalmente aos familiares. A perda de emprego ou as dificuldades de inserção no sistema de trabalho são reais e diretamente associadas à evolução da doença".

A esse respeito, a literatura mostra outra perspectiva, de que a enfermidade pode determinar o aumento do estado de pobreza da família, por conta dos gastos dispensados com a manutenção do tratamento, que incluem transporte e possível afastamento do trabalho. Assim, não é raro que o medo que envolve a tuberculose determine que muitos indivíduos busquem o tratamento na medicina empírica, acreditando que a cura pode advir mais facilmente (Yamada et al., 1999; Edginton; Sekatane; Goldstein, 2002; Watkins; Plant, 2004).

Assim, Edginton, Sekatane e Goldstein (2002), ao estudarem os conhecimentos sobre a tuberculose junto aos doentes e membros da comunidade, na África do Sul, em 1999, falam sobre a necessidade de 
apreender os conhecimentos locais sobre a doença, o que pode permitir a diminuição do estigma e, conseqüentemente, facilitar a adesão.

Outro aspecto que foi encontrado no presente estudo diz respeito ao fato de que à tuberculose associa o alcoolismo, o tabagismo, ou mesmo o consumo de drogas ilícitas, situações que devem ser (e parecem ser) consideradas no processo terapêutico. A respeito do alcoolismo, por exemplo, um dos depoimentos fez referência ao fato de que a pessoa é orientada a "diminuir a ingesta, mas não parar". Conforme documento da Secretaria de Estado da Saúde de São Paulo (2006), o alcoolismo é considerado uma co-morbidade que interfere no processo do tratamento, e esteve presente em $12 \%$ dos casos novos de tuberculose diagnosticados no ano de 2005 no Estado de São Paulo.

Bertolozzi (2005), em estudo no Município de São Paulo, refere que o uso do álcool ou drogas constitui-se como um processo de desmaterialização da vida social, de busca de outros sentidos e sensações perante uma vida que, via de regra, revela carecimentos e sofrimento.

Outro aspecto que também foi encontrado no presente estudo diz respeito ao fato de que o estigma em relação à tuberculose não está presente somente no âmbito do convívio entre familiares ou pessoas do círculo mais próximo do cotidiano do paciente, mas também se revela nas situações de atendimento de rotina na unidade de saúde, por parte dos trabalhadores da saúde. Os coordenadores de UBS mencionaram esse fato, apontando que os profissionais médicos, as enfermeiras e os agentes comunitários de saúde teriam maior sensibilidade em lidar com os doentes. 
Os profissionais de saúde, na prática diária da assistência, mencionaram que há medo da contaminação e que, em decorrência, o atendimento aos pacientes portadores de tuberculose, em geral, é rápido, para diminuir as situações de exposição.

Por outro lado, também evidenciou-se uma reflexão de que o fato de a tuberculose estar mais presente na mídia faz com que as pessoas a apreendam como enfermidade de que todos podem ser alvo, universalizando, de certa forma, a possibilidade de contraí-la, sem correlacioná-la a aspectos que potencializariam a vulnerabilidade.

Neste estudo, foi mencionado pelos próprios profissionais de saúde que os trabalhadores de saúde não têm conhecimento sobre a doença e, conseqüentemente, não sabem orientar os doentes. Evidentemente que essa questão tem várias facetas. Dentre elas, o fato de que, ainda que a tuberculose se constitua em enfermidade prevalente no cenário epidemiológico, há dificuldade em "pensar" em tuberculose. Não é raro que os currículos de graduação de enfermagem, por exemplo, não contemplem abordagem sobre a enfermidade. Por outro lado, é bastante comum que os profissionais médicos também não sejam expostos, na formação acadêmica, à situações continuadas de atuação em relação à doença.

Edginton, Sekatane e Goldstein (2002), ao estudarem os conhecimentos de doentes e membros da comunidade sobre a tuberculose na África do Sul, em 1999, afirmam a falta de conhecimento dos profissionais, e que as ações destes estão associadas ao estigma, o que determina que deixem de ofertar orientações adequadas aos doentes. Tal 
questão também é confirmada por Yamada et al. (1999), ao buscarem os conhecimentos de imigrantes filipinos a respeito da tuberculose, em estudo realizado nos Estados Unidos, 1994, Johansson et al. (2000) ao estudarem os fatores envolvidos na demora pela busca de tratamento pelos doentes, sob a análise de gênero no Vietnã, em 1996, Watkins e Plant (2004) ao estudarem o comportamento dos doentes frente a tuberculose em Bali, em 2000, Hoa et al. (2004) ao estudarem o impacto da educação em saúde junto aos doentes sob tratamento no Vietnã, 2002 e Macq et al. (2005), ao estudarem o estigma da tuberculose junto aos doentes na Nicarágua, em 2003. De modo geral, esses autores citam que, durante o atendimento, os profissionais de saúde, além de reduzir o período de tempo com o doente, mantém excessivas condições de proteção pessoal, restringindo a circulação do doente no serviço de saúde. Dessa forma, o momento do encontro entre o profissional e o paciente não permite a troca de conhecimento sobre a doença e, tampouco, que os doentes revelem atitudes e sentimentos.

Segundo Macq et al. (2005), ao estudarem o estigma da tuberculose junto aos doentes na Nicarágua, em 2003, alguns serviços de saúde separam os doentes de outros pacientes que circulavam no serviço, mesmo após o término da primeira fase do tratamento, atitude que colabora para a manutenção do estigma.

Neste estudo, aludiu-se a importância de se orientarem os doentes e familiares sobre os modos de transmissão da doença, para facilitar a aceitação do diagnóstico da tuberculose junto de sua família. 
Mas os depoimentos também reforçam que as ações dos profissionais de saúde são essenciais para o processo de aceitação do diagnóstico e do tratamento da tuberculose, principalmente quanto à equipe de enfermagem, que está mais presente no processo de tratamento.

Kelly (1999), Edginton, Sekatane e Goldstein (2002), Ali et al. (2003) e Hoa et al. (2004) confirmam que os profissionais de saúde são considerados pilares no processo da adesão ao tratamento pelos doentes, por terem como papel fundamental oferecer orientações ao doente e sua família sobre a tuberculose, assim como os riscos do tratamento inadequado, envolvendo os familiares, incentivando-os no processo terapêutico. Segundo Kelly (1999), principalmente a equipe de enfermagem necessita criar condições para estimular a adesão ao tratamento, impedindo que atitudes decorrentes do estigma, principalmente quando envolvem a comunidade, interfiram no tratamento.

Ainda em relação aos achados do presente estudo, apontou-se um aspecto muito importante, que se refere ao diagnóstico tardio. Indicou-se que o rechaço, a negação da enfermidade podem retardar o diagnóstico, "pois não se pensa em tuberculose". E esta questão deve ser alvo, conforme mencionado anteriormente, do conteúdo dos cursos que formam profissionais de saúde, buscando trabalhar aspectos que dizem respeito à fisiopatologia e tratamento, assim como questões envolvendo o preconceito associado à forma como se concebe a enfermidade (Bertolozzi, 2005).

De modo geral, é necessário mencionar que os profissionais de saúde apresentam uma visão mais pautada na realidade do que os gerentes, 
evidentemente por vivenciarem o cotidiano nos aspectos que permitem o encontro com o doente, o relacionamento com as pessoas.

\subsection{A forma como se organiza o trabalho na UBS}

Os depoimentos dos gerentes apresentam uma dimensão mais ampla que reflete seu lugar no processo de produção de serviços. Assim, conseguem articular a questão da tuberculose a esse processo e ao contexto em que operam as políticas de saúde. Por isso, fazem referência ao período do PAS no Município de São Paulo, que resultou em muitos casos de "abandono" do tratamento da tuberculose, à "falta de informação" e ao "desaparecimento" dos casos de tuberculose. Tal modelo transferia a gestão dos Postos de Saúde e Hospitais para Cooperativas, que recebiam o equivalente a $\mathrm{R} \$ 10,00$ por mês, por morador da área geográfica.

Segundo Elias e Cohn (1998), o PAS foi um modelo de gestão que tinha como pressuposto a falência estatal na produção dos serviços de saúde, seguindo as prescrições de muitas agências internacionais que respaldavam o modelo econômico vigente, neoliberal. Esse modelo se consagra pela separação entre aquele que financia e aquele que produz serviços, reformulando a relação público/ privado, na qual, ao ente público, reserva-se o papel de agente financiador, enquanto que a produção de 
serviços é responsabilidade do âmbito privado (Elias, 1999). Tal gestão, o PAS, ocorreu no período de 1996 a 2000.

Nessa época, foram desativados e/ou minimizados diversos programas de caráter coletivo, que haviam evidenciado melhora dos indicadores sociais da cidade de São Paulo. Segundo os depoimentos do presente estudo, após a mudança da gestão de saúde do Município, o trabalho na área da vigilância epidemiológica reiniciou-se, principalmente no âmbito do Programa de Controle da Tuberculose.

Com isso, a UBS tornou-se a principal porta de entrada para os casos de tuberculose, o que reafirma os princípios e diretrizes do SUS. Nessa época, houve menção de que os profissionais de saúde foram instados a proceder à busca de casos, seguindo as recomendações do Programa de Controle da Tuberculose, uma vez que, na gestão anterior, muitos casos foram perdidos e não integravam o monitoramento conforme requer o atual sistema de vigilância epidemiológica (Brasil, 2000).

Apesar da reestruturação que ocorreu nos serviços, alguns depoimentos apontam que os doentes não têm confiança na resolubilidade do trabalho nas unidades de saúde, uma vez que não é raro que sua trajetória incorpora percorrer vários serviços até receber o diagnóstico correto. Outra questão importante que foi apontada diz respeito ao fato de que as mudanças de gestão para gestão causam impacto importante na assistência, quebrando a continuidade das práticas assistenciais.

A respeito da procura de outras possibilidades de assistência, que não os serviços de saúde. Eastwood e Hill (2004), ao estudarem as 
diferenças na busca por tratamento e conhecimentos sobre a tuberculose com base na categoria gênero na Gâmbia, em 2002, citam que muitos doentes buscam atendimento em farmácia, em curandeiros, ou outros, além de seguir orientações de familiares, pois sentem suas necessidades satisfeitas mais imediatamente. Nessa linha, Rubel e Garro (1992), discutem as reações culturais e sociais advindas da descoberta do diagnóstico da tuberculose, discutem a importância de se considerarem os valores dos indivíduos no momento do tratamento. E aqui, acrescenta-se, conforme aponta Bertolozzi $(1998,2005)$, as concepções a respeito da enfermidade, pois estas podem influir diretamente nos processos de adesão ao tratamento.

Segundo Bertolozzi (1998), perante as falhas do serviço de saúde em considerar as necessidades dos indivíduos, os doentes passam, de certa forma, a selecionar as suas queixas, expondo o que sentem em função do que potencialmente podem ter como resposta do serviço de saúde. Tal situação se configura como na realidade dos serviços de saúde, onde, de maneira geral, desenvolvem-se as ações fracionadas de saúde, com restrição do atendimento na queixa de ordem puramente biológica, sem que outras questões possam aflorar na assistência.

Segundo Muniz (1999), os profissionais de saúde conduzem suas orientações no sentido de diminuir o risco de transmissão da doença na comunidade, mas o enfoque da atenção privilegia a dimensão curativa, centrada na terapêutica.

Vendramini (2001) diz que o processo de trabalho em saúde está pautado no paradigma racional da doença-cura, limitando a proposição de 
intervenções que respondam efetivamente às necessidades de saúde dos diversos grupos sociais. Para Bertolozzi (1998), as questões sociais são apreendidas pelos trabalhadores de saúde, como mais um componente, um fator ou elemento no rol das possíveis causas da doença, não se levando em conta a determinação social do processo saúde-doença como uma vertente explicativa do fenômeno, fato que acaba por resultar em "ações tampão", sem impacto nos perfis epidemiológicos.

No que diz respeito à demora para o início do tratamento, Jaramillo (1998), ao estudar a trajetória percorrida pelo doente em busca de tratamento na Colômbia, em 1995, deixa ver que a demora na obtenção do diagnóstico nos serviços de saúde faz com que o doente perca confiança nestes. Enquanto Kiwuwa, Charles e Harriet (2005), ao estudarem o período de tempo decorrido até o recebimento do diagnóstico em Uganda, em 2002, apontam que os doentes levavam, em média, dois a três meses.

Bertolozzi (2005), ao estudar uma população onde prevaleciam pessoas com importantes graus de exclusão social, no Município de São Paulo, menciona que a falta de familiares presentes no cotidiano do doente, associada a outras perdas decorrentes da inserção precária na estrutura social, proporciona marcas importantes na forma como essas pessoas exercem o auto-cuidado, com repercussão para a demora na busca da assistência à saúde. Esta não está isolada, também, do acesso que têm em relação aos serviços de saúde, ainda que sob a égide do SUS, que, em tese, garantiria a universalidade de acesso. 
Voltando aos resultados deste estudo, as atividades junto à vigilância epidemiológica foram retomadas por ocasião da mudança de gestão da Prefeitura do Município, e a reconfiguração do trabalho exigiu dos profissionais passar por processo de aprendizagem, a partir da própria prática cotidiana. Equipes de saúde foram compostas e os casos de tuberculose eram acompanhados a partir das fichas de notificação e do livro de registro de casos, tradicionalmente conhecido como "Livro Preto". Esse trabalho carecia de profissionais capacitados, o que exigiu um grande esforço na reestruturação do modelo de assistência.

Bertolozzi (2005), ao fazer menção à tuberculose, aponta para o caráter processual do trabalho em vigilância à saúde, que requer prontidão, instrumental técnico e processos de sensibilização, que proporcionem meios para compreender a problemática da enfermidade que envolve situações de complexidade extrema, dada a sua marca social.

Ora, a qualificação dos profissionais incide diretamente na melhora do trabalho prestado à clientela. Os processos de sensibilização e de capacitação permanente são importantes também para promover apoio emocional no processo do tratamento, assim como permitir a escuta do doente, firmando o compromisso ético-profissional perante o mesmo (Brasil, 2002b).

Os depoimentos dos profissionais de saúde que atuavam na assistência apontam que os treinamentos, na maioria das vezes, são oferecidos aos gerentes das unidades de saúde ou aos profissionais que apenas coordenam o trabalho, fato que, em decorrência, determina que 
informações importantes não sejam veiculadas e cheguem às bases onde concretamente ocorre o encontro com o doente.

Além disso, apontou-se que os treinamentos, em geral, são teóricos, considerados incompatíveis para a sua realização nos serviços, por falta, principalmente, de recursos humanos, assim como não correspondem às necessidades advindas da população adscrita. Apontou-se, ainda, a organização do serviço, que não contempla a possibilidade de desenvolver o PCT na íntegra. Também se verificou nos depoimentos que os treinamentos são demasiadamente curtos, e que não contemplam a prática, o que restringe o seu aproveitamento para a implementação no cotidiano. Acrescese, ainda, o fato de que conteúdo ofertado pode não suprir as necessidades daqueles que atuam diretamente junto ao PCT (Campinas, 2004).

Os depoimentos apontam, ainda, que nem todas as unidades de saúde estão sensibilizadas para atender os doentes, principalmente levando em conta as necessidades dos indivíduos. Conforme estudo de Oliveira e Moreira Filho (2000), realizado em Campinas, São Paulo, no período de 1993 a 1994, tal situação pode interferir negativamente no processo de adesão ao tratamento pelo doente. Os autores citam a necessidade melhorar as orientações oferecidas aos doentes, assim como apontam a necessidade de que as UBS disponham de suporte técnico, incluindo supervisão das atividades desenvolvidas.

No presente estudo, defendeu-se que a equipe de enfermagem está mais próxima do doente durante o tratamento, enquanto o médico é responsável especificamente pelo tratamento. Tanto os coordenadores de 
UBS como os profissionais de saúde apontaram a importante presença dos auxiliares de enfermagem na observação da tomada da medicação pelos doentes. Lima et al. (2001), ao estudarem os fatores que determinam o abandono pelos doentes num Centro de Saúde em Fortaleza, Ceará, no período de 1995 a 1996, também apontam que os profissionais médicos, em geral, restringem-se ao momento clínico de abordagem do doente, e isto é endossado pelos doentes que deles esperam o diagnóstico. Ainda segundo os autores, as enfermeiras focalizam o trabalho na supervisão de certas ações que integram o acompanhamento de alta, a transferência de paciente, assim como o acompanhamento de resultados de exames laboratoriais.

Campinas (2004), em estudo realizado em São Paulo, em 2003, comparou o atendimento realizado em USF com ambulatórios de especialidades, verificando que o papel do enfermeiro se destaca nas primeiras unidades de saúde mencionadas. Isto porque realizam consulta de enfermagem e participam do acolhimento do doente e sua família, diferentemente do atendimento oferecido em ambulatórios de especialidades, onde as práticas se restringem à racionalidade orientada para a queixa, sendo o auxiliar de enfermagem o protagonista do atendimento mais próximo ao doente.

No presente estudo, os coordenadores de UBS apontaram que a enfermeira conhece os pacientes, realiza consulta de enfermagem, visita domiciliária, faz o controle de faltosos, elabora relatórios, solicita medicação. E que o fato de a vigilância epidemiológica, e especificamente a realização da DOTS, requererem o preenchimento de impressos, prejudica o cotidiano 
da assistência, no contato com o doente. Além dessas atividades mencionadas pelos gerentes, os profissionais de saúde arrolaram outras, como anotação em prontuário, solicitar exames, proceder ao controle dos comunicantes, assim como preparar a equipe de enfermagem para a operacionalização da DOTS.

É importante destacar, ainda, que coordenadores de UBS e profissionais de saúde defendem a necessidade de se dispor de equipe que atue especificamente na operacionalização do TS.

Outra questão abordada refere-se ao fato de que os coordenadores de UBS apontaram que a UBS tem um papel primordial na diminuição da disseminação da tuberculose, no controle de bacilíferos e na diminuição das taxas de abandono. Consideram a UBS como a porta de entrada do sistema de saúde, ao contrário dos profissionais de saúde que apontam que isto deveria ocorrer. Mas, o que de fato se verifica é que os casos não são identificados no primeiro nível de assistência, o que faz com que os pacientes tenham seu quadro de saúde agravado. Mesmo assim, os profissionais declaram que a tuberculose se constitui em prioridade no atendimento, uma vez que envolve a saúde da coletividade.

A esse respeito, os depoimentos revelam que não ocorre a busca de casos, fato que os sujeitos de estudo parecem lamentar. A falta da busca de casos foi apontada como decorrente da limitação de recursos humanos, repercutindo na operacionalização da assistência e ferindo os princípios do SUS, assim como o próprio Programa de Controle da Tuberculose. A busca 
de sintomáticos respiratórios e contatos deve ser uma atividade permanente e incorporada à rotina (Brasil, 2000).

\subsection{Os significados sobre o Tratamento Supervisionado (DOTS)}

De maneira geral, as interpretações dos coordenadores das Unidades Básicas de Saúde, assim como dos profissionais de saúde que realizam a DOTS nas UBS, não diferem. Nos depoimentos há menção de que a DOTS apóia a adesão ao tratamento, ainda que não seja suficiente para superar o problema da tuberculose. A DOTS, ao possibilitar o seguimento continuado do doente, permite que se estabeleça uma relação com o profissional de saúde, que reflete, inclusive, no fato de que o paciente sinta-se acolhido ao apresentar alguma queixa e encontrar acesso mais facilitado junto aos trabalhadores da saúde.

Segundo Mishra et al. (2006), ao estudarem o processo da comunicação entre os profissionais de saúde e os doentes no Nepal, no período de 1996 e 2001, revelam que o sucesso da manutenção de altas taxas de adesão ocorreu devido à DOTS e ao empenho dos profissionais de saúde em manter comunicação adequada com os doentes. Ora, evidentemente que o processo comunicacional não se encerra nessa lógica retilínea, mas pressupõe o canal aberto para escuta. Daí o fato de o TS não 
se restringir à observação da ingesta da medicação, mas se ampliar para a escuta e compartilha de necessidades, conforme aponta Bertolozzi (2005).

Conforme os depoimentos apresentaram, o TS é interpretado como atividade que "assegura" a manutenção do tratamento e que deve ser mantida na unidade de saúde, dado que não repercute negativamente na dinâmica da unidade de saúde, apesar de requerer infra-estrutura que ainda se apresenta precária.

Vendramini (2001) corrobora tal afirmação e acrescenta que o TS se constituiu como momento oportuno para o doente compartilhar dúvidas, angústias, problemas e necessidades, permitindo a ampliação do foco terapêutico para além do diagnóstico médico. Bertolozzi (1998) aponta que o profissional de saúde pode aproveitar esse momento como espaço para desmistificar a doença, além de buscar fortalecer o doente no enfrentamento do processo saúde-doença, estimulando-o para o exercício da cidadania.

No presente trabalho, os depoimentos revelam que o Tratamento Supervisionado é prática que se inicia na recepção do doente, e que se continua na observação da ingesta da medicação, permitindo o estabelecimento de vínculo entre o profissional de saúde e o doente. Nesse processo, que certamente não é linear, e estão em cena sentimentos, necessidades, como a própria estrutura do serviço de saúde, que muitas vezes limita a aproximação com o doente.

Além disso, o Tratamento Supervisionado é apreendido pelos trabalhadores de saúde como estratégia que torna a Unidade de Saúde mais "acolhedora" pela proximidade de contato com o doente, além de envolver o 
profissional de saúde e o paciente numa relação em que ocorre entendimento, captura e encaminhamento das necessidades que emergem por ocasião da interação.

Neste estudo, o vínculo é considerado fundamental para o processo de adesão ao tratamento, e envolve desenvolver responsabilidades mútuas, tomada de decisões compartilhadas, em parceria, considerando sempre as opiniões do doente. Jaiswal et al. (2003), ao estudarem as necessidades e perspectivas dos profissionais de saúde e dos doentes sob DOTS na Índia, no período de 1996 e 1998, e Mishra et al. (2006) ao estudarem o processo da comunicação entre os profissionais de saúde e os doentes no Nepal, período de 1996 e 2001, defendem que a DOTS possibilita o desenvolvimento de vínculo, o que contribui para a adesão ao tratamento.

Mencionou-se que o TS é gratificante aos profissionais de saúde, pois percebem a melhora do doente, já que o monitoramento ocorre continuadamente. Bertolozzi (2005), em estudo realizado no município de São Paulo-SP, também refere que o TS é apreendido como estratégia que torna a UBS acolhedora, na medida em que envolve relação entre sujeitos. Para tanto, a autora aponta a necessidade de dispor de funcionários em tempo integral para assistir esses doentes. Esse, em geral, é um dos problemas do TS, pois os funcionários atuam simultaneamente em outras atividades do cotidiano do serviço. Essa multiplicidade de ações, ainda que seja interessante no sentido de que permite uma certa noção dos processos de trabalho da unidade como um todo, deve ser avaliada com propriedade, uma vez que não é raro que os profissionais se vejam obrigados a atuar 
"emergencialmente", fato que repercute negativamente na qualidade do serviço ofertado.

Segundo os profissionais de saúde, os pacientes parecem não criticar a operacionalização da estratégia. Ao contrário, avaliam-na como possibilidade de acesso à unidade de saúde e aos profissionais, conforme anteriormente apontado.

No processo de atendimento em que se coloca o vínculo como elemento fundante, os profissionais de saúde propõem alternativas que podem possibilitar ao doente manter-se sob DOTS durante o tratamento, como, por exemplo, a flexibilidade nos horários para a supervisão da medicação, ou a modificação da freqüência à unidade de saúde, conforme as necessidades particulares advindas da vida do paciente. Nessa linha, Bertolozzi (2005) aponta para a necessidade de que, no encontro cotidiano, sejam identificadas vulnerabilidades que podem conduzir ao abandono do tratamento.

Segundo Vendramini (2001), é importante considerar o doente como único em suas necessidades, sempre entendendo-o em um contexto maior que diz respeito à sociedade onde se realiza a produção e a reprodução social. Isto quer dizer, conforme já apontava Bertolozzi (1998), que há que se considerar que a adesão requer o entendimento do lugar social ocupado pela pessoa, pois deste decorrem as possibilidades de acesso à vida.

Por outro lado, ainda que se conceba a estratégia como possibilidade de apreensão das necessidades do doente, assim como de escuta para viabilizar o encontro de alternativas de solução, um dos profissionais de 
saúde mencionou que há profissionais que não a oferecem a todos os pacientes, apesar das recomendações do próprio Programa de Controle da Tuberculose (São Paulo, 2005b). Nos depoimentos parece estar claro que essa atitude decorre do desconhecimento a respeito da potencialidade da estratégia, assim como de seus elementos acessórios, como os incentivos, além da possibilidade de flexibilizá-la segundo as necessidades dos indivíduos.

No que diz respeito ao perfil dos pacientes a quem deve ser indicado o TS, no presente estudo foram mencionados os pacientes "difíceis", os recidivantes, e os que abandonaram o tratamento anteriormente, ainda que alguns sujeitos do estudo propõem que seja indicado a todos os doentes, indiscriminadamente, tendo em vista as altas taxas de incidência da doença.

Por outro lado, um dos coordenadores de UBS mencionou que a estratégia deve ser oferecida ao doente, a quem cabe, em primeira instância, decidir por adotá-la. Parece estar claro, portanto, que em algumas unidades de saúde, os profissionais de saúde procuram interagir com o doente, procurando conhecer suas necessidades, para então determinar, conjuntamente, a freqüência e o período de tempo a ser mantido no TS, não seguindo, portanto, plenamente, as recomendações do PCT. O Programa de Controle da Tuberculose recomenda que o TS é prioritário apenas nos dois primeiros meses do tratamento, devendo ser desenvolvido durante toda a semana. Assim, o doente requer o apoio de membro da família, ou outra pessoa, para dar continuidade ao tratamento no final de semana. Nos quatro meses restantes, a supervisão deve ser realizada pelo menos uma vez por 
semana (Organización Mundial de la Salud, 1997; Brasil, 2005b; RuffinoNeto e Villa, 2006).

Em estudo realizado em Ribeirão Preto, São Paulo, no período de 1998 a 1999, apontou-se que o TS deve ser principalmente indicado para os doentes que apresentam alto risco para o abandono, como os alcoolistas, os usuários de drogas, as pessoas sem moradia, os moradores de asilos ou encarcerados, além daqueles sob precárias condições sociais (Hino et al., 2005).

No que diz respeito à atuação dos profissionais de saúde junto a DOTS, conforme mencionado anteriormente, a equipe de enfermagem e, mais particularmente o auxiliar de enfermagem e, em alguns casos, os agentes comunitários de saúde, apresentam maior contato com o doente e sua família.

Nesse sentido, ainda que não tenha sido captada essa dimensão no presente estudo, vale apontar que, segundo os autores Gleissberg et al. (1999), Macq et al. (2003) e Hino et al. (2005), destacam a participação expressiva da enfermagem na operacionalização da DOTS, ao realizar a supervisão da ingesta da medicação, ao ofertar suporte emocional ao doente e ao orientar sobre a doença e acompanhar os comunicantes.

Bertolozzi (2005), ao estudar a DOTS no Município de São Paulo, verificou a importante participação dos auxiliares de enfermagem a presença frágil das enfermeiras no cotidiano da assistência. Estas, em geral, se dedicavam a ações que apóiam o gerenciamento do serviço. 
Voltando aos resultados do presente estudo, via de regra, avalia-se que a DOTS não repercute negativamente na rotina da Unidade de Saúde, e é incorporada na rotina do serviço. Aqueles que se posicionaram do lado oposto, mencionaram que a atividade é trabalhosa, altera a dinâmica da unidade de saúde, e é excessivamente burocrática, exigindo maior número de funcionários. Além disso, apontou-se a necessidade de que os profissionais de saúde sejam capacitados para o seu desenvolvimento.

Jaiswal et al. (2003), Macq et al. (2003) e Hino et al. (2005) apontam que a implementação da estratégia no serviço de saúde requer a realocação de funcionários, a redefinição de suas funções e, se necessário, aumentar o número de profissionais, além da necessidade de capacitá-los para desenvolver tal atividade, destacando que se trata de uma atividade que requer comunicação respeitosa para com o doente e sua família.

Segundo Ruffino-Netto e Villa (2006), para manter a qualidade da DOTS é necessário dispor de um plano permanente de capacitação para os profissionais de saúde e um cronograma de supervisão sistemática e periódica aos serviços de saúde, de forma a acompanhar os aspectos positivos, mas também as vulnerabilidades do Programa de Controle.

Quanto ao local onde é realizado o TS, a totalidade dos doentes comparecia à unidade de saúde para receber a medicação. Em alguns depoimentos apontou-se que a DOTS no domicílio seria mais adequada, mas a limitação de recursos humanos não permite que isso ocorra. Entretanto, houve menção de que o TS na moradia colaboraria para a perpetuação do estigma, pois o doente manter-se-ia "escondido", não 
possibilitando que se relacione com outras pessoas. Mohan, Nassir e Niazi (2003), ao avaliarem a eficácia do tratamento supervisionado no domicílio do doente, em Bagdá, no ano de 2003, apontam que o TS tem sua eficácia potencializada quando realizada no domićlio, uma vez que contribui para que o doente sinta que o serviço de saúde o acolhe, pelo fato de receber um agente de saúde na própria residência.

Segundo Ruffino-Netto e Villa (2006), no Estado de São Paulo, no ano de 2005 , cerca de $13 \%$ dos municípios desenvolveram a DOTS no domicílio dos doentes, o que não é um montante desprezível. É evidente que, muito provavelmente, tratam-se de experiências pontuais e que a estatística pode mascarar, mas é importante ter em mente que a participação dos agentes comunitários de saúde no cotidiano da saúde, assim como a possibilidade de contar com o apoio de pessoas da família ou da comunidade podem se constituir em alternativas que contribuem para maior conforto do doente. Isto porque, no início do tratamento, não é raro que os doentes sintam-se muito debilitados em termos de condições físicas, o que demanda um esforço muito significativo terem que deslocar-se até a unidade de saúde.

Ainda é muito importante destacar que a DOTS, conforme apontado em muitos depoimentos, constitui-se num instrumento para modificar a difícil situação epidemiológica da tuberculose. Com isso, não se quer descartar a necessidade de mudança das condições que levam, de fato, ao adoecimento, e que estão diretamente associadas à determinação social. De qualquer forma, o TS se coloca como uma tecnologia, conforme aponta Bertolozzi (2005), de cunho substantivamente relacional, que apóia o desenvolvimento 
do tratamento e que não deve ser descartada a priori, principalmente em se tratando de pacientes cuja trajetória apresenta situações de vulnerabilidade e que os fazem mais propensos a não dar continuidade ao tratamento.

A respeito dos incentivos, segundo menção dos sujeitos do estudo, todos os doentes sob a DOTS os recebem, dada a situação de carência com que se apresentam, de maneira geral. A esse respeito, houve menção de que são necessários para manter a adesão ao tratamento. Entretanto, a irregularidade em sua distribuição e a baixa qualidade dos produtos faz com que muitos profissionais não se sintam confortáveis em oferecê-los, além do fato de que não são apropriados em todos os casos, como por exemplo nas situações dos hipertensos e diabéticos.

Ruffino-Netto e Villa (2006) mencionam que os incentivos são adotados em vários municípios brasileiros com o intuito de facilitar a adesão ao tratamento e facilitar o desenvolvimento do vínculo entre este e o profissional de saúde.

Apesar de que parecem ter sido apontadas com maior expressividade as considerações positivas sobre a eficácia da DOTS, os depoimentos também fazem referência a certos aspectos negativos que devem ser considerados. Dentre eles, apontou-se que a estratégia inibe a autonomia do doente durante o tratamento e que não permite que a pessoa se responsabilize pelo próprio cuidado.

Bertolozzi (2005), em estudo realizado na região central do Município de São Paulo, com pacientes que, em sua maioria, apresentavam carências sociais muito importantes, pois eram moradores de rua e usuários de 
albergue, advoga que, para tal população, a estratégia possibilitava, de certa forma, a participação da pessoa no cotidiano, excluída que se encontrava, de maneira geral, perante a vida. A mesma autora prossegue em suas ponderações, questionando de qual autonomia se fala, quando verdadeiramente a enfermidade decorre de situações de carecimentos em em função de seu lugar social. Encontram-se, pois, destituídas de cidadania e de direitos. Assim, a doença se inclui na perniciosa desigualdade social.

A mesma autora encontrou em seus achados que os doentes, assim como os profissionais de saúde, consideravam o TS menos restritivo do que a internação, dado que esta diminuía a possibilidade de encontros com outras pessoas, contribuindo para o isolamento que é uma das importantes questões que se conjugam à tuberculose.

Outra dificuldade mencionada, em relação à estratégia, e de certa forma já apontada anteriormente, diz respeito ao fato de que nos fins de semana pode haver solução de continuidade, ou seja, a estratégia pode ser descontinuada, fato que exigiria a disponibilidade de algum membro familiar, vizinho, ou outro para acompanhar a tomada da medicação. Isto é particularmente importante no caso dos moradores de rua e das pessoas que não contam com o apoio de familiares. Tal se constitui em questão que deve ser considerada pelos profissionais da saúde. Há que se lembrar que o envolvimento da comunidade no controle da tuberculose tem sido progressivamente indicado, pois é no espaço onde ocorre a vida e o trabalho que tem origem a enfermidade, assim como as alternativas para a sua solução (Bertolozzi, 2005). Não se está aqui remetendo à responsabilidade 
aos indivíduos de forma particular, mas o que se quer apontar é que no espaço mais próximo do doente, no território onde habita, podem ser encontradas alternativas de participação da comunidade.

\subsection{Os significados sobre a adesão ao tratamento}

Para os profissionais de saúde, a adesão não é um processo linear. É "complicada", e está diretamente relacionada ao vínculo estabelecido entre o doente e o profissional de saúde.

Por um lado, mencionou-se que o vínculo deve decorrer do profissional de saúde, que deve se abrir ao paciente, e lhe possibilitar a expressão de sentimentos e de necessidades. Por outro lado, a adesão é um processo construído no cotidiano: (1) decorre do oferecimento do medicamento, de orientações, (2) da inserção do doente no serviço, (3) de seu acesso sempre que necessário e (4) da disponibilidade de um profissional que seja referência para o atendimento. Portanto, requer-se de profissional de saúde que conheça as rotinas da unidade de saúde.

A adesão ocorre, ainda, com o apoio de familiares, com atividades que o profissional realiza no âmbito extra-muros, como no caso de visitas domiciliárias, que permitem conhecer as necessidades das pessoas e de suas famílias. Para tanto, apontou-se os agentes de saúde como 
fundamentais, porque encontram-se mais próximos ao cotidiano da comunidade.

Portanto, a adesão é ameaçada quando práticas de assistência não permitem flexibilização (em termos de mudança de horário por exemplo), tendo-se apontado que as práticas que determinam o acesso ao serviço de saúde na rigidez da estrutura do processo de produção de serviços ferem a cidadania e o exercício da liberdade como direito.

De modo geral, avalia-se que os incentivos contribuem para a adesão dos pacientes ao tratamento, dada a situação de precarização com que se apresenta a maior parte dos doentes. Mas há ambigüidade nesse posicionamento, pois encontraram-se profissionais de saúde que explicaram que os incentivos garantem univocamente a adesão e o vínculo.

Como elementos que influem negativamente na adesão foram apontados, dentre outros, o número de medicamentos, os efeitos colaterais e a longa duração do tratamento. Alvarez-Gordillo et al. (2000), ao estudarem as percepções e práticas do doente sobre a enfermidade e o tratamento no México, no período de 1997 e 1998, e Hoa et al. (2004), ao analisarem o impacto da educação em saúde junto aos doentes sob tratamento (estudo realizado no Vietnã, em 2002), apontam que a adesão se consolida a partir do momento em que o doente entende os riscos do abandono do tratamento, e conhece o plano de tratamento. Na mesma linha, Kaona et al. (2004), ao examinarem os conhecimentos dos doentes sobre a transmissão da tuberculose na Zâmbia, em 2004, mencionam que quando os 
doentes não conhecem os riscos do abandono, ao sentirem-se melhor após o início do tratamento, podem descontinuá-lo.

Gleissberg et al. (1999), em pesquisa realizada na Sibéria em 1997, referem que a equipe de saúde necessita constantemente apoiar o doente no processo terapêutico para evitar a sensação de desânimo que não é incomum durante a enfermidade. Nessa linha, Mishra et al. $(2005,2006)$, ambos as pesquisas realizados no Nepal, reforçam que a baixa adesão está diretamente relacionada à comunicação inefetiva, sem vínculo, entre profissionais e doentes.

Ora, esquemas de tratamento de longa duração, em geral, estão associados às dificuldades no seu seguimento. Conforme aponta Bertolozzi (1998), há uma enorme disponibilidade de relatos científicos que multifatorializam o abandono no caso de enfermidades crônicodegenerativas ou em enfermidades que requerem tratamento continuado.

Para lidar com os problemas que se colocam no processo de adesão, a mesma autora citada anteriormente advoga interpretar a adesão conformada a partir de elementos do cotidiano que guardam relações de interdependência e subordinação. Nesse sentido defende que a adesão, conforme conceito que embasa o presente estudo deve abarcar a forma como o doente interpreta o próprio processo saúde-doença, assim como a compreensão sobre sua posição no processo de produção e de reprodução social, que vai possibilitar potencialidades diferenciadas em termos de acesso aos elementos que compõem a vida e o trabalho. Ademais, a autora incorpora a faceta relativa à organização dos serviços de saúde que devem 
estar orientados a atender as necessidades dos doentes (Bertolozzi 1998, 2005).

Em estudo mais recente, a mesma, Bertolozzi (2005) incorpora com mais densidade a necessidade do estabelecimento do vínculo para a efetivação da adesão. Este - não como relação de dependência, mas de construção de emancipação - permite aos profissionais de saúde conhecerem a situação de vida do doente, o que pode proporcionar possibilidades de enfrentamento do processo saúde-doença, fortalecendo, inclusive, a inclusão social para determinados doentes. Dado que, em geral, no caso da tuberculose, a determinação social é fato concreto.

Ainda que a mesma autora faça referência a outro elemento que fortalece o vínculo, conforme será visto a seguir, Lima et al. (2001), em análise realizada em Fortaleza, Ceará, no período de 1995 e 1996, já defendiam que, além da organização dos serviços, colaboram na adesão (1) a relação de afeto entre os profissionais e o doente; (2) o esclarecimento de dúvidas, assim como a (3) veiculação de informações de maneira clara aos clientes durante a visita domiciliária, ou na UBS.

Neste presente trabalho, encontrou-se paralelo com essas questões, uma vez que houve alusão de que o papel do profissional de saúde vai além do desenvolvimento dos protocolos de atendimento elaborados pelo Ministério da Saúde, uma vez que colocavam o atendimento do doente em primeiro plano. Como exemplo disso, mencionou-se a alternativa de flexibilização da realização da DOTS segundo as necessidades do doente. 
Segundo Vendramini (2001), os profissionais que mostram compromisso com o trabalho em saúde e com os doentes buscam superar as dificuldades apresentadas pelo doente e pelo serviço, para colaborar no processo de adesão.

Ruffino-Netto e Villa (2006) mencionam que o atendimento ao doente exige visão ampliada e humanizada, orientada às necessidades para além da doença. Mishra et al. (2005, 2006), em estudo anteriormente mencionado, apresentam posições semelhantes ao afirmar que o vínculo se desenvolve a partir do compromisso mútuo, firmado entre a equipe de saúde e o doente, no qual a equipe de saúde deve oferecer apoio ao doente e seus familiares no processo terapêutico, permitindo que sejam ouvidos, assim com proporcionar orientação sobre a doença e sobre os medicamentos.

No presente trabalho, apontou-se a importância da atuação dos Agentes Comunitários de Saúde no processo de adesão ao tratamento, pois estes, em geral, além do doente, conhecem seus familiares, assim como situações que evidenciam a forma como vivem o dia-a-dia. Portanto, estes acabam por atuar como facilitadores do processo de adesão. A esse respeito, Ruffino-Netto e Villa (2006) apontam que os ACS constituem atores que se mostram flexíveis na assimilação de novas estratégias, incorporando mais facilmente conceitos, atuando com criatividade e favorecendo um ambiente propício ao desempenho do Tratamento Supervisionado.

Alvarez-Gordillo e Dorantes-Jiménez (1998), mencionam, em pesquisa desenvolvida no México, no ano de 1996, defendem que os incentivos oferecidos, a curto prazo, contribuem para a adesão ao 
tratamento. Da mesma forma, Bertolozzi (2005) e Ruffino-Netto e Villa (2006), confirmam que os incentivos facilitam o processo da adesão ao tratamento pelo doente e a criação do vínculo. Destaca-se que a primeira autora, ainda que considere que estes contribuem na adesão, advoga a instauração de ações e de políticas que possibilitem a inserção social dos indivíduos, pois tratam-se de benefícios que, se conjunturalmente, apóiam o processo, não modificam a realidade da vida.

Ainda no presente trabalho, os efeitos colaterais dos medicamentos também influenciam na adesão. Daí a importância do profissional de saúde em colocar-se disponível para solucionar eventuais dúvidas, assim como para ouvir o doente e procurar orientá-lo a respeito. Alvarez-Gordillo et al. (2000), em trabalho realizado no México, no período de 1997 e 1998, discutem a participação da equipe de saúde no esclarecimento de dúvidas sobre o tratamento, a partir das necessidades de cada doente, buscando fazê-lo perceber a importância da terapêutica, e que consiga superar as dificuldades advindas desse processo.

$\mathrm{Na}$ revisão bibliográfica realizada no desenvolvimento da presente dissertação, não se encontrou produção científica que apresente a adesão ao tratamento da tuberculose na visão mais abrangente proposta por Bertolozzi (1998). Conforme anteriormente apontado, a autora constrói um conceito de adesão que se coloca como síntese que conjuga a dimensão singular, referente (1) à forma como o paciente concebe a doença, (2) à dimensão particular, que incorpora a apreensão da forma como a pessoa participa do processo de produção e reprodução social, e (3) à dimensão 
estrutural, que se refere à forma como se organizam os serviços de saúde para 0 atendimento às necessidades dos doentes, garantindo a acessibilidade aos serviços. Adverte que, a depender das condições em que se encontra o indivíduo, outras questões podem apresentar-se mais relevantes do que a busca por assistência à saúde, como, por exemplo, a necessidade de responder às demandas decorrentes da sua própria sobrevivência e de sua família, processo que pode fazê-lo deixar para segundo plano o cuidado consigo próprio. Portanto, buscar entender o significado da enfermidade para o doente é fundamental no cotidiano da assistência, e a DOTS contribuiria para facilitar essa apreensão de situações e de condições que constituem a própria vida do sujeito. Assim, Bertolozzi $(1998,2005)$ entende que o TS transcende a ingesta da medicação, e deve considerar os modos de vida do indivíduo e sua dinâmica familiar, além de suas crenças, opiniões e conhecimentos sobre a doença e o tratamento. 


\section{CONCLUSÕES E CONSIDERAÇÕES FINAIS}




\section{CONCLUSÕES E CONSIDERAÇÕES FINAIS}

Este estudo se constituiu em um esforço no sentido de analisar a adesão ao tratamento da tuberculose segundo profissionais de saúde e coordenadores de UBS, de uma determinada região de saúde, a partir da operacionalização da estratégia DOTS. Teve ainda como objetivos identificar os limites e as potencialidades dessa estratégia na adesão ao tratamento para a tuberculose.

Para isso, o trabalho organizou-se a partir das seguintes categorias analíticas: significados sobre o processo saúde-doença, significados sobre a DOTS e sobre a adesão ao tratamento. No percurso da investigação, outra categoria emergiu, e referiu à forma como se organiza o trabalho na unidade de saúde, segundo os profissionais de saúde.

Dos depoimentos, foi possível verificar que, de modo geral, os sujeitos do estudo consideram a tuberculose a partir da perspectiva da multicausalidade, mas com importante ênfase no social. Apresentam os doentes acometidos pela enfermidade, como dotados de profundas carências e marginalizados pela sociedade. A exclusão do convívio familiar e atitudes que revelam preconceito se fizeram presentes, tanto no âmbito familiar, como das práticas cotidianas com os profissionais de saúde. Alguns doentes sentem vergonha ao descobrirem a doença, o que os leva a prolongar a busca por diagnóstico e tratamento. As atitudes que revelam estigma, por parte dos profissionais de saúde, foram admitidas como 
decorrentes de falta de conhecimento a respeito da enfermidade e da forma como relacionar-se com o doente.

Quanto ao trabalho na UBS, apontou-se que mudanças de gestão cujo projeto político e ético não se coadunam com os princípios e diretrizes do SUS interferem na sua organização e práticas, com efeitos negativos, que acabam por repercutir, em última instância, na adesão ao tratamento. Esses efeitos incluem a restrição ou mesmo ausência de ações de vigilância epidemiológica, tal como ocorreu durante o Plano de Atendimento à Saúde no Município de São Paulo, há cerca de uma década. Em decorrência, a tuberculose pareceu deixar de integrar o cenário epidemiológico no âmbito dos serviços de saúde, mas a negligência em relação à sua situação passou a concretizar-se nos óbitos e na disseminação da enfermidade.

Outro aspecto importante, e que ainda perdura, refere-se à trajetória que os doentes são obrigados a percorrer para ter, por fim, o diagnóstico de tuberculose. Essa questão foi apontada como um dos pontos de estrangulamento do processo de produção dos serviços de saúde, na medida em que o paciente pode deixar de acreditar no desempenho da atenção primária. Em decorrência, as unidades de saúde deixaram de ser a porta de entrada para o ingresso de pessoas que apresentavam sintomas respiratórios.

No que se refere à organização interna para desenvolver a DOTS, verificou-se que tal estratégia é desenvolvida de maneiras diferentes em cada unidade de saúde que compôs o presente cenário de estudo. Isso parece ocorrer, em parte, segundo os depoimentos dos sujeitos do estudo, 
para considerar a necessidade dos doentes no processo terapêutico e, por outro lado, pela falta de conhecimento dos próprios profissionais, no que diz respeito à sua operacionalização.

Foi possível perceber, ainda, que os profissionais de saúde desenvolvem o TS a partir do que "pensam ser adequado", uma vez que não houve processo de capacitação. Tampouco, a operacionalização da estratégia é alvo de debate em reuniões técnicas.

Houve ambigüidade no que diz respeito à forma como consideram a estratégia nos serviços, pois, em alguns, apontou-se que causa impacto negativo na rotina da unidade, apesar de sempre ser avaliada como efetiva para a adesão ao tratamento e, assim, para o controle da tuberculose. É importante apontar que, em outras unidades de saúde, a DOTS foi considerada como instrumento que colabora para a organização do serviço, dado que requer uma estrutura própria.

Os profissionais de saúde que mais apresentavam envolvimento na operacionalização da DOTS pertenciam à equipe de enfermagem. Isto muito provavelmente decorre do trabalho que, historicamente, essa categoria desenvolve no cuidado dos indivíduos. Entretanto, não se detectou participação homogênea dos seus vários integrantes, uma vez que a enfermeira supervisiona o trabalho, e os auxiliares de enfermagem têm o maior contato com os doentes no âmbito intra-muros, ao passo que os agentes comunitários realizam importante trabalho no que diz respeito ao conhecimento das necessidades dos doentes e de suas famílias, no âmbito extra-muros. 
Para os profissionais de saúde, a DOTS significa manter a atenção perante o doente para que não abandone o tratamento. Reitera-se que é estratégia eficaz para a adesão, e que possibilita a criação de vínculo entre o profissional de saúde e o doente. O vínculo permite que este se sinta acolhido, encontrando espaço para solucionar dúvidas e "falar" sobre o seu processo terapêutico.

A operacionalização da DOTS exige conhecer as necessidades do doente, para que possa ser adequado o tratamento, de forma que este se torne parte da vida da pessoa. Mas, além do apoio do profissional de saúde, para facilitar a adesão ao tratamento, o doente necessita do respaldo familiar, que é facilitado a partir do momento em que o profissional de saúde consegue integrar algum membro da família no tratamento.

Verificou-se, ainda, que a adesão à DOTS é facilitada pela presença dos incentivos, principalmente por ocasião da instauração do projeto terapêutico, momento em que, via de regra, o doente apresenta-se mais debilitado em decorrência da enfermidade.

Por fim, o desenvolvimento deste estudo fez possível captar que, na região da Supervisão de Saúde do Butantã, a adesão ao tratamento está diretamente associada ao DOTS. Os profissionais de saúde parecem se empenhar nesse processo, valendo-se de uma série de estratégias. E o vínculo é a base da adesão ao tratamento. Constatou-se que a estratégia apóia a adesão ao tratamento, mas não é suficiente, quando analisada com base no conceito de Adesão proposto por Bertolozzi $(1998,2005)$, utilizado 
neste estudo como base do referencial teórico. Isto porque a adesão está relacionada aos processos de vida e de trabalho dos sujeitos.

Dentre as principais potencialidades da DOTS, foram encontradas:

- Contribui para o aumento das taxas de cura;

- Possibilita conhecer as necessidades do doente e adaptar o tratamento para que este se torne parte da vida da pessoa;

- Permite oferecer espaço para a pessoa expressar-se sobre o processo terapêutico e sobre necessidades que envolvem a vida;

- Está pautada no compromisso mútuo firmado entre a equipe de saúde e o doente;

- Promove o vínculo entre a pessoa e o profissional de saúde;

- Não causa disrupção na rotina do processo de produção de serviços;

- Permite o acompanhamento do doente e de sua família por parte da equipe de saúde;

- Possibilita o acompanhamento dos comunicantes pelos profissionais de saúde;

- Permite o envolvimento da família, colaborando para a diminuição do estigma; 
As seguintes limitações da DOTS foram encontradas, ressaltando-se que as duas primeiras menções não se restringem à estratégia:

- A falta de sensibilização para pensar em tuberculose, no cotidiano dos serviços de saúde - que faz decorrer impacto negativo na busca de sintomáticos respiratórios, assim como na detecção precoce da enfermidade. Em virtude disso, as UBS não constituem porta de entrada para os doentes de tuberculose, rompendo com os princípios do SUS;

- As mudanças constantes na gestão do sistema de saúde - com propostas que ferem os princípios e diretrizes do SUS e dificultam a continuidade dos programas desenvolvidos nas UBS;

- A falta de capacitação para o desenvolvimento da estratégia que faz decorrer o desencontro de ações e a não compreensão sobre seus objetivos;

- Falta de profissionais de saúde com disponibilidade para fixar-se na condução da estratégia, e que sirvam de referência para o doente;

- O atraso ou irregularidade na entrega dos incentivos (lanche e, principalmente a cesta básica), que repercutem no processo de confiança construído no cotidiano;

- A falta de estrutura física nas UBS;

- A grande quantidade de impressos a serem preenchidos na operacionalização da DOTS, que burocratizam o trabalho, retirando o profissional de saúde do contato com o doente; 
A partir das limitações apresentadas no presente estudo, é possível apontar propostas para a superação desses problemas, que é o terceiro objetivo proposto por este estudo. Assim, pode-se sugerir que a prática de assistência à tuberculose seja revista na região da SUVIS Butantã. Esta revisão deve ser iniciada a partir de processos de sensibilizações dos profissionais de saúde que atuam diretamente junto aos doentes portadores de tuberculose.

Ademais, sugere-se oferecer espaços para reflexão sobre a prática cotidiana, evitando que os serviços desenvolvam atividades conforme o que cada profissional acredite como ser correto. Sugere-se que as atividades sejam embasadas no conhecimento das necessidades dos indivíduos atendidos nos serviços e daqueles que habitam o território de abrangência da unidade de saúde.

Há necessidade de repensar a prática, a partir das necessidades da comunidade adscrita, para que as ações de controle da tuberculose possam ser retomadas. Tais como a busca ativa dos casos e promover a acessibilidade dos doentes ao serviço para que as UBS possam cumprir com seu papel de porta de entrada para o sistema de saúde. Para tanto, é necessário que os membros das equipes de saúde compreendam a finalidade de seu trabalho, que está diretamente articulado à compreensão das condições de existência dos doentes, incluindo as condições de produção e de reprodução social.

Por fim, é possível reafirmar o conceito de adesão proposto por Bertolozzi (1998, 2005), o que requer a mudança da compreensão dos 
profissionais de saúde para além da doença, assim como o seu engajamento no trabalho em saúde de forma a considerar as necessidades dos indivíduos e do coletivo, buscando compreender os processos pelos quais se adoece e morre. Para isso, os profissionais de saúde necessitam identificar as vulnerabilidades dos indivíduos, famílias e grupos sociais que integram o território, para que se constituam como alvo de intervenções compartilhadas com a comunidade e com outros setores sociais. 
REFERÊNCIAS BIBLIOGRÁFICAS 


\section{REFERÊNCIAS BIBLIOGRÁFICAS}

Albuquerque MFM, Leitão CCS, Campelo ARL, Souza WV, Salustino A. Fatores prognósticos para o desfecho do tratamento da tuberculose pulmonar em Recife, Pernambuco, Brasil. Rev Panam Salud Publica. 2001;9(6):368-74.

Ali SS, Rabbani F, Siddiqui UN, Zaidi AH, Sophie A, Virani SJ, et al. Tuberculosis: do we know enough? A study of patients and their families in an out-patient hospital setting in Karachi, Pakistan. Int J Tuberc Lung Dis. 2003;7(11):1052-8.

Alvarez-Gordillo GC, Dorantes-Jiménez JE. Tratamiento acortado estrictamente supervisado para tuberculosis pulmonar / Shortened directly observed treatment applied to the tuberculosis control program. Salud Publica Mex. 1998;40(3):272-5.

Alvarez-Gordillo GC, Alvarez-Gordillo JF, Dorantes-Jiménez JE, HalperinFrisch D. Perceptions and practices of tuberculosis patients and nonadherence to therapy in Chiapas, Mexico. Salud Pública Mex. 2000;42(6):520-8.

Bertazone EC. A assistência ao portador de tuberculose pulmonar sob a ótica dos trabalhadores de enfermagem [tese]. Ribeirão Preto: Escola de Enfermagem de Ribeirão Preto, Universidade de São Paulo; 2003.

Bertolozzi MR, Takahashi RF. Avaliação do conhecimento sobre a tuberculose em um grupo da comunidade do município do Estado de São Paulo. Ciênc Cultura. 1990;42(7 Supl.1):45-6.

Bertolozzi MR. Pacientes com tuberculose pulmonar no município de Taboão da Serra: perfil e representações sobre a assistência prestada nas unidades básicas de Saúde [dissertação]. São Paulo: Faculdade de Saúde Pública, Universidade de São Paulo; 1991.

Bertolozzi MR. A adesão ao programa de controle da tuberculose no Distrito Sanitário do Butantã, São Paulo [tese]. São Paulo: Faculdade de Saúde Pública, Universidade de São Paulo; 1998. 
Bertolozzi MR. A adesão ao tratamento da tuberculose na perspectiva da estratégia do tratamento diretamente observado ("DOTS") no Município de São Paulo - SP [tese livre docência]. São Paulo: Escola de Enfermagem, Universidade de São Paulo; 2005.

Brasil. Ministério da Saúde. Fundação Nacional de Saúde. Centro de Epidemiologia. Coordenação Nacional de Pneumologia Sanitária. Plano Nacional de Controle da Tuberculose. Brasília; 1999.

Brasil. Ministério da Saúde. Secretaria de Políticas Públicas de Saúde. Coordenação Nacional de Pneumologia Sanitária. Plano de Controle da Tuberculose no Brasil no período de 2001-2005. Brasília; 2000.

Brasil. Ministério da Saúde. Fundação Nacional de Saúde. Centro de Epidemiologia. Coordenação Nacional de Pneumologia Sanitária. Tuberculose: guia de vigilância epidemiológica. Brasília; 2002a.

Brasil. Ministério da Saúde. Fundação Nacional de Saúde. Centro de Referência Prof. Hélio Fraga. Sociedade Brasileira de Pneumologia e Tisiologia. Controle da tuberculose: uma proposta de integração ensinoserviço. 5a ed. Rio de Janeiro: Funasa/CRPHF/ SBPT; 2002b.

Brasil. Ministério da Saúde. Sistema de Vigilância em Saúde. Relatórios da situação da tuberculose. Brasília; 2005a.

Brasil. Ministério da Saúde. Secretaria de Vigilância em Saúde. Departamento de Vigilância Epidemiológica. Guia de vigilância epidemiológica: tuberculose. 6ª ed. Brasília; 2005b.

Campinas LLSL. O acolhimento ao doente com tuberculose: estudo comparativo entre uma unidade de saúde da família e um ambulatório de especialidades médicas, São Paulo/SP, 2003 [tese]. São Paulo: Faculdade de Saúde Pública, Universidade de São Paulo; 2004.

Costa JSD, Gonçalves H, Menezes AMB, Devéns E, Piva M, Gomes M, et al. Controle epidemiológico da tuberculose na cidade de Pelotas, Rio Grande do Sul, Brasil: adesão ao tratamento. Cad Saúde Pública. 1998;14(2):409-15. 
Deheinzelin D, Takagaki TY, Sartori AMC, Leite OHM, Amato Neto V, Carvalho CRR. Fatores preditivos de abandono de tratamento por pacientes com tuberculose. Rev Hosp Clin Fac Med S Paulo. 1996;51(4):131-5.

Eastwood SV, Hill PC. A gender-focused qualitative study of barriers to accessing tuberculosis treatment in The Gambia, West Africa. Int J Tuberc Lung Dis. 2004;8(1):70-5.

Edginton ME, Sekatane CS, Goldstein SJ. Patient's beliefs: do they affect tuberculosis control? A study in a rural district of Shouth Africa. Int J Tuberc Lung Dis. 2002;6(12):1075-82.

Egry EY, Fonseca RMGS, Bertolozzi MR. Assistência de enfermagem em saúde coletiva: entendendo o processo para a aplicação de um instrumento transformador da prática e da teoria. Rev Bras Enferm. 1994;47(3):28-94.

Egry EY. Saúde coletiva: construindo um novo método em enfermagem. São Paulo: Ícone; 1996.

Elias PE, Cohn A. O PAS no município de São Paulo: novos desafios para velhas questões. Rev Adm Pública. 1998;32(2):176-84.

Elias PE. PAS: um perfil neoliberal de gestão do sistema público de saúde. Est Avançados. 1999;13(35):125-37.

Ferreira MCL. O quadro atual da análise de discurso no Brasil: um breve preâmbulo. In: Indursky F, Ferreira MCL, organizadores. Michel Pêcheux e a análise do discurso: uma relação de nunca acabar. São Paulo: Claraluz; 2005. p. 13-22.

Fiorin JL. Elementos de análise de discurso. São Paulo: Contexto/EDUSP; 1989.

Fiorin JL. Linguagem e ideologia. São Paulo: Ática; 1990. 
Fonseca RMGS, Bertolozzi MR. A epidemiologia social e a assistência à saúde da população. In: Egry EY, Fonseca RMGS. A classificação das práticas de enfermagem em saúde coletiva e o uso da epidemiologia social. Brasília: ABEn; 1997. p.78.

Fonseca RMGS. O processo saúde-doença (das mulheres) como fenômeno social [tese]. São Paulo: Escola de Enfermagem, Universidade de São Paulo; 1998.

Fonseca RMGS, Egry EY, Bertolozzi MR. O materialismo histórico e dialético como teoria da cognição e método para a compreensão do processo saúde doença. São Paulo: EEUSP; 2001.

Galesi VMN. Mortalidade por tuberculose no Município de São Paulo: análise de uma década, 1986 a 1995 [dissertação]. São Paulo: Faculdade de Saúde Pública, Universidade de São Paulo; 1998.

Gleissberg VG, Maximova ZD, Golubchikova VT, Wares DF, Banatvala N. Developing nursing practice as part of the collaborative TB control programme, Tomsk, Siberia. Int J Tuberc Lung Dis. 1999;3(10):878-85.

Hino P, Santos CB, Villa TCS, Muniz JN, Monroe AA. Tuberculosis patients submitted to supervised treatment. Ribeirão Preto - São Paulo - Brazil. Rev Lat Am Enferm. 2005;13(1):27-31.

Hoa NP, Diwan VK, Co NV, Thorson AE. Knowledge about tuberculosis and its treatment among new pulmonary TB patients in the north and central regions of Vietnam. Int J Tuberc Lung Dis. 2004;8(5):603-8.

Jaiswal A, Singh V, Ogden JA, Prter JDH, Sharma PP, Sarin R, et al. Adherence to tuberculosis treatment: lessons from the urban setting of Delhi, Índia. Trop Med Int Health. 2003;8(7):625-33.

Jaramillo E. Pulmonary tuberculosis and health-seeking behaviour. Trop Med Int Health. 1998;3(2):138-44.

Johansson E, Long NH, Diwan VK, Winkvist A. Gender and tuberculosis control perspectives on health seeking behaviour among men and women in Vietnam. Health Policy. 2000;52(1):33-51. 
Kaona FAD, Tuba M, Siziya S, Sikaona L. An assessment of factors contributing to treatment adherence and knowledge of TB transmission among patients on TB treatment. BMC Public Health. 2004;4(1):68.

Kelly P. Isolation and stigma: the experience of patients with active tuberculosis. J Community Health Nurs. 1999;16(4):233-41.

Kiwuwa MS, Charles K, Harriet MK. Patient and health service delay in pulmonary tuberculosis patients attending a referral hospital: a crosssectional study. BMC Public Health. 2005;5(1):122.

Lima MB, Mello DA, Morais AP, Silva WC. Estudo de casos sobre abandono do tratamento da tuberculose: avaliação do atendimento, percepção e conhecimentos sobre a doença na perspectiva dos clientes. Cad Saúde Pública. 2001;17(4):877-85.

Long $\mathrm{NH}$, Johansson E, Diwan VK, Winkvist A. Fear and social isolation as consequences of tuberculosis in Vietnam: a gender analysis. Health Policy. 2001;58(1):69-81.

Macq JCM, Theobald S, Dick J, Dembeles M. An exploration of the concept of directly observed treatment (dot) for tuberculosis patients: from a uniform to a customized approach. Int J Tuberc Lung Dis. 2003;7(2):103-9.

Macq J, Solis A, Martinez G, Martiny P, Dujardin B. An exploration of the social stigma of Tuberculosis in five "municipios" of Nicaragua to reflect on local interventions. Health Policy. 2005;74(2):205-17.

Martins HHTS. Metodologia qualitativa de pesquisa. Educ Pesq. 2004;30(2):289-300.

Mendes MCT. A clientela e os profissionais de saúde diante da tuberculose. [dissertação]. Campinas: Faculdade de Ciências Médicas, Universidade Estadual de Campinas; 1998.

Meulemans H, Mortelmans D, Liefooghe R, Mertens P, Zaidi AS, Solangi MF, et al. The limits to patient compliance with directly observed therapy for tuberculosis: a sócio-medical study in Pakistan. Int J Health Plann Manage. 2002;17(3):249-67. 
Minayo MCS, Sanches O. Quantitativo-qualitativo: oposição ou complementaridade? Cad Saúde Pública. 1993;9(3):239-48.

Minayo MCS. O desafio do conhecimento: pesquisa qualitativa em saúde. $8^{a}$ ed. São Paulo: Hucitec; 2004.

Mishra P, Hansen EH, Sabroe S, Kafle KK. Socio-economic status and adherence to tuberculosis treatment: a case-control study in a district of Nepal. Int J Tuberc Lung Dis. 2005;9(10):1134-39.

Mishra P, Hansen EH, Sabroe S, Kafle KK. Adherence is associated with the quality of professional-patient interaction in Directly Observed Treatment Short-course, DOTS. Patient Educ Couns. 2006;63(1/2):29-37.

Mohan A, Nassir H, Niazi A. Does routine home visiting improve the return rate and outcome of DOTS patients who delay treatment? East Mediterr Health J. 2003;9(4):702-8.

Muniz JN. O tratamento supervisionado no controle da tuberculose em Ribeirão Preto sob a percepção da equipe de saúde [dissertação]. Ribeirão Preto: Escola de Enfermagem de Ribeirão Preto, Universidade de São Paulo; 1999.

Oliveira HB, Moreira Filho DC. Abandono de tratamento e recidiva da tuberculose: aspectos de episódios prévios, Campinas, SP, Brasil, 19931994. Rev Saúde Pública. 2000;34(5):437-43.

Organización Mundial de la Salud (OMS). Tratamiento de la tuberculosis: directrices para los programas nacionales. Ginebra; 1997.

Organización Pan-Americana de la Salud (OMS). Tuberculosis: hoja informativa 2004, Américas. Ginebra; 2004. [citado 2005 jul. 4]. Disponível em: htt://www.paho.org/Spanish/AD/DPC/CD/tb-fact/sheet-2004.html

Organización Mundial de la Salud (OMS). Tuberculosis [texto na Internet]. Ginebra; 2005. [citado 2005 abr. 18]. Disponível em:

http://www.who.int/mediacentre/factsheets/fs104/es/index.html 
Organizacão Pan-Americana da Saúde (OPAS). Escritorio Regional da Organização Mundial da Saúde. Pessoal da saúde: heróis da luta contra a tuberculose [texto na Internet]. 2005. [citado 2005 jul. 4]. Disponível em: http://www.paho.org/Portuguese/AD/DPC/CD/tb-2005brochure.pdf

Rajeswari R, Muniyandi M, Balasubramanian R, Narayanan PR. Perceptions of tuberculosis patients about their physical, mental and social well-being: a field report from south Índia. Soc Sci Med. 2005;60(8):1845-53.

Rubel AJ, Garro LC. Social and cultural factors in the successful control of tuberculosis. Public Health Rep.1992;107(6):626-36.

Ruffino-Netto A. Impacto da reforma do setor saúde sobre os serviços de tuberculose no Brasil. Bol Pneumol San. 1999;7(1):7-18.

Ruffino-Netto A. Souza AMAF. Reforma do setor saúde e controle da Tuberculose no Brasil. Inf Epidemiol SUS. 1999;8(4):35-51.

Ruffino-Netto A. Tuberculose: a calamidade negligenciada [artigo de atualização]. Rev Soc Bras Med Trop. 2002;35(1):51-8.

Ruffino Netto A, Villa TCS, organizadores. Tuberculose: implantação da DOTS em algumas regiões do Brasil: histórico e peculiaridades. Ribeirão Preto: Wdesign e Associados; 2006.

São Paulo (Cidade). Prefeitura do Município. Números da cidade: sumário de dados 2004, Butantã - Região Oeste [texto na Internet]. São Paulo; 2004. [citado 2005 jul. 7]. Disponível em:

http://ww2.prefeitura.sp.gov.br//arquivos/secretarias/governo/sumario_dados/ ZO_BUTANTA_Caderno29.pdf

São Paulo (Cidade). Secretaria Municipal de Saúde. Coordenação de Vigilância em Saúde. Informes em tuberculose. São Paulo; $2005 a$. 
São Paulo (Cidade). Secretaria Municipal de Saúde. Coordenação de Vigilância em Saúde. Avaliação do Programa de Tuberculose do Município de São Paulo. São Paulo; 2005b. [citado 2007 abr. 7]. Disponível em: http://ww2.prefeitura.sp.gov.br//arquivos/secretarias/saude/vigilancia_saude/ publicacao_covisa/0001/Informe_TB_dez_05.pdf

São Paulo (Cidade). Secretaria Municipal de Saúde. PRO-AIM: mortalidade no Município de São Paulo: óbitos ocorridos por ano. Distrito Administrativo Butantã. Causa específica: tuberculose no período de 1996 à 2004. São Paulo; 2005c.

São Paulo (Estado). Secretaria de Estado da Saúde. Centro de Vigilância Epidemiológica. Tuberculose no Brasil [texto na Internet]. São Paulo; 2005d. [citado 2005 set. 18]. Disponível em:

http://www.cve.saude.sp.gov.br/tuberculose/tb/tb_num/tbbrasil.pps

São Paulo (Estado). Secretaria de Estado da Saúde. Centro de Vigilância Sanitária. Divisão de Controle da Tuberculose. Tuberculose: Série Histórica de 1998-2004 [texto na Internet]. São Paulo; 2005e.[citado 2005 set. 18]. Disponível em:_http://www.cve.saude.sp.gov.br/tuberculose/

São Paulo (Estado). Secretaria de Estado da Saúde. Coordenadoria de Controle de Doenças. Centro de Vigilância Epidemiológica "Professor Alexandre Vranjac". Tuberculose no Estado de São Paulo: indicadores de morbimortalidade e indicadores de desempenho. Bol Epidemiol Paul. 2006;3 Supl 4:36.

Souza WV, Albuquerque MDM, Barcellos CC, Ximenes RAA, Carvalho MS. Tuberculose no Brasil: construção de um sistema de vigilância de base territorial. Rev Saúde Pública. 2005;39(1):82-9.

Vendramini SHF. O tratamento supervisionado no controle da tuberculose em Ribeirão Preto sob a percepção do doente [dissertação]. Ribeirão Preto: Escola de Enfermagem de Ribeirão Preto, Universidade de São Paulo; 2001.

Watkins RE, Plant AJ. Pathways to treatment for tuberculosis in Bali: patient perspectives. Qual Health Res. 2004;14(5):691-703.

World Health Organization (WHO). TB: a global emergency. Geneva; 1993. 
World Health Organization (WHO). Guidelines for workplace TB control activities: the contribution of workplace TB control activities to TB control in the community. Geneva; 2003.

World Health Organization (WHO). Global Tuberculosis Control. Country profile- Brazil. Geneva: Switzerland; 2005a.

World Health Organization (WHO). Global Tuberculosis Control. Brazil: surveillance, planning, financing. Report Who 2005. Geneva; 2005b.

World Health Organization (WHO). Tuberculosis. Centro de prensa. [texto da Internet]. Geneva; 2007. [citado 2007 abr. 28]. Disponível em:

http://www.who.int/mediacentre/factsheets/fs104/es/index.html

Yamada S, Caballero J, Matsunaga DS, Agustín G, Magana M. Attitudes regarding tuberculosis in Immigrants from the Philippines to the United States. Fam Med. 1999;31(7):477-82. 
ANEXOS 


\section{ANEXO I}

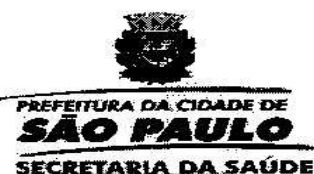

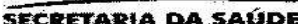

\author{
Prefeitura do Município de São Paulo \\ Secretaria Municipal da Saúde \\ Coordenação de Desenvolvimento de Programas e Políticas de Saúde \\ CODEPPS \\ COMITÊ DE ÉTICA EM PESQUISA
}

São Paulo, 31 de Janeiro de 2006

PARECER N 021/2006 - CEP-SMS

Prezado (a) Senhor (a),

Pelo presente, informo que o Comitê de Ética em Pesquisa da Secretária Municipal de Saúde de São Paulo analisou, e APROVOU, de acordo com a Resolução CNS 196/96, 0 protocolo de pesquisa CAAE: 092/05 "Estudo da Estratégia do Tratamento Diretamente Supervisionado (DOTS) no Controle da Tuberculose no Município de São Paulo", de autoria do(a) pesquisador(a) Maria Rita Bertolozzi

Como procedimento adotado por este Comitê de Ética em Pesquisa, solicitamos a inclusão, no Termo de Consentimento Livre e Esclarecido do seguinte: qualquer questão, dúvida, esclarecimento ou reclamacão sobre os aspectos éticos dessa pesquisa, favor entrar em contato com: Comitê de Ética em Pesquisas da Secretaria Municipal da Saúde de São Paulo - Rua General Jardim, 36-2 andar - Telefone: 3218-4043 - e-mail: smscep@prefeitura.sp.gov.br.

Lembramos que este parecer não basta para que seu estudo possa se realizar dentro da unidade, é necessária também a permissão administrativa da autoridade sanitária.

Salientamos os seguintes aspectos a serem considerados pelo pesquisador:

- O sujeito da pesquisa tem a liberdade de recusar-se a participar ou de retirar seu consentimento em qualquer fase da pesquisa, sem penalização alguma ou sem prejuízo ao seu cuidado (Res. CNS 196/96 - item IV.1f) e deve receber uma cópia do Termo de Consentimento livre e esclarecido, na íntegra, por ele assinado (item IV.2.d)

- O pesquisador deve desenvolver a pesquisa conforme delineada no protocolo aprovado. Eventuais modificações ou emendas ao protocolo devem ser apresentadas ao CEP de forma clara e sucinta, identificando a parte do protocolo a ser modificada e suas justificativas. O relatório final deve ser apresentado ao CEP, logo que o estudo estiver concluído.

Atenciosamente

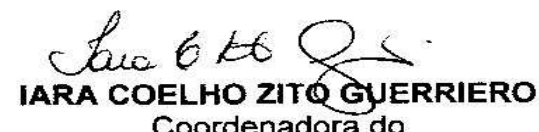

Coordenadora do

Comitê de Ética em Pesquisa da

Secretária Municipal da Saúde - CEPSMS

llustríssimo (a). Senhor (a).

MARIA RITA BERTOLOZZ

NESTA

Rua General dardim, $36-2^{\circ}$ andar - Vila Buarque - São Paulo, SP - CEP 01223-010 Telefone: (11) 3218-4043 e-mail: smscep(Cprefeitura.sp.gov.br homepage: http://portal prefeitura.sp.gov.br/secretarias/saude/organizacao/cepsms/ 


\section{ANEXO II}

Formulário de entrevista para os profissionais das UBS.

Entrevista ํㅜ․

Data: UBS/Local:

\section{Identificação}

1. Iniciais:

2. Sexo: () feminino ( ) masculino

3. Idade:

4. Categoria Profissional:

5. Cargo no Serviço de Saúde:

Processo de trabalho

6. Fale do seu trabalho aqui no Serviço de Saúde:

\section{Organização da DOTS}

7. Há quanto tempo você realiza o TS?

8. Você recebeu treinamento para realizar o TS dentro do PCT?

9. Fale sobre um dia de trabalho junto ao PCT?

10. Como é oferecido o Tratamento Supervisionado ao paciente?

11. O TS é oferecido para todos? Qual o critério para iniciar o TS?

12. Como é desenvolvido o Tratamento Supervisionado aqui no Serviço?

13.É realizado Tratamento Supervisionado domiciliário?

14. Quem oferece a medicação no TS aqui no serviço?

15. Quando o paciente falta no TS, qual a conduta da equipe?

16. O paciente sob o Tratamento Supervisionado recebe algum benefício?

17. Quais os pontos positivos do Tratamento Supervisionado?

18. Quais os pontos negativos do Tratamento Supervisionado? 


\begin{abstract}
ANEXO III
Formulário de entrevista para os gerentes das Unidades de Saúde e o Coordenador do Programa de Controle da Tuberculose na região da Supervisão Técnica de Saúde do Butantã.
\end{abstract}

Entrevista $\mathrm{n}^{0}$ : Data: UBS/Local:

\title{
$\underline{\text { Identificação }}$
}

1. Iniciais:

2. Sexo: () feminino ( ) masculino

3. Idade:

4. Profissão:

5. Cargo no Serviço de Saúde:

Organização do trabalho no serviço e organização da DOTS

6. O que é o Tratamento Supervisionado?

7. Quando começou o Tratamento Supervisionado neste serviço?

8. Por que começou o Tratamento Supervisionado neste serviço?

9. Quem desenvolve o Tratamento Supervisionado aqui no Serviço? 10. Qual o impacto da DOTS no processo de trabalho do Serviço de Saúde? 11.O que o Serviço de Saúde espera do Tratamento Supervisionado? 


\begin{abstract}
ANEXO IV
TERMO DE CONSENTIMENTO LIVRE E ESCLARECIDO:

Profissionais de saúde das Unidades Básicas de Saúde e Responsáveis pelo Programa de Controle da Tuberculose junto à Coordenadoria de Saúde da Secretaria de Saúde do Município de São Paulo
\end{abstract}

Eu, Maria Fernanda Terra, enfermeira e aluna do curso de PósGraduação da Escola de Enfermagem da Universidade de São Paulo estou realizando o estudo: "O Tratamento Diretamente Supervisionado (DOTS) como estratégia para a adesão ao tratamento da tuberculose: significados segundo os profissionais de saúde da Supervisão Técnica de Saúde do Butantã, São Paulo - SP", sob a orientação da Prof ${ }^{a}$ Dr $^{a}$ Maria Rita Bertolozzi. Estou estudando estratégias de tratamento para a tuberculose, com a finalidade de propor recomendações para o aprimoramento do controle dessa enfermidade.

Assim, gostaria de contar com sua colaboração, participando de uma entrevista, que deve durar aproximadamente 20 minutos, e que será gravada. Será mantido o sigilo de sua identidade e, caso não queira responder alguma questão, ou não participar da pesquisa, sinta-se à vontade. As informações serão objeto restrito deste estudo e não causarão quaisquer prejuízos em relação ao seu trabalho.

Os dados compilados serão analisados e objeto de divulgação junto à Secretaria de Saúde do Município, particularmente junto a COVISA-Tuberculose, além de eventos de caráter científico e em publicações da área da saúde. Assumimos, ainda, o compromisso de apresentar os resultados aos participantes do estudo.

Caso tenha alguma dúvida, estamos à disposição através do telefone: 30667652.

Muito obrigada,

Assinatura da (o) entrevistada (o)

Assinatura da entrevistadora

Caso tenha alguma dúvida, ou queira algum tipo de esclarecimento ou reclamação sobre os procedimentos éticos deste estudo, por favor, entrar em contato com o Comitê de Ética em Pesquisa da Secretaria Municipal de Saúde de São Paulo, na Rua General Jardim, 36, no 2ํㅡㄴ andar, ou pelo telefone: 32184043, ou pelo e-mail: smscep@prefeitura.sp.gov.br 


\title{
ANEXO V \\ FRASES TEMÁTICAS ORIUNDAS DOS DEPOIMENTOS DOS SUJEITOS DO ESTUDO
}

\author{
Profissionais de saúde das Unidades Básicas de Saúde
}

\section{Unidade Básica de Saúde A}

Coordenador da UBS A (A1)

- Gerente refere trabalhar nesta UBS desde o ano de 1999, e que no período do PAS houve um desmantelamento de serviços, pois tudo estava confuso, equipamentos sucateados (Ger.A1.2).

- Gerente refere que o atendimento na época do PAS era como pronto atendimento e que a população estava acostumada, e que quando mudou a gestão, houve mudanças significativas no sistema, e que foi muito confuso (Ger.A1.3).

- Gerente refere que o TS envolve a vinda do paciente para a UBS e o profissional fica olhando ele engolir o remédio (Ger.A1.4).

- Para a gerente a realização do TS na UBS é uma proposta inviável, pois refere como dificuldade o pequeno espaço físico para a grande demanda que atende (Ger.A1.5).

- Gerente refere que iniciou uma nova experiência no atendimento dos casos de tuberculose junto com a médica, onde o trabalho era dividido e organizado, sendo a responsabilidade da médica ver o paciente clinicamente (Ger.A1.6).

- Gerente refere que a organização do atendimento do paciente com tuberculose sob o TS era organizado para atender ao doente semanalmente, ver se estava bem clinicamente, ver se estava ganhando peso, oferecer espaço para ouvir o doente e entregar a medicação e lanchinho da semana toda (Ger.A1.7).

- Gerente refere que o atendimento no TS permitia uma maior interação com o doente, gerente refere que ele tinha um espaço para dizer sobre sintomas, efeitos da medicação (Ger.A1.8).

- Gerente refere que o objetivo da UBS é não ter abandono, para isso faz uso do TS (Ger.A1.9).

- Gerente refere que o atendimento dos casos envolvia o acolhimento para fazer vínculo com o doente, fazia a visita domiciliar e era solicitado ao paciente comparecer à UBS 1x/semana (Ger.A1.10).

- Gerente refere que por meio do acolhimento é possível criar vínculo com o doente no TS (Ger.A1.11).

- Gerente refere que o paciente também se comprometia com a equipe (Ger.A1.12).

- Gerente refere que os incentivos, que são: cesta básica mensalmente, os achocolatados, cereais, são colaboradores na adesão ao tratamento pelo doente (Ger.A1.13).

- Gerente refere que o paciente é resgatado através de visita domiciliar, quando ele falta no TS (Ger.A1.14).

- Gerente refere que a sanitarista é quem atende a todos os casos de tuberculose na unidade, todos os atendimentos são centralizados nela (Ger.A1.15).

- Gerente refere que na época do PAS não era feitos acompanhamentos de pacientes com tuberculose, ela refere que a gente até brincava que o PAS acabou com a tuberculose (Ger.A1.16). 
- Gerente refere que o sistema de laboratório é rápido na análise e isso repercute na agilidade da atenção ao doente (Ger.A1.17).

- Gerente refere que os pacientes sob o TS são orientados a retornar na UBS se passarem mal por algum motivo (Ger.A1.18).

- Gerente refere que sempre atrás da tuberculose, tem uma coisa de abandono, que sempre o doente tem algum problema além da doença tuberculose (Ger.A1.19).

- Gerente refere que o vínculo é fundamental para a adesão ao tratamento da tuberculose, colaborando na diminuição do abandono (Ger.A1.20).

- Gerente refere um atendimento realizado em TS diário, para descrever como conseguiu que o paciente mantivesse a adesão ao tratamento, apesar das dificuldades (Ger.A1.21).

- Gerente faz referencia a um caso, em que a equipe sabia das dificuldades de relacionamento do paciente que seria internado, por isso, antes de sua internação deixou alternativas de tratamento, caso ele não se adaptasse com a internação (Ger.A1.22).

- Gerente refere que mesmo o paciente não mantendo a regularidade dos horários das medicações, a equipe de saúde mantinha o atendimento (Ger.A1.23).

- Gerente faz referência a um caso que foi atendido na UBS, e que por conta do vínculo, o paciente voltou apresentado a queixa de tosse (Ger.A1.24).

- Gerente faz referência de que o bom vínculo mantido com o paciente usuário de droga permitiu que limites fossem colocados sobre o uso de droga durante o período de tratamento da tuberculose (Ger.A1.25).

- Gerente refere que quando o vínculo é estabelecido, muitas vezes é difícil até mesmo do paciente tomar a medicação com outra pessoa (Ger.A1.26).

- Para a gerente, a UBS tem sorte por ter a atual sanitarista e a caracteriza como "boa médica" (Ger.A1.27).

- Gerente refere que o TS não interfere na rotina, pois a UBS tem uma sanitarista para atender aos casos, apesar da tuberculose não ser considerada "coisa tranqüila" ( Ger.A1.28).

- Gerente refere que não é difícil acompanhar os pacientes com TB sem a sanitarista, mas também faz referência de que o trabalho era mais complicado sem a presença do profissional (Ger.A1.30).

- Gerente refere que os serviços que atendem aos casos de tuberculose devem ter vínculo com o doente, ele precisa de uma pós consulta para receber as devidas orientações, a doente precisa de retornos freqüente, necessidade de acompanhar a todos os casos, mesmo aqueles vindos do convênio (Ger.A1.31).

- Gerente faz referência a alternativas utilizadas para que o TS seja viabilizado para os casos dos pacientes que não podem faltar do trabalho (Ger.A1.32).

- Gerente refere que a DOTS, se aplicado diariamente tem postura de polícia sobre o doente, afetando sua privacidade (Ger.A1.33).

- Gerente refere que durante o acompanhamento clínico do doente é possível perceber se ele está ou não mantendo a terapia medicamentosa corretamente, para tanto refere sobre a não necessidade do tratamento diário (Ger.A1.34).

- Gerente faz referência a um caso de paciente "difícil" que foi atendida na UBS e que conseguiu alcançar a cura a partir da organização da equipe para o TS diariamente (Ger.A1.35).

- Gerente refere que é necessário adequar o profissional de saúde para realizar o TS (Ger.A1.36).

- Gerente refere que a adolescente atendida no serviço sentia-se acolhida a ponto de pedir para ser adotada (Ger.A1.37).

- Gerente refere não atender diretamente aos doentes com tuberculose, mas envolve-se ao olhar o relatório de acompanhamento e tenta monitorar (Ger.A1.38).

- Gerente refere que constantemente são feitos mobilizações com os funcionários da UBS sobre tuberculose (Ger.A1.39).

- Gerente refere orientar aos funcionários a estarem de prontidão para buscar os possíveis sintomáticos respiratórios que entrem na UBS (Ger.A1.40). 
- Gerente refere que o TS envolve a vinda do paciente para a UBS e o profissional fica olhando ele engolir o remédio (Ger.A1.41).

\section{Profissional de saúde da saúde A (A2)}

- Sanitarista refere insatisfação no trabalho por constantes mudanças na gestão, que impedem a continuidade dos projetos já iniciados (Méd.A2.1).

- Sanitarista refere não se envolver com os assuntos da unidade, por conta das constantes mudanças na gestão (Méd.A2.2).

- Sanitarista refere ter de atender a todos os acompanhamentos de notificação compulsória (Méd.A2.3).

- Sanitarista refere manter o trabalho, relativo ao TS, que já era desenvolvido na unidade (Méd.A2.4).

- Sanitarista refere os limites que determinam a realização do TS 1x/semana (Méd.A2.5).

- Sanitarista refere que seu trabalho no PCT e TS envolve atender pacientes diariamente, exceto as quartas feiras, que é o dia da realização das visitas domiciliares (Méd.A2.6).

- Sanitarista refere que as pessoas aceitam o TS, pois moram perto da unidade de saúde e que a maioria dos pacientes não trabalham, ou se trabalho, é dentro da comunidade (Méd.A2.7).

- Sanitarista refere oferecer os benefícios (cesta básica, lanches) somente após observar o interesse do paciente em se tratar, após a aceitação do TS, é feito o cadastramento para o recebimento da cesta básica (Méd.A2.8).

- Para a sanitarista, o TS é efetivo, pois os pacientes moram perto da UBS, ou não trabalham, ou trabalham próximos de casa (Méd.A2.9).

- Para a sanitarista, a efetividade na adesão ao TS depende da comunidade (Méd.A2.10).

- Para a sanitarista, a pouca quantidade de pacientes em tratamento para TB na outra UBS em que trabalha é por não ser feito o diagnóstico para TB (Méd.A2.11).

- Para a sanitarista, o TS permite uma ótima relação médico-paciente, e acha que seria maravilhoso se todos pudessem fazer o TS (Méd.A2.13).

- Para a sanitarista, existem limitações para realizar o TS, que são principalmente vindas do próprio paciente (Méd.A2.14).

- A sanitarista refere que faz a busca dos faltosos, inicialmente via telefone, se não é feito o contato, ela então realizado a VD acompanhada por uma auxiliar de enfermagem (Méd.A2.15).

- Sanitarista refere fazer uso dos benefícios para estimular a adesão (Méd.A2.16).

- Sanitarista refere que os pacientes podem procurar atendimento, não apenas no dia de sua consulta (Méd.A2.17).

- Para a sanitarista, o contrato para a realização do TS depende da consideração das necessidades do doente (Méd.A2.18).

- Sanitarista refere que seu atendimento não fica restrito apenas ao tratamento da tuberculose, mas que se estende para a parte emocional e nutricional do doente (Méd.A2.19).

- Para a sanitarista, o TS permite a criação de vínculo com o doente (Méd.A2.20). 


\section{Unidade Básica de Saúde B}

\section{Coordenador da UBS B (B1)}

- Gerente refere que seu contato a tuberculose se deu apenas quando trabalhava como médico de família (Ger.B1.1).

- Gerente refere que entende o TS como uma proposta interessante da OMS para tentar contornar a grande dificuldade de se manter 0 paciente tomando o remédio regularmente por 6 meses (Ger.B1.2).

- Gerente refere não ter experiência com a DOTS, mas já leu em artigos que a DOTS melhora muito a chance do paciente tomar os medicamentos, desse modo acha que a DOTS é positivo (Ger.B1.3).

- Gerente refere que a quantidade de comprimidos e os possíveis efeitos colaterais podem ser os motivos que dificultam a manutenção da terapia medicamentosa (Ger.B1.4).

- Gerente refere que a rotina da UBS é manter todos os pacientes sob o esquema normal (auto administrado) e que a DOTS é aplicado em casos que precisam de atenção diferenciada (Ger.B1.5).

- Gerente refere que não sabe dizer como está sendo realizado o TS do atual caso de tuberculose na UBS (Ger.B1.7).

- O gerente refere que o TS trás impacto no processo de trabalho, mas considera-o pequeno na rotina de trabalho da UBS, mas não tem certeza, dado que não trabalha diretamente com a estratégia (Ger.B1.8).

- Gerente refere que o desenvolvimento do TS depende do profissional de saúde escolher o caso, e considera essa possibilidade de escolha razoável (Ger.B1.9).

- Gerente refere o TS seria como centralização de trabalho na UBS, e que vai ao sentido contrário do oferecimento de mais autonomia ao paciente (Ger.B1.10).

- Gerente refere que a atual situação da tuberculose, da resistência aos medicamentos a DOTS é uma estratégia que tem de ser implementada, sob a perspectiva de você poder escolher os casos para o DOT (Ger.B1.11).

\section{Profissional de saúde da saúde da UBS B (B2)}

- Enfermeira refere que trabalha há 4 anos nesta UBS (Enf.B2.1).

- Enfermeira refere que em sua rotina de trabalho diária envolve o acolhimento, consulta de enfermagem que se divide em pré-natal, consulta do adulto, grupos de adolescente, hipertenso, grupos para os cuidadores (Enf.B2.2).

- Enfermeira refere não ter um período específico para desenvolver as atividades da vigilância epidemiológica, e faz nos períodos que consegue entre as consultas, ou na falta de um paciente (Enf.B2.3).

- Enfermeira refere que é responsável pela vigilância epidemiológica, mas que as outras enfermeiras também fazem notificação ou outras atividades da vigilância (Enf.B2.4).

- Enfermeira refere não ter tido treinamento para trabalhar com a vigilância, pois tem apenas experiências hospitalares, aprende no dia a dia com outra enfermeira ou em contato com a SUVIS (Enf.B2.5).

- Enfermeira refere que o TS é indicado para os pacientes rebeldes, que não fazem o tratamento adequadamente, para os indivíduos que tem dificuldades financeiras e não tem o que comer em casa (Enf.B2.6).

- Enfermeira refere-se ao papel do Agente Comunitário de Saúde como super importante, pois já conhecem as famílias, no acompanhamento dos pacientes sob tratamento para 
tuberculose, pois eles observam se o paciente está tendo alguma reação ao medicamento, a adaptação ao tratamento (Enf.B2.7).

- Enfermeira refere que os Agentes Comunitários de Saúde são importantes, pois eles conhecem as famílias e podem orientar a equipe de saúde se o doente vai se adequar ao tratamento ou não (Enf.B2.8).

- Enfermeira refere que desde o primeiro atendimento é possível perceber a pessoa, se ela tem apoio familiar, como é a sua situação de vida, de moradia (Enf.B2.9).

- Enfermeira refere-se a tuberculose como um problema social (Enf.B2.10).

- Segundo a enfermeira, os incentivos como a cesta básica, ajudam muito as famílias e apóia a manutenção do tratamento (Enf.B2.11).

- Para a enfermeira, a estratégia do TS só oferece benefícios para o doente, e ele não precisa fazer nada, o paciente não tem responsabilidade no tratamento (Enf.B2.12).

- Enfermeira refere que os pacientes aceitam o TS mais pelos benefícios, como a cesta básica, do que pela consciência de sua condição de saúde (Enf.B2.13).

- Enfermeira faz referência a um caso atendido, com histórico de abandono, que só aceitou o TS pois está com dificuldades financeiras (Enf.B2.14).

- Enfermeira refere que os auxiliares de enfermagem da equipe do doente que realizam o TS (Enf.B.15).

- Enfermeira refere que o TS é oferecido para todos os pacientes, independe da condição da família ou da preferência do doente sobre como fará seu tratamento (Enf.B2.16).

- Enfermeira refere que é preenchido o formulário para a inclusão do paciente em TS e então esse documento é encaminhado para a UVIS, que cadastra o paciente a receber a cesta básica (Enf.B2.17).

- Enfermeira refere que a partir do conhecimento que os Agentes Comunitários têm das famílias, é possível saber se é preciso dar mais amparo ou não para o doente, assim como se é necessário ficar mais em cima (Enf.B.18).

- Enfermeira refere que também é realizado VD para conhecer como vive a família (Enf.B2.19).

- Segundo a enfermeira, quando o paciente falta no TS, o ACS junto com as auxiliares de enfermagem vão fazer VD para saber o que está acontecendo (Enf.B2.20).

- A enfermeira refere que o TS é realizado diariamente na UBS, e sempre é marcado um horário com o doente para ele tomar a medicação e aos finais de semana a equipe de saúde deixa conversado com um familiar para administrar a medicação (Enf.B2.21).

- O paciente sob o TS é referido pela enfermeira como o SUPERVISIONADO (Enf.B2.22).

- Enfermeira refere integrar os membros da família no TS (Enf.B2.23).

- Enfermeira faz referência a um caso atendido na UBS, que era um morador de rua, e toda a equipe se mobilizou para a manutenção do tratamento (Enf.B2.24).

- Enfermeira refere que todo tratamento é difícil e refere que o tratamento de tuberculose é difícil como o tratamento em pacientes crônicos (Enf.B2.25).

- Enfermeira refere que é horrível quando tem algum caso de abandono, e que sente-se impotente e frustrada na ocorrência de algum caso de abandono (Enf.B2.26).

- Enfermeira refere que muitos doentes tem dificuldade em acesso as UBS, as vezes por morar muito longe da Unidade de Saúde (Enf.B2.27).

- Enfermeira faz referência em possibilitar o TS para os pacientes cujas residências ficam distantes da UBS que seria o auxiliar de enfermagem fazer o TS no domicílio (Enf.B2.28).

- Enfermeira refere que vê como ponto negativo a postura de muitos pacientes em não assumir a responsabilidade de si e que o TS, assim como o PSF, contribui em carregar os doentes, oferecendo benefícios, sem cobrar (Enf.B2.29).

- Enfermeira refere que o TS proporciona grande vínculo com o doente (Enf.B2.30).

- Enfermeira refere que a saúde é tudo, saúde, não apenas o físico, mas o psicológico, o social (Enf.B2.31). 


\section{Profissional de saúde da saúde DA UBS B (B3)}

- Auxiliar refere trabalhar há 16 anos em posto de saúde (AE.B3.1).

- Auxiliar de enfermagem refere ajudar no trabalho da vigilância epidemiológica, sob supervisão da enfermeira (AE.B3.2).

- Auxiliar de enfermagem refere já ter feito visitas domiciliárias para os pacientes com tuberculose acompanhando a enfermeira quando trabalhava em outra Unidade de Saúde (AE.B3.4).

- Auxiliar de enfermagem refere ter recebido orientação para desenvolver as atividades no PCT (AE.B3.5).

- Auxiliar de enfermagem refere-se a esse treinamento recebido como "tipo de orientação", sobre como proceder e que a tem ajudado no desenvolvimento das atividades da vigilância, sob a supervisão da enfermeira (AE.B3.6).

- Auxiliar de enfermagem refere achar o envolvimento emocional com os pacientes pesado, pois você tenta passar as informações da doença e sua gravidade, mas as vezes o doente não leva a sério (AE.B3.7).

- Para a auxiliar de enfermagem, o TS é indicado para os casos de pacientes que não fazem o tratamento em casa (AE.B3.8).

- Para a auxiliar de enfermagem, mesmo sob o TS acontece do paciente faltar e refere que mesmo com TS não tem como evitar que o paciente não compareça para tomar a medicação (AE.B3.9).

- Segundo a auxiliar de enfermagem, o paciente comparece na UBS pela manhã, é oferecida a medicação em jejum, o lanche e logo após a outra medicação (AE.B3.10).

- Auxiliar de enfermagem refere oferecer a medicação, e caso o paciente não queira tomar o lanche no momento, ele volta mais tarde para tomar as outras medicações (AE.B3.11).

- Segundo a auxiliar de enfermagem, quando o paciente vai pra comer em casa ele não retorna para tomar as outras medicações (AE.B3.12).

- Auxiliar de enfermagem refere ter uma boa relação com o paciente que está em tratamento na UBS, que ele conversa, mas sente-o rebelde em não seguir as orientações oferecidas (AE.B313).

- Segundo a auxiliar de enfermagem, o caso em acompanhamento na Unidade, ele apesar de rebelde em aceitar as orientações, indiretamente ele tem consciência dos riscos da doença (AE.B3.14).

- Segundo a auxiliar de enfermagem, existe uma planilha para o seguimento dos doentes em TS (AE.B3.15).

- Auxiliar de enfermagem refere que o TS é bom já que não é para todos os casos de TB da unidade (AE.B3.16).

- Auxiliar de enfermagem refere não ser difícil fazer o TS na UBS, que não atrapalha na rotina e ela gosta, pois acha que é uma forma de estar ajudando, dando força (AE.B3.17).

- Auxiliar de enfermagem refere que todos na UBS sabem do caso do paciente que está sob TS, e acompanham todo o tratamento (AE.B3.18).

- Para a auxiliar de enfermagem, não tem pontos negativos o TS (AE.B3.19).

- Para a auxiliar de enfermagem, quando o paciente falto no TS, eles vão atrás do paciente, conversar com a mãe do doente, pois ela aconselha e conversa bastante com 0 doente (AE.B3.20).

- Para a auxiliar de enfermagem, quando há abandono do tratamento a doença volta mais forte (AE.B3.21).

- Para a auxiliar de enfermagem, não são todos os casos que necessitam do TS, depende do caso (AE.B3.22).

- Para a auxiliar de enfermagem, o tratamento da tuberculose evoluiu e não é mais discriminado (AE.B3.23). 
- Para a auxiliar de enfermagem, a tuberculose é divulgada na televisão, a equipe de saúde tem folhetos informativos, sempre tem campanha que aborda o assunto e é oferecido o exame (AE.B3.24).

- Para a auxiliar de enfermagem, a equipe não está para amedrontar o paciente, mas orientar sobre a gravidade da doença (AE.B3.25).

- Auxiliar de enfermagem refere gostar de ir à casa das pessoas, conversar e orientar (AE.B3.26).

- Segundo a auxiliar de enfermagem, na UBS não dá para conversar com os pacientes, mas quando os encontra em outros lugares, é possível conversar e dar atenção (AE.B3.27).

- Para a auxiliar de enfermagem, o trabalho dos agentes comunitários de saúde é importante, pois eles vão ao domicílio semanalmente saber se está tudo bem com o paciente (AE.B2.28).

- Segundo a auxiliar de enfermagem, tanto as enfermeiras como os próprios médicos participam no atendimento do doente quando ele está com alguma queixa (AE.B3.29).

- Auxiliar de enfermagem refere que o atual caso em tratamento só vai pra UBS para tomar a medicação, mas não aceita as orientações ofertadas (AE.B3.30).

\section{Unidade Básica de Saúde C}

\section{Coordenador da UBS C (C4)}

- Caracterização do profissional (Ger.C4.1)

- Caracterização do TS na UBS (Ger.C4.2)

- Gerente refere estar como gerente da UBS há 5 anos (Ger.C4.3)

- Gerente refere que sua trajetória não é de UBS, mas hospitalar e que quando ingressou como gerente teve sorte, pois teve apoio de outros profissionais de nível superior (Ger.C4.4)

- Gerente refere que a UBS tinha problema estrutural, principalmente recursos humanos, devido a contratos de emergência (Ger.C4.5)

- Gerente refere não ser a pessoa indicada para falar saber sobre o TS e que o conhecimento que tem foi adquirido a partir de conversa com outros profissionais da UBS (Ger.C4.6)

- Para a gerente o TS é indicado para os pacientes com dificuldade em aderir ao tratamento, que são os casos de recidiva ou abandono(Ger.C4.7)

- Para a gerente, a operacionalização do TS envolve o comparecimento do paciente para tomar a medicação na UBS, sob supervisão da enfermeira, auxiliar de enfermagem ou a médica sanitarista (Ger.C4.8)

- A gerente refere que os pacientes que estão sob TS recebem benefícios que são: cesta básica e lanche (Ger.C4.9)

- Gerente refere não saber como ocorre a busca de faltosos e é a enfermeira quem administra toda a rotina de atendimento do doente (Ger.C4.10)

- Segundo a gerente, é a enfermeira que tem conhecimento de todos os pacientes, e ela sabe quando precisa ir fazer visita domiciliária ou ligar para os pacientes (Ger.C4.11)

- Gerente refere que o atendimento aos doentes com tuberculose ocorre como o atendimento prestado aos pacientes que fazem uso de insulina na UBS, e que há organização para atender esses pacientes (Ger.C4.12)

- Gerente refere, baseado em comentários de outros profissionais que a irregularidade na entrega da cesta básica dificulta o trabalho e que a equipe passa "carão" perante o paciente (Ger.C4.13)

- A gerente refere que são muitos os papéis a serem preenchidos para que o paciente receba o benefício (Ger.C4.14) 
- Gerente refere que acontece do paciente receber a cesta básica após já ter recebido alta do tratamento (Ger.C4.15)

- Para a gerente, o lanche aos pacientes não é variado, determinando que o paciente enjoe e o distribua para os familiares (Ger.C4.16)

- Para a gerente, o TS é o que menos atrapalha na rotina da UBS na medida em que é muito rápido diferentemente dos agendamentos para especialidades e exames (Ger.C4.17)

- Para a gerente, a experiência de atender o paciente freqüentemente, trás retorno (Ger.C4.18)

- Para a gerente, o vínculo do paciente com a unidade é bom (Ger.C4.19)

- Para a gerente, o tratamento para a TB permite "ver" a cura do doente, diferentemente de outras doenças e isso é gratificante (Ger.C4.20)

- Gerente refere que o tratamento para a tuberculose é tranqüilo (Ger.C4.21)

- Para a gerente, a equipe de enfermagem é que mais se dedica ao TS (Ger.C4.22)

- Gerente refere ter uma equipe para tratar do PCT, mas esta se encontra sobrecarregada com outros problemas e demandar (Ger.C4.23)

- Para a gerente, a busca ativa não é feita na UBS, nem mesmo por ocasião do atendimento médico (Ger.C4.24)

- Para a gerente não há pontos negativos no TS, exceto muita burocracia, que acha necessário para o controle do trabalho e que essa tarefa do PCT não é o que sobrecarrega a UBS (Ger.C4.25)

- Para a gerente, a UBS atua como central de atendimento, fazendo uso de profissional qualificado, que poderia desenvolver outras atividades, voltadas para a população (Ger.C4.26)

- Segundo a gerente, se o sistema de contra referência fosse organizado, a equipe teria mais tempo para fazer convocações de pacientes (Ger.C4.27)

- Para a gerente a ocupação do médico e da enfermeira deveria ser com a busca dos faltosos no tratamento, assim como os faltosos de vacina (Ger.C4.28)

- Para a gerente, o sistema de referência e contra-referência é desorganizado, sem integração podendo resultar em perdas para aqueles que mais necessitam (Ger.C4.29)

- Para a gerente, o paciente com tuberculose é aquele mais próximo da equipe e da unidade (Ger.C4.29)

\section{Profissional de saúde da UBS C (C1)}

- Caracterização do profissional (Enf.C1.1).

- Enfermeira refere ter feitos todos os cursos do CVE sobre tuberculose (Enf.C1.2).

- Enfermeira refere que foi monitora de tuberculose num treinamento direcionado aos profissionais de nível superior (Enf.C1.3).

- Enfermeira refere que seu trabalho na UBS é de "uma auxiliar de enfermagem melhorada", por falta de recursos humanos (Enf.C1.4).

- Enfermeira refere que assumiu a vigilância epidemiológica na UBS por conta da saída da sanitarista (licença), ocasião em que deu início ao TS na UBS (Enf.C1.5).

- Enfermeira refere que as atividades de vigilância epidemiológica se concentram no controle da tuberculose (Enf.C1.6).

- Enfermeira refere que as auxiliares sentiram-se bem em fazer o TS, ainda que sem prévia preparação para desenvolver tal tarefa (Enf.C1.7).

- Enfermeira refere que as auxiliares de enfermagem criaram vínculo com os pacientes sob DOTS, mesmo sem preparo suficiente (Enf.C1.8).

- Enfermeira refere que, quando os benefícios do Município não chegavam aos pacientes, a equipe de saúde se organizava para oferecer alimentos, roupas, devido a situação de pobreza dos pacientes (Enf.C1.9). 
- Enfermeira refere que, em decorrência do vínculo estabelecido por ocasião do TS, alguns pacientes ainda mantém contato, mesmo após ter recebido alta do tratamento (Enf.C1.10).

- Segundo a enfermeira, os pacientes se engajaram muito bem no TS (Enf.C1.11).

- Para a enfermeira à todos os pacientes deveria ser oferecido o TS, mas isso não ocorre por parte de toda a equipe de saúde (Enf.C1.12).

- Enfermeira refere oferecer o TS para todos os pacientes (Enf.C1.13).

- Para a enfermeira, tuberculose deve ser considerada emergência numa UBS e que, mesmo na ausência do médico, já inicia a terapia medicamentosa (Enf.C1.14).

- Enfermeira refere oferecer o TS para todos os doentes, independente do estado social, pois considera que o TS permite desenvolver vínculo (Enf.C1.15).

- Enfermeira refere que o TS é executado por ela mesma ou pelas auxiliares de enfermagem (Enf.C1.16).

- Para a enfermeira, o atendimento ao paciente com TB deve ser diferenciado em termos de prioridade (Enf.C1.17).

- Enfermeira refere que o lanche é oferecido para o doente e seus familiares, inclusive no final de semana e feriados (Enf.C1.18).

- Enfermeira refere que apenas os pacientes sob TS recebem os incentivos (Enf.C1.19).

- Segundo a enfermeira, o paciente assina um contrato para iniciar o TS, com dias da semana e horários pré-definidos (Enf.C1.20).

- Enfermeira refere oferecer passe diariamente ao paciente que precisar para fazer o TS, ou oferece para o paciente e acompanhante quando este precisa fazer algum exame em lugares distantes de seu domicílio ou no Clemente Ferreira (Enf.C1.21).

- Enfermeira refere que a cesta básica se constitui num "pesadelo" e que há pacientes que já tiveram alta e ainda continua recebendo as cestas atrasadas (Enf.C1.22).

- Para a enfermeira, os benefícios colaboram na criação de vínculo (Enf.C1.23).

- Para a enfermeira, o fato de não receber a cesta básica prometida, pode comprometer o vínculo (Enf.C1.24).

- Para a enfermeira, a necessidade dos pacientes é muito grande, e como a entrega da cesta básica é irregular, a equipe de saúde vai ajudando ao doente (Enf.C1.25).

- Enfermeira refere acompanhar os doentes quinzenalmente e que as atividades que o compõem são: verificação da PA, glicemia capilar, pesar o doente, orientar sobre medicações e perguntar como o doente está, diferentemente do acompanhamento médico (Enf.C1.26).

- Enfermeira refere orientar o paciente a ingerir ranitidina durante o início do tratamento e quando eles sentirem que não precisa mais, parar com a medicação (Enf.C1.27).

- Enfermeira refere deixar o número de seu telefone com os pacientes para eventuais emergências (Enf.C1.28).

- Enfermeira refere que os pacientes dão satisfação sobre a manutenção do tratamento (Enf.C1.29).

- Enfermeira refere que os pacientes sob tratamento de tuberculose, geralmente são etilistas (Enf.C1.30).

- Enfermeira refere que teve um caso de TS no domiciliário, sob cuidados da esposa, que era orientada pela enfermeira (ação que a enfermeira refere como "apadrinhamento") (Enf.C1.31).

- Enfermeira refere que o vínculo é fundamental para evitar o abandono e nesse sentido o TS é mais positivo (Enf.C1.32).

- Para a enfermeira, os pacientes que trabalham "do outro lado da cidade" não podem fazer o TS, e se não for criado o vínculo, ele pode abandonar o tratamento (Enf.C1.33).

- Enfermeira refere usar de estratégias como visitas repetidas para evitar um abandono, apesar da falta de sucesso em alguns casos (Enf.C1.34).

- Enfermeira refere que o TS é realizado na UBS, pois a equipe não dispõe de Agente Comunitário de Saúde para fazer o TS no domicílio (Enf.C1.35).

- Enfermeira refere que a cuidadora, durante o TS domiciliário, ia pra UBS e levava toda a medicação pra mostrar a quantidade que tinha em casa (Enf.C1.36). 
- Enfermeira refere controlar a entrega da medicação ao paciente, e que os doentes não percebem que isso ocorre no início do tratamento (Enf.C1.37).

- Enfermeira refere não orientar o doente a parar de fumar ou beber, apenas diminuir, para evitar o abandono (Enf.C1.38).

- Enfermeira refere dispor do telefone de todos os pacientes sob DOTS (Enf.C1.39).

- Enfermeira refere fazer visita rápida aos pacientes em TS (Enf.C1.40

- Para a enfermeira, o doente que iniciou o tratamento nesta semana, ela fará uma visita, pois conhece a rua na favela onde ele mora (Enf.C1.41).

- Enfermeira refere que fará visita a este paciente para "ver" as condições da casa deste doente (Enf.C1.42).

- Enfermeira refere que a cesta básica chega no final do mês, mas que o paciente precisa se alimentar hoje (Enf.C1.43).

- Para a enfermeira, o lanche oferecido não leva em consideração se o doente é diabético ou hipertenso (Enf.C1.44).

- Enfermeira refere que é preciso saber se o paciente é hipertenso, diabético, para que se possa pensar nos lanches a serem oferecidos (Enf.C1.45).

- Enfermeira refere que o primeiro contato com os faltosos é pelo telefone, ou alguém da família entra em contato para informar se alguma coisa aconteceu (Enf.C1.46).

- Para a enfermeira, as pessoas têm medo da tuberculose (Enf.C1.47).

- Enfermeira refere que na UBS a equipe não tem medo de atender ao doente, pois eles atendem e dispensam rapidamente o doente (Enf.C1.48).

- Para a enfermeira, o ponto negativo no TS é não ter recursos humanos (Enf.C1.49).

- Para a enfermeira, no início do TS as auxiliares de enfermagem manifestaram-se negativamente em relação ao TS, por ser diário, sensação que vai diminuindo pelas atitudes do próprio doente (Enf.C1.50).

- Enfermeira refere apresentar o doente para as auxiliares de enfermagem, mas sempre deixa uma ou duas responsáveis por aquele doente (Enf.C1.51).

- Enfermeira manifesta a dificuldade de trabalhar com certos familiares dos doentes, que querem ser atendidos com prioridades (Enf.C1.52).

- Enfermeira refere deixar o atendimento à sanitarista, pois ela não tem como dar seguimento sozinha a todas as atividades que tem para desenvolver, por falta de recursos humanos na UBS (Enf.C1.53).

- Enfermeira refere que a sanitarista não oferece e nem faz o TS (Enf.C1.54).

- Para a enfermeira, o TS não é paternalismo e deve ser até "forçado" para ser realizado (Enf.C1.55).

- Para a enfermeira, sem o TS, pode-se perder o controle dos casos (Enf.C1.56).

- Para a enfermeira, alguns casos não podem fazer o TS por trabalharem longe, e nessas situações a equipe entende se o paciente não estiver sob DOTS (Enf.C1.57).

- Segundo a enfermeira, para os pacientes que trabalham distante, há possibilidade de entrar em contato com outra unidade, próxima ao trabalho do doente, para que este faça o TS lá (Enf.C1.58).

- Para a enfermeira, atender ao doente com tuberculose demora e exige do profissional, pois é necessário orientar de maneira que o doente absorva as orientações e crie vínculo (Enf.C1.59).

- Para a enfermeira, no TS é possível conversar com o doente "bater papo", dar um lanche a mais, até para a criança que está junto do doente, eles gostam e cria vínculo (Enf.C1.60).

- Para a enfermeira, os profissionais de saúde devem ser conscientizados sobre o TS (Enf.C1.61).

- Para a enfermeira, os profissionais de saúde devem ser conscientizados sobre a necessidade de realizar o TS, pois a TB não é um problema que se restringe ao doente (Enf.C1.62).

- Para a enfermeira, todos correm risco de ter a tuberculose (Enf.C1.63). 


\section{Profissional de saúde da UBS C (C2)}

- Caracterização do profissional (AE.C2.1).

- Caracterização do TS na UBS (AE.C2.2).

- Auxiliar de enfermagem refere trabalhar há 16 anos na UBS Jd Jaqueline (AE.C2.3).

- Auxiliar de enfermagem refere só fazer o TS no PCT, mas que não teve treinamento sobre vigilância ou sobre o TS (AE.C2.4).

- Auxiliar de enfermagem refere que foi montada equipe na UBS para atender aos pacientes com tuberculose (auxiliar de enfermagem, enfermeira e médica (AE.C2.5).

- Segundo a auxiliar de enfermagem, o TS envolve receber o paciente, conversar e explicar o tratamento e sua a duração, oferecer a medicação e o lanche, diariamente (AE.C2.6).

- Segundo a auxiliar de enfermagem, a medicação do final de semana é entregue ao paciente junto com o lanche para que ele tome (AE.C2.7).

- Segundo a auxiliar de enfermagem, o contrato para o TS é de ser realizado pela manhã (AE.C2.8).

- Segundo a auxiliar de enfermagem, ela e a enfermeira são as pessoas a que o paciente procura diariamente para o TS (AE.C2.9).

- Para a auxiliar de enfermagem, o TS tem resultado, pois atualmente já não há tantos casos na UBS (AE.C2.10).

- Para a auxiliar de enfermagem, a gratificação, o agradecimento do paciente são pontos positivos do TS (AE.C2.11).

- Para a auxiliar de enfermagem o TS permite que o serviço seja gratificante ao profissional (AE.C2.12).

- Segundo a auxiliar de enfermagem, durante o TS tem-se abertura na vida do paciente, ele fala, desabafa e é possível fazer um bom acolhimento (AE.C2.13).

- Para a auxiliar de enfermagem, o ponto negativo do TS é o abandono do tratamento pelo paciente (AE.C2.14).

- Para a auxiliar de enfermagem os pacientes com tuberculose são prioridades na UBS (AE.C2.15).

\section{Profissional de saúde da UBS C (C3)}

- Caracterização do profissional (AE. C3.1).

- Auxiliar de enfermagem refere que trabalha há quase 4 anos nesta UBS (AE. C3.2).

- Auxiliar de enfermagem refere só auxiliar a enfermeira na vigilância epidemiológica (AE.C3.3).

- Para a auxiliar de enfermagem, no TS, precisa ser firme com o doente, o que contribui para o controle da doença (AE.C3.4).

- Para a auxiliar de enfermagem, o profissional precisa ser firme para que o paciente se trate, o que contribui para evitar as formas mais graves e uma epidemia (AE.C3.5).

- A auxiliar de enfermagem refere desenvolver o TS desde o aparecimento do primeiro caso de TB (AE.C3.6).

- Auxiliar de enfermagem refere só ter recebido orientações da enfermeira sobre como fazer o TS (AE.C3.4).

- A auxiliar de enfermagem refere que foi orientada pela enfermeira a fazer o acolhimento para a criação de vínculo com o doente, pois com o tempo o paciente desanima do tratamento (AE.C3.5).

- Auxiliar de enfermagem refere que a enfermeira, ao orientar sobre o TS, frisou a questão da criação de vínculo com o doente, de sempre cumprimentar, criar amizade, para que não seja apenas dar a medicação (AE.C3.6). 
- Auxiliar de enfermagem menciona não saber o fluxo de atendimento dos pacientes portadores de TB na unidade (AE.C3.7).

- Auxiliar de enfermagem refere que o paciente chega até ela para iniciar o TS através da enfermeira, que apresenta o paciente (AE.C3.8).

- Auxiliar de enfermagem refere orientar o paciente a não ficar esperando para receber o TS (AE.C3.9).

- Auxiliar de enfermagem refere que no TS oferece a medicação, pergunta para o paciente sobre possíveis reações a medicação e entrega o lanche (AE.C3.10).

- Para a auxiliar de enfermagem, o TS tem que ser realizado num horário que seja bom para o doente e principalmente para profissional (AE.C3.11).

- Auxiliar de enfermagem considera importante o TS, devido a possibilidade de cura e para que não seja risco para a população (AE.C3.12).

- Auxiliar de enfermagem refere não haver pontos negativos no TS, mas percebe que a aceitação do tratamento diário na UBS pelo doente é negativa (AE.C3.13).

- Para a auxiliar de enfermagem há pacientes que perdem a paciência, pois acredita que a UBS deve "ficar esperando de braços abertos (AE.C3.14).

- Auxiliar de enfermagem aponta que com alguns pacientes ainda permanece o vínculo, mesmo após o término do TS (AE.C3.15).

- Auxiliar de enfermagem refere como ponto negativo o desinteresse que pode ser crescente no término do tratamento pelos pacientes, o que pode ser modificado conversando e aproximando-se do paciente (AE.C3.16).

- Para a auxiliar de enfermagem, o fato de alguns pacientes necessitarem prorrogar o tratamento pode causar decepção aos pacientes, e que nesses casos é necessário explicar sobre a paciência e que o tratamento é importante (AE.C3.17).

\section{Profissional de saúde da UBS C (C5)}

- Segundo a médica, seu trabalho na UBS é com a vigilância epidemiológica, atendimento das doenças infecto-contagiosas, organização do fluxo (Med.C5.1)

- Sanitarista refere que são oferecidas a todos os pacientes as opções de tratamento: auto administrado ou supervisionado (Med.C5.2)

- Segundo a médica, o TS é executado na UBS pela equipe de enfermagem e por ela (Méd.C5.3)

- Para a médica, integra a operacionalização do TS o comparecimento diário na UBS pela manhã, oferecer a medicação e ver o paciente ingeri-la, e oferecer o lanche (Méd.C5.4)

- Segundo a médica, o paciente assume o compromisso de vir diariamente à unidade diariamente, pela assinatura do termo de aderência (Med.C5.5)

- Segundo a médica, a equipe que faz o TS dá preferência para que o paciente compareça a UBS pela manhã (Méd.C5.6)

- A médica refere que a irregularidade no oferecimento do lanche e cesta básica constitui um grande problema do TS (Méd.C5.7)

- Para a médica, a irregularidade na distribuição da cesta básica gera demanda para a equipe que faz o TS, pois o paciente cobra muito o recebimento da cesta, mesmo pacientes que louva ter criado vínculo (Méd.C5.8)

- Médica refere que os lanches são oferecidos apenas aos pacientes sob TS (Méd.C5.9)

- Médica refere que o TS permite ter maior controle dos pacientes com TB (Méd.C5.10)

- Médica refere não apresentar abandono de tratamento devido à sua disponibilidade na UBS aos pacientes (Méd.C5.11)

- Médica refere fazer visitas domiciliares quando o paciente falta no atendimento seja sob TS, seja sob tratamento auto administrado (Méd.C5.12)

- Para a médica, a cesta básica cobre um problema social, e não contribui para a adesão, nos casos em que ocorre o acompanhamento do doente e disponibilidade por parte do médico (Méd.C5.13) 
- Para a médica, a distribuição da cesta básica é desorganizada, não tem lógica e seu conteúdo é muito pobre e que não contém quase nada (Méd.C5.14)

- Sanitarista refere ter tido muitos problemas com familiares dos pacientes sob TS em decorrência da irregularidade na distribuição da cesta básica (Méd.C5.15)

- Para a médica, a irregularidade na distribuição dos benefícios enfurece os pacientes, gerando expectativas, e isso se constitui como problema (Méd.C5.16)

- Médica refere que já teve de ajudar pacientes com leite, pois o paciente precisava e a cesta não chegava (Méd. C5.17)

- Para a médica, o TS é importante nos primeiros dois meses de tratamento (Méd.C5.18)

- Para a médica, a irregularidade na distribuição dos benefícios do TS cria problemas em sua rotina de trabalho (Méd.C5.19)

- Médica manifesta constrangimento ao oferecer sempre o mesmo lanche aos pacientes, e devido a sua irregularidade na distribuição (Méd.C5.20)

- Médica refere que se a distribuição dos benefícios fosse regular, ela ofereceria para todos os pacientes Méd.C5.21)

- Médica refere como "obrigatório" oferecer o TS (Méd.C5.22)

- Para a médica, por morarem perto do posto, é fácil para o paciente ir fazer o TS (Méd.C5.23)

- Para a médica, o vínculo não depende do TS, mas depende da disponibilidade de quem atende ao paciente (Méd.C5.24)

- Para a médica, o paciente procura a UBS toda semana, não apenas na data de seu retorno, e em cada semana ele tem uma queixa (Méd.C5.25)

- Para a médica, os pacientes com tuberculose sentem-se diferenciados, e querem um atendimento diferenciado (Méd.C5.26)

- Para a médica, o paciente com tuberculose não quer ser atendido pela pessoa que oferece o lanche, que veja só a TB, mas pelo profissional médico que o veja por inteiro (Méd.C5.27)

\section{Unidade Básica de Saúde D}

\section{Coordenador da UBS D (D1)}

- Caracterização do profissional (Ger.D1.1)

- Caracterização do TS na UBS (Ger.D1.2)

- Gerente refere que antes do PAS não se tem informação dos casos de tuberculose da região (Ger.D1.3)

- Gerente refere que após o PAS, a equipe começou a "ficar em cima" dos casos e então organizou o atendimento com o TS (Ger.D1.4)

- Gerente refere que sempre tratou de tuberculose durante na carreira profissional (Ger.D1.5)

- Gerente refere ter recebido treinamento bem longo sobre tuberculose, oferecido pela prefeitura Municipal de São Paulo em 1984 (Ger.D1.6)

- Gerente refere que atualmente são oferecidos cursos de reciclagem e atualização, ainda que em períodos muito reduzidos (Ger.D1.7)

- Para a gerente, o TS é controlar e observar a ingesta da medicação pelo paciente, verificando se ele está tomando corretamente (Ger.D1.8)

- Para a gerente, a diferença entre o tratamento auto administrado e o TS, é a possibilidade de saber onde o paciente armazena o medicamento e saber se ele está tomando corretamente e evitar do paciente confundir a medicação (Ger.D1.9)

- Para a gerente, o TS permite que a equipe de saúde fique "mais em cima" do doente (Ger.D1.10)

- Para a gerente, o TS evita que o paciente fique com acúmulo de medicação (Ger.D1.11) 
- Para a gerente, o TS não precisa ser diário, mas pode ser semanal ou a cada 3 a 4 dias (Ger.D1.12)

- Gerente refere não ter conhecimento das informações sobre tuberculose no bairro antes do ano de 2000, pois não tinha controle nenhum dos casos durante o período do PAS (Ger.D1.13)

- Segundo a gerente, durante o período do PAS, os doentes estavam "mais ou menos" abandonados (Ger.D1.14)

- Segundo a gerente, o TS iniciou por conta de uma política da prefeitura do município para conter as altas taxas de abandono e casos de recidiva (Ger.D1.15)

- Segundo a gerente, a equipe de saúde precisa ficar "em cima" dos doentes (Ger.D1.16)

- Gerente refere que o TS não é feito semanalmente (Ger.D1.17)

- Segundo a gerente, a freqüência do retorno do paciente é modificada se é observado que o paciente é "difícil" para manter o tratamento (Ger.D1.18)

- Gerente refere que alguns casos são necessários o TS diariamente (Ger.D1.19)

- Segundo a gerente, a tuberculose é "uma doença que você adota o paciente" durante os 6 meses de tratamento (Ger.D1.20)

- Gerente refere que o tratamento da tuberculose é trabalhoso, principalmente no TS (Ger.D1.21)

- Para a gerente, o TS vale a pena, pois é possível alcançar a cura do doente (Ger.D1.22)

- Para a gerente, o TS é proveitoso e evita as conseqüências piores do tratamento incorreto (Ger.D1.23)

- Para a gerente, é preciso ter vínculo para atingir o término do tratamento (Ger.D1.24)

- Para a gerente, é trabalhoso o TS, pois o paciente não comparece no horário combinado, mas na hora em que eles querem (Ger.D1.25)

- Para a gerente, se o paciente não for atendido, ele não retorna mais para a unidade (Ger.D1.26)

- Para a gerente a equipe de saúde precisa estar disposta a adotar o paciente durante os 6 meses de tratamento. (Ger.D1.27)

- Para a gerente, o TS é trabalhoso para toda a equipe de saúde: médico, enfermeiro e auxiliar de enfermagem (Ger.d1.28)

- Gerente refere que o doente com tuberculose, não pode se mandado embora da unidade pela recepção (Ger.D1.29)

- Para a gerente, no tratamento auto administrado, às vezes a equipe não quer saber da data do retorno do paciente, diferente dos pacientes que estão sob TS, que a equipe tem controle sobre as datas de retorno do paciente (Ger.D1.30)

- Para a gerente, é importante ter uma equipe para atender aos doentes no TS (Ger.D1.31)

- Para a gerente, é preciso investir na equipe (médico, enfermeiro e auxiliar de enfermagem), pois o trabalho não dá para ser feito sozinho (Ger.D1.32)

- Para a gerente, o TS não prejudica o processo de trabalho na UBS, mas é "obrigação" da UBS (Ger.D1.33)

- Para a gerente, o TS TEM COMO ASPECTO negativo, o fato de ser trabalhoso, além da questão negativa que é o final de semana (Ger.D1.34)

- Segundo a gerente, o paciente que estava sob DOTS não tinha um familiar responsável por oferecer a medicação no final de semana pelo fato do paciente ser etilista (Ger.D1.35)

- Para a gerente, a meta da UBS é não ter abandono de tratamento (Ger.D1.36)

- Gerente refere que a maioria dos pacientes recebe a cesta básica (Ger.D1.37)

- Gerente refere que os pacientes com nível "pouquinho melhor" financeiramente, não fazem questão de receber os lanches (Ger.d1.38) 


\section{Unidade Básica de Saúde E}

\section{Coordenador da UBS E (E1)}

- Caracterização do profissional (Ger.E1.1)

- Caracterização do TS na UBS (Ger.E1.2)

- Gerente refere trabalhar há 4 anos nesta mesma unidade de saúde (Ger.E1.3)

- Para a gerente, o TS significa ver o que está acontecendo com o doente, se ele está aderindo ao tratamento (Ger.E1.4)

- Gerente refere-se ao TS como "pegar no pé" do doente (Ger.E1.5)

- Gerente refere que o TS pode ser realizado diariamente ou a cada dois dias (Ger.E1.6)

- Segundo a gerente, o TS acontece por que a rede começou a incentivar enviando os lanches para as unidades (Ger.E1.7)

- Gerente refere que o TS é feito apenas pelo enfermeiro (Ger.E1.8)

- Gerente refere que faz parte do TS explicar sobre o tratamento, e que o paciente deve comparecer a UBS para receber a medicação (Ger.E1.9)

- Gerente refere que no TS, o paciente é orientado sobre a necessidade de se fazer a supervisão do tratamento que é saber se a doença está se desenvolvendo (Ger.E1.10)

- Gerente refere que a única dificuldade de realizar a DOTS é com morador de rua (Ger.E1.11)

- Gerente refere que, ao perceber que o paciente adere ao tratamento, ele recebe liberdade no tratamento, que é chamado pela gerente de "desmame" (Ger.E1.12)

- Gerente refere que a farmácia não entrega as medicações para o tratamento da tuberculose (Ger.E1.13)

- Segundo a gerente, quando chega algum paciente na farmácia com receita para o tratamento da tuberculose, o paciente é encaminhado para o enfermeiro (Ger.E1.14)

- Segundo a gerente, a unidade de saúde recebe muitos casos diagnosticados no Hospital Universitário (Ger.E1.15)

- Gerente refere que o TS não interfere no processo de trabalho da UBS, não obstrui o volume de atendimento (Ger.E1.16)

- Gerente refere que o enfermeiro fica sobrecarregado, pois ele precisa estar disponível (Ger.E1.17)

- Gerente refere que o TS não tem pontos negativos (Ger.E1.18)

- Gerente refere que, em algumas situações, o cliente questiona o motivo de comparecer na UBS diariamente para tomar a medicação (Ger.E1.19)

- Gerente refere que é preciso dar flexibilidade no tratamento do doente para evitar o abandono (Ger.E1.20)

- Gerente refere que ponto positivo no TS é o vínculo com o doente (Ger.E1.21)

- Gerente refere que no TS é possível orientar a importância do tratamento ao doente para que tenha responsabilidade na manutenção do tratamento sob TS (Ger.E1.22)

\section{Profissional de Saúde da UBS E (E2)}

- $\quad$ Caracterização do profissional (Enf.E2.1)

- Enfermeiro refere que a maioria dos pacientes vai até a UBS pela manhã (Enf.E2.2)

- Enfermeiro refere atender diariamente pacientes sob TS, incluindo manipulação de prontuário e solicitação de exames (Enf.E2.3)

- Para o enfermeiro, a qualificação para lidar com a tuberculose ocorre na prática diária (Enf.E2.4)

- Enfermeiro refere que os pacientes oriundos de outros serviços procuram primeiramente a farmácia e daí são encaminhados ao enfermeiro que notifica o caso, fornece a 
medicação e estabelece a necessidade da vinda diária do paciente ao serviço para o TS (Enf.E2.5)

- Enfermeiro refere que o primeiro atendimento ao doente envolve a abertura da ficha de notifica, informar ao doente sobre a tomada de medicação na UBS, informar sobre os benefícios (cesta básica) e, se for necessário, oferecer o passe (Enf.E2.6)

- Enfermeiro refere que o acolhimento faz diferença no atendimento ao doente, pois há discriminação no caso de doença infecto-contagiosa (Enf.E2.7)

- Para o enfermeiro, as pessoas sentem medo em relação à TB, pois "abate a pessoa" (Enf.E2.8)

- Para o enfermeiro, a maioria dos pacientes sob tratamento da tuberculose é discriminada por ser "pobre" (Enf.E2.9)

- Para enfermeiro, alguns profissionais se distanciam do doente por medo de contaminar-se (Enf.E2.10)

- Para o enfermeiro, os doentes sentem o distanciamento dos profissionais de saúde e, por isso acabam por rejeitar comparecer à UBS (Enf.E2.11)

- Para enfermeiro, quando o paciente é acolhido, e não há distanciamento entre ele e o profissional, o paciente adere mais, tanto ao TS como ao tratamento como um todo (Enf.E2.12)

- Para o enfermeiro, os pacientes se esforçam para terminar o tratamento (Enf.E2.13)

- Enfermeiro refere que a falta de acolhimento, fez que um paciente atendido na UBS desistisse do tratamento (Enf.E2.14)

- Para o enfermeiro, pacientes que se sentem bem, após o terceiro ou quarto mês de tratamento, querem voltar ao trabalho (Enf.E2.15)

- Para o enfermeiro, o paciente que trabalha pode ter horário especial para que faça o TS sem prejuízos em relação ao salário (Enf.E2.16)

- Enfermeiro refere que no caso dos doentes que faltam ao TS, ocorre contato telefônico para "regatá-lo", ocasião em que é reforçada a importância do tratamento (Enf.E2.17)

- Segundo o enfermeiro, no caso de impossibilidade de localizar o doente por telefone, é feita a visita domiciliar para oferecer orientação e buscar saber sobre o motivo da falta e dificuldades na manutenção do tratamento, tentando ajudar o doente (Enf.E2.18)

- Segundo o enfermeiro, os benefícios oferecidos aos pacientes sob TS são: lanche, vale transporte e cesta básica em casa após o primeiro mês de tratamento (Enf.E2.18)

- Para o enfermeiro, o TS permite ao profissional "ter visão" sobre a evolução do doente, sobre a adesão ao tratamento e permite corrigir feitos colaterais, encaminhar para hospitalização, exames e consegue "recuperar o doente mais rápido" (Enf.E2.20)

- Segundo o enfermeiro, o paciente tem muitos efeitos colaterais no início do tratamento, e devem ser corrigidos (Enf.E2.21)

- Para o enfermeiro, o paciente sob TS sente-se acolhido, e tem melhor recuperação (Enf.E2.22)

- Enfermeiro refere a importância da integração entre a equipe e o doente (Enf.E2.23)

- Enfermeiro refere que na UBS faltam recursos humanos e quem assume o TS são apenas os enfermeiros (Enf.E2.24)

- Enfermeiro refere a necessidade de" montar" uma equipe formada por 2 enfermeiros e 2 auxiliares de enfermagem para atender aos doentes (Enf.E2.25)

- Para o enfermeiro, são "pontos negativos" no TS a falta de uma equipe para o atendimento e falta de espaço físico e equipamentos n UBS (Enf.E2.26)

- Para o enfermeiro, o TS não é feito no domicílio por falta de "condições" da equipe de saúde (Enf.E2.27)

- Para o enfermeiro, se a UBS dispõe de bom espaço físico, é melhor trazer o doente para que ele não fique isolado e para que não se acomode com o TS (Enf.E2.28)

- Enfermeiro considera que o TS no domicílio pode contribuir para "esconder" o doente da sociedade e isso contribui para baixar sua auto estima (Enf.E2.29)

- Enfermeiro refere que a dificuldade de todas as UBS é realizar a busca ativa (Enf.E2.30)

- Enfermeiro refere a necessidade dos gerentes também estarem preparados para estimular a busca ativa na UBS (Enf.E2.31) 
- Para enfermeiro, muitos pacientes não se tratam por medo e por "questões psicológicas" (Enf.E2.32)

- Enfermeiro refere que a equipe que atende ao doente precisa pensar na recuperação do doente, e não apenas ficar lembrando dos medicamentos (Enf.E2.33)

\section{Unidade Básica de Saúde F}

\section{Coordenador da UBS F (F2)}

- Caracterização do profissional (Ger.F2.1)

- Gerente refere que o TS é uma maneira de garantir o tratamento e quebrar a cadeira de transmissão da TB (Ger.F2.2)

- Gerente refere que o tratamento auto administrado causava pouco impacto nos índices de cura (Ger.F2.3)

- Para a gerente, o pouco impacto nos índices de cura sob tratamento auto administrado causava insatisfação no profissional, pois o abandono do tratamento acontecia no quinto mês de tratamento (Ger.F2.4)

- Para a gerente, a causa do abandono no quinto mês de tratamento, estava associado ao "relaxamento" na atenção dos profissionais de saúde para com o doente, por pensar que o tratamento estava na "reta final" (Ger.F2.5)

- Para a gerente, o TS permite que o profissional de saúde mantenha a disponibilidade de atenção ao doente e permite manter a motivação do doente para completar o tratamento (Ger.F2.6)

- Para a gerente, o TS é uma estratégia que está sendo possível de realizar e permitindo quebrar a cadeira de transmissão da doença (Ger.F2.7)

- Para a gerente, a rede de saúde possui os elementos necessários para diminuir os casos de tuberculose que são: raio x, o exame de escarro, os profissionais, medicação (Ger.F2.8)

- Para a gerente, se houver falta de materiais, principalmente para o exame de escarro na UBS, é por falha da equipe, que na solicitou o material (Ger.F2.9)

- Para a gerente, há necessidade de organização do fluxo interno para controlar os materiais e não deixar faltar, o que não existe atualmente (Ger.F2.10)

- Para a gerente, a UBS deve ser a porta de entrada para os casos de tuberculose e não as Unidades de Especialidades (Ger.F2.11)

- Gerente refere que o TS iniciou há 3 meses na UBS por conta do trabalho de uma nova enfermeira no serviço (Ger.F2.12)

- Segundo a gerente, o TS é realizado pela equipe de enfermagem (Ger.F2.13)

- Segundo a gerente, foi montada uma pequena equipe composta por uma enfermeira e dois auxiliares de enfermagem, para pensar a organização do serviço de vigilância (Ger.F2.14)

- Segundo a gerente, a equipe da vigilância tem uma ajuda da enfermeira da EE-USP, que encaminha alguns relatórios que ficam pendentes na UBS (Ger.F2.15)

- Para a gerente, a enfermeira do PSF é sobrecarregada, pois tem a vigilância, o acolhimento e os pacientes da área para dar conta. (Ger.F2.16)

- Segundo a gerente, existe uma organização do trabalho na vigilância, onde a enfermeira é responsável pelos relatórios, pedido de medicação, enquanto o auxiliar de enfermagem é responsável pelo livro de registro de casos, SINAN e oferecer o TS 9Ger.F2.17)

- Segundo a gerente, o auxiliar de enfermagem é responsável por oferecer a medicação no TS (Ger.F2.18)

- A gerente refere que o TS não é realizado diariamente, mas não ter certeza se os dias de TS são segunda, quarta e sexta (Ger.F2.19) 
- Para a gerente, a UBS não tem espaço físico para realizar o TS diariamente na UBS (Ger.F2.20)

- Para a gerente, a UBS não está sensibilizada para atender casos de tuberculose (Ger.F2.21)

- Segundo a gerente, a UBS está num outro momento que é de organização para começar o trabalho corretamente, então o foco ainda não é a tuberculose (Ger.F2.22)

- Para a gerente, os Agentes Comunitários de Saúde, os médicos e enfermeiras estão sensibilizados sobre tuberculose (Ger.F2.23)

- Para a gerente, a UBS não funciona como uma Busca Ativa, pois os casos que chegam não foram diagnosticados na UBS (Ger.F2.24)

- Para a gerente, a realização do TS não atrapalha, pois foi classificado como prioridade na UBS (Ger.F2.25)

- Segundo a gerente, o TS não atrapalha, mas exige dispender recurso humano e ter organização de trabalho (Ger.F2.26)

- Para a gerente, atualmente, a atividade do TS já está "orgânica" na UBS, mas não é uma atividade tranqüila (Ger.F2.27)

- Segundo a gerente, o TS é oferecido para todos os pacientes (Ger.F2.28)

- Segundo a gerente, o TS é um meio de segurar os casos de tuberculose (Ger.F2.29)

- Segundo a gerente, o TS permite manter o vínculo com o doente, pois eles moram perto da UBS (Ger.F2.30)

- Segundo a gerente, foi mantida a decisão da enfermeira da vigilância em manter o TS 3 vezes por semana (Ger.F2.31)

- Para a gerente, no atual processo de organização do serviço, o TS é importante para manter o "Tom" da vigilância (Ger.F2.32)

- Para a gerente, o TS é importante para manter o compromisso da equipe de vigilância com o doente (Ger.F2.33)

- Para a gerente, existe preconceito por parte de alguns funcionários da UBS para com os pacientes sob TS na UBS (Ger.F2.34)

- Segundo alguns funcionários já expressaram o medo em pegar a tuberculose por conta dos pacientes que estão sob TS na UBS (Ger.F2.35)

- Gerente refere orientar os funcionários a terem medo dos casos que não foram diagnosticados, para diminuir o estigma (Ger.F2.36)

- Segundo a gerente, os pacientes verbalizam, choram por conta do preconceito que sentem no ambiente de trabalho (Ger.F2.37)

- Para a gerente, as pessoas não sabem sobre o tratamento da tuberculose, e que após o tratamento a pessoa deixa de eliminar o bacilo (Ger.F2.38)

- Para a gerente, trabalhar com a vigilância é complicado, pois são doenças que a pessoa sente-se azarada (Ger.F2.39)

\section{Profissional de Saúde da UBS F (F1)}

- Caracterização do profissional (AE.F1.1)

- Auxiliar de enfermagem refere trabalhar na equipe do PSF e desenvolve atividades na vigilância epidemiológica (AE.F1.2)

- Auxiliar de enfermagem caracteriza o TS na UBS (AE.F1.3)

- Auxiliar de enfermagem refere que desenvolve muitas atividades no dia a dia, e precisa se "desdobrar" para realizá-las (AE.F1.4)

- Segundo o auxiliar de enfermagem, existe na UBS uma equipe responsável pela vigilância epidemiológica que é composta pela enfermeira e dois auxiliares de enfermagem (AE.F1.5)

- Auxiliar de enfermagem refere que a outra auxiliar de enfermagem que também atua na vigilância está afastada (AE.F1.6) 
- Segundo o auxiliar de enfermagem, não foi oferecido treinamento, mas tiveram um "bate papo" sobre vigilância na SUVIS (AE.F1.7)

- Para o auxiliar de enfermagem, o aprendizado para atuar na vigilância acontece no dia a dia, com a própria equipe (AE.F1.8)

- Segundo o auxiliar de enfermagem, o TS na UBS é caracterizado pela observação da ingesta do medicamento pelo doente, logo em seguida o oferecimento do lanche e a assinatura do contrato pelo doente (AE.F1.9)

- Para o auxiliar de enfermagem, o correto seria o doente comparecer a UBS diariamente, mas pelas dificuldades do doente, o TS é realizado 3 vezes por semana (AE.F1.10)

- Auxiliar de enfermagem refere que é disponibilizado o passe para os doentes que moram distante da UBS (E.F1.11)

- Auxiliar de enfermagem refere que é preciso procurar saber o motivo do paciente ter faltado no TS (AE.F1.12)

- Segundo o auxiliar de enfermagem, para iniciar o TS, a equipe de saúde conversa com o doente sobre as possibilidades de ele comparecer na UBS para o TS (AE.F1.13)

- Auxiliar de enfermagem refere que o paciente tem direito a receber o lanche, passe (se necessário) e a cesta básica após o primeiro mês de tratamento (AE.F1.14)

- Auxiliar de enfermagem refere a necessidade de conversar com o doente, pois as medicações têm efeitos adversos que podem não facilitar a adesão do doente ao tratamento (AE.F1.15)

- Auxiliar de enfermagem refere que alguns pacientes sob TS fazem uso de bebida alcoólica, mas que é necessário conversar com o doente, reforçando a manutenção do tratamento (AE.F1.16)

- Auxiliar de enfermagem refere que um paciente sob TS, a equipe de saúde precisa estar atenta, "pegar no pé" (AE.F1.17)

- Auxiliar de enfermagem refere ser o responsável por oferecer a medicação no TS (AE.F1.18)

- Para o auxiliar de enfermagem, sendo a adesão complicada, o paciente precisa ser atendido prontamente, não ficar esperando para evitar o abandono do tratamento (AE.F1.19)

- Auxiliar de enfermagem refere não saber se algum paciente está sob TS no domicílio (AE.F1.20)

- Segundo o auxiliar de enfermagem, todos os casos na UBS serão mantidos sob TS (AE.F1.21)

- Para o auxiliar de enfermagem, o TS permite ter certeza de que o paciente está tomando a medicação (AE.F1.22)

- Para o auxiliar de enfermagem, o TS permite que o paciente seja estimulado a aderir ao tratamento pelo profissional de saúde (AE.F1.23)

- Segundo o auxiliar de enfermagem, os pacientes ficam com todas as medicações e as trazem para tomar sob supervisão na UBS (AE.F1.24)

- Para o auxiliar de enfermagem, o lanche e a cesta básica são incentivos para o paciente manter o tratamento (AE.F1.25)

- Para o auxiliar de enfermagem, o paciente com tuberculose é excluído da sociedade, os amigos se distanciam dele (AE.F1.26)

- Segundo o auxiliar de enfermagem, quando o paciente fala no TS, a equipe entra em contato por telefone, caso ele não seja localizado, o Agente Comunitário de Saúde vai até a casa dele para saber o que aconteceu (Ae.F1.27)

- Para o auxiliar de enfermagem, a equipe de saúde deve apoiar o doente para manter o tratamento, pois a equipe de saúde não sabe as dificuldades que o doente tem na casa com os familiares como rejeição, isolamento (AE.F1.28)

- Para o auxiliar de enfermagem não há pontos negativos no TS, mas a equipe precisa se dedicar ao trabalho (AE.F1.29)

- Auxiliar de enfermagem refere como ponto negativo, sob a visão de paciente, a necessidade de deslocar-se para a UBS quando este trabalha ou tem filhos (AE.F1.30)

- Para o auxiliar, o vínculo com o doente é "tudo", é toda a base do TS (AE.F1.31) 
- Para o auxiliar de enfermagem, o vínculo é o principal pilar para manter o paciente manter a adesão ao tratamento (AE.F1.32)

- Para o auxiliar de enfermagem, o paciente não pode esperar muito tempo por atendimento, pois isso pode ser motivo para ele abandonar o tratamento (AE.F1.33)

\section{Profissional de Saúde da UBS F (F3)}

- Caracterização do profissional (Enf.F3.1)

- Segundo a enfermeira, essa é a primeira experiência de trabalho em UBS (Enf.F3.2)

- Segundo a enfermeira, a UBS não tinha organizado o trabalho na vigilância epidemiológica, que era desenvolvido por vários trabalhadores e cada um fazia o que sabia (Enf.F3.3)

- Segundo a enfermeira, ao entrar na UBS ela ficou responsável por organizar uma comissão para atuar na vigilância (Enf.F3.4)

- Enfermeira refere que seu contato com o TS foi a partir do trabalho na organização da vigilância (Enf.F3.5)

- Enfermeira refere que o TS é o paciente tomar a medicação na unidade, sob a observação de um profissional, durante todo o tratamento (Enf.F3.6)

- Segundo a enfermeira, o TS é realizado sempre pela manhã (7:30 - 8:00), o paciente toma a medicação, recebe o lanche, ele recebe orientações, é conversado com o doente sobre possíveis reações medicamentosas, dúvidas do doente e em seguida ele é dispensado (Enf.F3.7)

- Segundo a enfermeira, ela também realiza o TS junto aos pacientes que atende na área de abrangência na equipe do PSF em que atua (Enf.F3.8)

- Enfermeira refere fazer o TS por conta do vínculo que o TS permite criar (Enf.F3.9)

- Para a enfermeira, o TS é importante por ajudar na criação de vínculo com o doente (Enf.F3.10)

- Para a enfermeira, o TS permite a garantia do término do tratamento pelo doente (Enf.F3.11)

- Enfermeira refere não ter sido treinada para atuar no PCT (Enf.F3.12)

- Segundo a enfermeira, atualmente a organização do serviço da vigilância e do PCT depende da leitura dos manuais e contatos para esclarecimento de dúvidas junto a SUVIS via telefone, conforme as necessidades da rotina de trabalho (Enf.F3.13)

- Segundo a enfermeira, o paciente resistente a algum medicamento, fica sob TS diário (Enf.F3.14)

- Segundo a enfermeira, os pacientes "percebidos" pela equipe como mais responsáveis com o tratamento, ficam sob TS 3 vezes por semana (Enf.F3.15)

- Segundo a enfermeira, a freqüência do TS é definida junto com o doente (Enf.F3.16)

- Segundo a enfermeira, o DOT é formalizado junto ao paciente a partir do contrato que apresenta os dias e horários da realização do TS (Enf.F3.17)

- Para a enfermeira, o ponto negativo do TS é ser burocrático (Enf.F3.18)

\section{Unidade Básica de Saúde G}

\section{Coordenador da UBS G (G1)}

- Caracterização do profissional (Ger.G1.1)

- Gerente refere que desde a formação trabalha em UBS (Ger.G1.2) 
- Para a gerente, o TS significa a UBS controlar o uso da medicação pelo doente para saber se o tratamento está sendo realizado (Ger.G1.3)

- Para a gerente, o compromisso da sanitarista em fazer controle rigoroso dos casos de tuberculose, ligar para o doente se ele falta em consulta é um TS (Ger.G1.4)

- Para a gerente, o PCT funciona, pois a UBS tem a sanitarista (Ger.G1.5)

- Gerente refere não saber a quanto tempo a UBS oferece TS (Ger.G1.6)

- Gerente refere não saber se o TS é feito na UBS, tem certeza apenas da doença esquistossomose (Ger.G1.7)

- Gerente refere que o TS traria muito impacto na rotina da UBS como o TS diário, pois a UBS não dispõe de recursos humanos (Ger.G1.8)

- Segundo a gerente, muitos funcionários estão aposentando e não estão sendo substituídos pela prefeitura do Município 9Ger.G1.9)

- Para a gerente, é necessário ter um local apropriado para o TS na UBS, oferecer alguma coisa ao doente, ter um profissional que veja as medicações, e que anote no prontuário (Ger.G1.10)

- Para a gerente, o objetivo da UBS é diminuir a disseminação da tuberculose e controlar os casos de bacilíferos (Ger.G1.11)

Profissional de Saúde da UBS G (G2)

- Caracterização do profissional (Méd.G2.1)

- Caracterização do TS (Méd.G2.2)

- Sanitarista refere que na UBS, é responsável por toda a vigilância (Méd.G2.3)

- Sanitarista refere que o TS é dirigido aos pacientes que tem dificuldade de aderir ao tratamento (Méd.G2.4)

- Para a sanitarista, o TS exige que o paciente tome a medicação na UBS sob a supervisão de um profissional de saúde, e por conta do recebimento da cesta básica, o paciente adere ao TS (Méd.G2.5)

- Segundo a sanitarista, a equipe de saúde não costuma fazer o TS, que seria o paciente tomar a medicação sob supervisão do trabalhador da saúde, por falta de recursos humanos (Méd.G2.6)

- Para a sanitarista, se a UBS dispusesse do PSF, seria fácil desenvolver o TS na UBS ou no domicílio (Méd.G2.7)

- Para a sanitarista refere que o TS é mais eficiente do que o tratamento auto administrado (Méd.G2.8)

- Para a sanitarista, os pacientes que são resistentes ao tratamento, o TS é feito na UBS diariamente, quase "uma coisa compulsória" (Méd.G2.9)

- Sanitarista refere que quando algum paciente precisa de monitoramento, a equipe de saúde elege uma pessoa da família que faz a supervisão (Méd.G2.10)

- Sanitarista refere que o TS é feito na UBS quando a equipe não consegue o apoio de um familiar para o monitoramento (Méd.G2.11)

- Segundo a sanitarista, todos os pacientes incluídos no PCT recebem a cesta básica, pois são muito carentes (Méd.G2.12)

- Sanitarista refere que os pacientes muito diferenciados não recebem cesta básica (Méd.G2.13)

- Segundo a sanitarista, quando o paciente é monitorado por um familiar, ele adere melhor ao tratamento (Méd.G2.14)

- Sanitarista refere fazer visitas domiciliárias aos pacientes periodicamente (Méd.G2.15)

- Segundo a sanitarista, os pacientes que mantém o tratamento corretamente não é vinculado supervisão do tratamento (Méd.G2.16)

- Para a sanitarista, a favela da Vila Alba é uma área de risco, é uma área grande a maioria dos trabalhadores desconhece essa informação (Med.G2.17) 
- Segundo a sanitarista, o diretor anterior da UBS tinha interesse pelo trabalho da vigilância e eram feitas articulações com OnGs para trabalhar a questão da tuberculose na região (Méd.G2.18)

- Segundo a sanitarista, já foram realizados trabalhos de busca ativa por ONGs,, sem resultados positivos (Méd.G2.19)

- Para a sanitarista, os casos que chegam à UBS são graves e não foram detectados durante a busca ativa (Méd.G2.20)

- Para a sanitarista, a busca ativa realizada na área de abrangência, conseguiu captar sintomáticos respiratórios, mas não conseguiu captar os doentes (Méd.G2.21)

- Segundo a sanitarista, os doentes percebem-se doentes, mas a maioria desconfia que seja pneumonia ou sinusite, pois passam por vários serviços e nunca recebe o diagnóstico de tuberculose (Méd.G2.22)

- Para a sanitarista, os serviços de saúde subestimam o diagnóstico de tuberculose, não perguntam se o doente está com tosse, sinais de cansaço respiratório ou fazem raio $X$ (Méd.G2.23)

- Para a sanitarista, alguns pacientes a procuram na UBS, pois algum conhecido do doente refere que ele pode ter tuberculose, pois os serviços de saúde não fazem diagnóstico de TB (Méd.G2.24)

- Para a sanitarista, se a UBS tivesse o PSF, a equipe de saúde alcançaria os doentes (Méd.G2.25)

- Para a sanitarista, depende do profissional que está na porta do serviço (na UBS ou hospital) para pensar em TB, isso seria o correto para pegar vários casos (Méd.G2.26)

- Sanitarista refere casos que após a internação no Hospital foi solicitado BK e descobriuse a tuberculose (Méd.G2.27)

- Segundo a sanitarista, a equipe tem dificuldade de fazer com que o doente vá até a UBS para fazer os exames necessários, pois UBS é longe da casa (Méd.G2.28)

- Segundo a sanitarista, o atendimento de tuberculose nesta UBS é bem antigo (Méd.G2.29)

- Sanitarista refere que os funcionários que estão se aposentando não estão sendo repostos (Méd.G2.30)

- Para a sanitarista, para o PCT funcionar é importante ter o Agente Comunitário, que é uma pessoa da comunidade, para fazer a busca ativa constantemente e fazer o TS (Méd.G2.31)

- Sanitarista refere que sua visitadora sanitária está em desvio de função por falta de funcionários na UBS (Méd.G2.32)

- Sanitarista refere não ter funcionários para realizar as visitas domiciliares, e atualmente é ela quem se desloca para esse trabalho (Méd.G2.33)

- Para a sanitarista, o TS evita o abandono do tratamento (Méd.G2.34)

- Para a sanitarista, na UBS não está sendo realizado o TS como deveria acontecer, pois TS é quando o paciente está dentro da UBS tomando a medicação sob a supervisão de um auxiliar de enfermagem ou outro trabalhador da saúde (Méd.G2.35)

- Para a sanitarista, a cesta básica faz diferente positiva na manutenção do tratamento pelo doente, pois os doentes necessitam desse benefício (Méd.G2.36)

- Para a sanitarista, no Brasil o PCT não funcionaria sem a cesta básica (Méd.G2.37)

- Sanitarista refere que a falta de recursos humanos é o ponto negativo do TS (Méd.G2.38)

- Para a sanitarista, todas as UBS deveriam ter o Agente Comunitário de Saúde para trazer as pessoas para a UBS (Méd.G2.39)

- Segundo a sanitarista, os pacientes doentes chegam com a doença já grave, podendo já ter contaminado muitas pessoas (Méd.G2.40)

- Segundo a sanitarista, as condições de moradia das pessoas na vila Alva são precárias, facilitando a disseminação da tuberculose, situação chamada de "ciclo vicioso" (Méd.G2.41)

- Para a sanitarista, a UBS não está conseguindo trabalhar na prevenção e controle dos casos por conta dos doentes que chegam com quadro grave da doença (Méd.G2.42) 


\section{Coordenador da UBS H (H3)}

- Caracterização do profissional (Ger.H3.1)

- Gerente refere que o TS é oferecido para todos os pacientes de TB (Ger.H3.2)

- Para a gerente, o TS garante a adesão ao tratamento e alcançar a cura (Ger.H3.3)

- Para a gerente, o TS é positivo na adesão, pois permite acompanhar mais de perto os pacientes que tem dificuldade em aderir ao tratamento, e ofertar apoio psicológico (Ger.H3.4)

- Para a gerente, o TS é absorvido na rotina do CR, sem prejuízos (Ger.H3.5)

- Segundo a gerente, o TS é realizado No CR (Ger.H3.6)

- Para a gerente, o TS é um investimento que oferece retorno, e "vale a pena" (Ger.H3.7)

- Gerente refere que a equipe de saúde procura fazer com que o doente participe na CR (Ger.H3.8)

- Para a gerente, o TS permite um espaço para acompanhar os comunicantes (Ger.H3.9)

- Para a gerente, o momento do TS é o momento para abordar as dificuldades no tratamento, assim como o uso correto da medicação (Ger.H3.10)

- Para a gerente, a atenção aos pacientes com Aids e tuberculose deve ser redobrado, pois a intolerância pode ser maior (Ger.H3.11)

- Gerente refere que o TS é oferecido para os pacientes usuários de drogas, pois considera-os mais difíceis em manter a adesão ao tratamento (Ger.H3.12)

- Para a gerente, a forma de contágio da tuberculose expõe mais as pessoas, o que merece atenção redobrada da equipe de saúde (Ger.H3.13)

- Para a gerente, é importante garantir o acompanhamento do doente, HIV positivo para que ele alcance a cura o mais rápido possível (Ger.H3.14)

- Gerente refere que os pacientes que "dão trabalho" na adesão ao tratamento, a equipe insiste para o doente aceite o TS (Ger.H3.15)

- Para a gerente, a equipe tem dificuldade em realizar o TS, pois o serviço não possui uma área de abrangência, é aberto, inclusive para outros municípios e as vezes distante para o doente comparecer diariamente (Ger.H3.16)

- Para a gerente, o paciente não quer se tratar próximo da residência por conta da questão do sigilo do HIV e da tuberculose e não pode comparecer no CR por ser longe de casa e do local de trabalho (Ger.H3.17)

- Para a gerente, alguns pacientes que fazem o tratamento da tuberculose não possuem registro em carteira, portanto não tem o auxílio doença para ficar em casa e recuperarse, dessa forma, ao sentirem-se em condições, voltam ao trabalho (Ger.H3.18)

\section{Profissional de Saúde da UBS H (H1)}

- Caracterização do profissional (Enf.H1.1)

- Enfermeira refere que seu trabalho no dia a dia é coordenar a equipe de enfermagem, além disso, fazer 0 acolhimento dos pacientes, dar assistência ao paciente e supervisionar os auxiliares de enfermagem (Enf.H1.2)

- Para a enfermeira, o número de enfermeiras é pequeno, impedindo que a enfermeira preste assistência ao doente (Enf.H1.3)

- Segundo a enfermeira, ela não trabalha diretamente com a vigilância, mas acompanha os casos mais complicados, "complexos" (Enf.H1.4)

- Segundo a enfermeira, os casos classificados como complicados são os pacientes usuários de drogas, e outros complicados que apresentam risco de não manter o tratamento corretamente (Enf.H1.5)

- Segundo a enfermeira, mesmo os casos complicados estão conseguindo terminar o tratamento (Enf.H1.6) 
- Para a enfermeira, o TS é aquele que é feito na UBS ou no domicílio do doente, e o paciente toma a medicação na frente do profissional de saúde (Enf.H1.7)

- Segundo a enfermeira, no TS o paciente toma a medicação em jejum no domicílio e apenas a medicação pirazinamida sob a supervisão da equipe, nas segundas, quartas e sextas feiras (Enf.H1.8)

- Para a enfermeira, o TS é para pegar no pé e cobrar do doente a manutenção do tratamento (Enf.H1.9)

- Segundo a enfermeira, ela tinha um contrato com a paciente de fazer o TS as segundas, quartas e sextas feiras no período da tarde (período de trabalho da enfermeira) (Enf.H1.10)

- Segundo a enfermeira, na sua ausência, a auxiliar de enfermagem faz o TS (Enf.H1.11)

- Segundo a enfermeira, no dia da consulta da paciente, ela tomava a medicação no período da consulta (Enf.H1.12)

- Enfermeira refere não saber se o TS é oferecido para todos os pacientes (Enf.H1.13)

- Para a enfermeira, o acompanhamento dos pacientes com tuberculose, quanto a assistência de enfermagem está falho (Enf.H1.14)

- Segundo a enfermeira, os casos que necessitam do TS (casos de abandono) são encaminhados para ela pela assistente social ou pelo médico do paciente (Enf.H1.15)

- Para a enfermeira, realizar o TS é acompanhar mais de perto o doente (Enf.H1.16)

- Segundo a enfermeira, o atual caso sob TS já avisou que, quando falta na supervisão é porque está no mundo das drogas (Enf.H1.17)

- Segundo a enfermeira, quando o paciente falta no TS, a equipe entra em contato e busca o doente (Enf.H1.18)

- Segundo a enfermeira, o atual caso sob TS só aceita o TS por conta do recebimento de passe, ela considera uma troca com a paciente (Enf.H1.19)

- Para a enfermeira, o que interessa no TS é BK negativo, como o atual caso, apesar das dificuldades (Enf.H1.20)

- Segundo a enfermeira, a paciente não está recebendo a cesta básica, pois atrasa a entrega (Enf.H1.21)

- Segundo a enfermeira, a paciente troca o passe por droga, mas mesmo assim, o que é importante é que os exames da paciente sejam negativos (Enf.H1.22)

- Enfermeira refere que o TS é positivo e ideal, pois garante a precocidade no controle da transmissão da TB (Enf.H1.23)

- Para a enfermeira, são poucos os pacientes que tomam corretamente a medicação e outros não conseguem tomar sem supervisão (Enf.H1.24)

- Para a enfermeira, alguns pacientes precisam ter alguém junto para que mantenha corretamente o tratamento (Enf.H1.25)

- Para a enfermeira, o paciente fica mais envolvido com o profissional que oferece a medicação do que com o tratamento (objetivo de obter a cura) (Enf.H1.26)

- Para a enfermeira, o ponto negativo do TS é quando o paciente não faz o tratamento com a intenção de obter a cura ou não transmitir mais a doença, mas receber cesta básica ou passe (Enf.H1.27)

- Para a enfermeira, a oferta de benefícios como: passe e cesta básica é a única forma de assegurar o término do tratamento junto ao doente (Enf.H1.28)

- Enfermeira refere que a atual paciente em TS, apesar de não tomar mais a medicação no $\mathrm{CR}$, continua sob a supervisão para que a equipe possa pegar no pé para manter o tratamento (Enf.H1.29)

- Enfermeira refere que para fazer TS, é necessária a dedicação do profissional de saúde (Enf.H1.30)

- Para a enfermeira, falta recurso humano no CR para que se realize a assistência de enfermagem (Enf.H1.31)

- Segundo a enfermeira, ela é a única enfermeira que presta assistência direta ao doente durante o acolhimento (Enf.H1.32)

- Segundo a enfermeira, o atual caso sob TS não conseguiu manter o tratamento da Aids e da tuberculose ao mesmo tempo, então a equipe orientou a paciente a manter o tratamento da TB, que é prioridade (Enf.H1.33) 
- Para a enfermeira, o tratamento da tuberculose é prioridade (Enf.H1.34)

\section{Profissional de Saúde da UBS H (H2)}

- Caracterização do profissional (AE.H2.1)

- A auxiliar de enfermagem refere não trabalhar na vigilância, mas tem grande envolvimento com os pacientes por ser um local de trabalho diferenciado (AE.H2.2)

- A auxiliar de enfermagem refere ser responsável pelo TS na ausência da enfermeira (AE.H2.3)

- Para a auxiliar de enfermagem, o TS é indicado para os pacientes que não são "assíduos" no uso da medicação (AE.H2.4)

- Para a auxiliar de enfermagem, o TS é "ver" se o paciente está fazendo o tratamento corretamente (AE.H2.5)

- Para a auxiliar de enfermagem, o TS inclui conversar com o doente, saber o que está acontecendo com a saúde para saber o que o impede de fazer o tratamento corretamente (AE.H2.6)

- Segundo a auxiliar de enfermagem, quando o paciente falta no TS é importante ligar pra saber o motivo do doente em ter faltado (AE.H2.7)

- A auxiliar de enfermagem refere não ter recebido treinamento para realizar o TS (AE.H2.8)

- Para a auxiliar de enfermagem, o TS é uma estratégia interessante, mas que não deveria ser necessário, pois o paciente deveria ter consciência da importância do tratamento (AE.H2.9)

- Para a auxiliar de enfermagem, alguns pacientes precisam de alguém para cobrar que o tratamento seja realizado corretamente, assim como a vinda para a consulta (AE.H2.10)

- Para a auxiliar de enfermagem, os pacientes atendidos no CR são diferenciados (AE.H2.11)

- Segundo a auxiliar de enfermagem, existe uma equipe no $C R$ responsável por controlar a falta dos doentes seja em consulta ou mesmo no TS (AE.H2.12)

- Para a auxiliar de enfermagem, o positivo do TS é ter um profissional de saúde que tenha conhecimento e esteja preocupado com o paciente (AE.H2.13)

- Para a auxiliar de enfermagem, alguns pacientes desanimam do tratamento por conta da própria doença (AE.H2.14)

- Para a auxiliar de enfermagem, alguns pacientes expressam o medo da doença (AE.H2.15)

- Para a auxiliar de enfermagem, o bom contato que possui com os doentes não acontece por conta de treinamento para pela experiência de trabalho que adquiriu no $\mathrm{CR}$ (AE.H2.16)

- Para a auxiliar de enfermagem, não existem pontos negativos em realizar o TS 9AE.H2.17)

- Para a auxiliar, os doentes não têm consciência da doença e da necessidade de manter o tratamento corretamente (AE.H2.18)

- Para a auxiliar de enfermagem, o TS só existe por que os pacientes não têm consciência de realizar corretamente o tratamento e se cuidar (AE.H2.19)

- Para a auxiliar de enfermagem, o paciente que faz o tratamento corretamente, precisaria de uma supervisão "por cima", para que continue o tratamento (AE.H2.20)

- Para a auxiliar de enfermagem, o TS não atrapalha na rotina de trabalho (AE.H2.21)

- Para a auxiliar de enfermagem, por conta do vínculo com os pacientes é possível conversar e os pacientes compartilham seus problemas (AE.H2.22)

- Para a auxiliar de enfermagem, por conta do vínculo, é possível incentivar o doente a se tratar (AE.H2.23) 


\section{Coordenador do PCT e DOTS I (I1)}

- Caracterização do profissional (COO.I1.1)

- Coordenadora refere que não existe uma pessoa responsável por coordenar a DOTS na região (COO.I1.2)

- Coordenadora refere ser responsável por coordenar as 16 UBS, o ambulatório de especialidades Peri Peri e o CRTAids (COO.I1.3)

- Responsável refere que TS é ver o paciente engolir a medicação (COO.I1.4)

- Para a coordenadora do PCT, o TS é preconizado na fase de ataque do tratamento, e depois manter 2 a 3 supervisões por semana (COO.I1.5)

- Para a coordenadora do PCT, em algumas situações a equipe de saúde precisa ir até o doente (no domicílio), que são: acamados ou sob tratamento diferente do esquema padrão (COO.I1.6)

- Segundo a coordenadora do PCT, após o recebimento dos incentivos pelas UBS, houve aumento no oferecimento do TS (COO.I1.7)

- Segundo a coordenadora do PCT, a justificativa para não ter o TS nas UBS era a falta dos incentivos (cesta básica e lanches) (COO.I1.8)

- Coordenadora refere que os lanches são oferecidos após a tomada da medicação pelo doente na unidade, e que é entregue a medicação e o lanche a ser tomado no final de semana (COO.I1.9)

- Para a coordenadora, o TS tem que ser oferecido para $100 \%$ dos casos (COO.I1.10)

- Para a coordenadora, o TS deve ser oferecido para todos os pacientes, mas deve-se considerar a história do doente para decidir como será realizado o TS (COO.I1.11)

- Segundo a coordenadora do PCT, após o primeiro mês de tratamento correto sob TS, os pacientes são inscritos para receber a cesta básica (COO.I1.12)

- Coordenadora refere que as UBS resistem em aceitar o TS, pois nem os incentivos dos lanches querem receber (COO.I1.13)

- Segundo a coordenadora, são apresentados dados de que o TS é mais efetivo no controle da tuberculose nas reuniões de gerência, mas muitas UBS não aceitam (COO.I1.14)

- Coordenadora refere não saber como o TS é desenvolvido nas UBS (COO.I1.15)

- Para a coordenadora, a depender do perfil do doente, pode-se solicitar que um familiar controle a ingesta da medicação pelo doente (COO.I1.16)

- Para a coordenadora do PCT, muitos pacientes são etilistas, dificultando a manutenção do tratamento (COO.I1.17)

- Segundo a coordenadora do PCT, após o início do TS os casos de retratamentos por abandono diminuíram (COO.I1.18)

- Segundo a responsável, o sistema de informação sobre tuberculose não era tão organizado e apurado como atualmente (COO.I1.19)

- Segundo a coordenadora, o TS está sendo desenvolvido há 3 anos, após i início do recebimento dos benefícios (lanches e cesta básica) pela Secretaria Municipal de Saúde (COO.I1.20)

- Responsável refere que o TS é o meio para melhorar as taxas de cura e diminuir o abandono, diminuir a resistência aos medicamentos e melhorar o serviço de saúde (COO.I1.21)

- Para a coordenadora do PCT, o TS permite organizar a UBS, pois desde o médico até a recepção precisam falar a mesma língua (COO.I1.22)

- Para a coordenadora do PCT, falta sensibilidade aos trabalhadores sobre o TS, assim como organização dos serviços para identificar trabalhadores com perfil para atuar no TS (COO.11.23)

- Para a coordenadora do PCT, as UBS que desenvolvem o TS não alcançam $100 \%$ por conta das dificuldades do doente em comparecer na UBS (COO.I1.24)

- Para a coordenadora, quando a UBS implanta o TS, o trabalho acontece normalmente na UBS (COO.I1.25) 
- Para a coordenadora, fazer o TS na unidade exige que a unidade preencha o leque de impressos e encaminhe para a SUVIS (COO.I1.26)

- Para a coordenadora do PCT, o TS não apresenta ponto negativo (COO.I1.27)

- Para a coordenadora do PCT, o programa da tuberculose é completo e complexo por conta das planilhas (COO.I1.28)

- Para a coordenadora do PCT, muitas UBS não aceitam o TS por conta dos impressos complexos a serem preenchidos (COO.I1.29)

- Para a coordenadora do PCT, o programa de controle da tuberculose permite resgatar o doente, chegando até o local onde ele está (COO.I1.30)

- Para a coordenadora do PCT, é necessário que a equipe para atuar no TS tenha perfil para essa modalidade de tratamento (COO.I1.31)

- Para a coordenadora do PCT, o TS permitiu melhorar as taxas de cura na região do Butantã, "bom impacto" (COO.I1.32)

- Para a coordenadora, alguns casos atendidos permitem a troca de experiências com a equipe do CCD (COO.I1.33)

- Responsável refere que, quando chegaram os incentivos para a realização do TS, a equipe da vigilância da SUVIS realizou uma reunião com pessoas de todas as unidades para apresentar os impressos, quem teria direito e o que era o TS (COO.I1.34)

- Para a coordenadora, o TS permite um maior envolvimento do doente com o profissional de saúde (COO.I1.35)

- Para a coordenadora do PCT, o TS facilita o atendimento do doente, caso ele esteja passando mal (COO.I1.36)

- Para a coordenadora do PCT, o doente sabe quais as UBS que oferecem benefícios, então eles cobram da UBS próxima da casa dele que não oferece (COO.I1.37)

- Segundo a coordenadora do PCT, é reforçado para as UBS a necessidade de oferecer o TS para $100 \%$ dos doentes (COO.I1.38)

- Para a coordenadora do PCT, o TS gera impacto na rotina dos serviços de saúde (COO.I1.39)

- Para a coordenadora do PCT, o TS atrapalha a dinâmica diária da UBS (COO.I1.40)

- Para a coordenadora do PCT, já existiram problemas na distribuição das cestas básicas, mas atualmente, é apenas necessário atualizar as fichas (COO.I1.41)

- Para a coordenadora, o atual problema na entrega da cesta básica aos doentes, acontece pela dificuldade dos entregadores entrarem nas vielas das favelas (COO.I1.42)

- Segundo a coordenadora do PCT, o doente tem a opção de retirar a cesta básica na loja da responsável pela distribuição, mas por dificuldades de transporte, sempre é oferecido para ser entregue no domicílio do doente (COO.I1.43)

- Coordenadora do PCT refere que quando os distribuidores não encontram o endereço, o CCD é avisado para que a unidade confirme o endereço (COO.I1.44)

- Coordenadora do PCT refere desconhecer que não há entrega mensal das cestas básicas (COO.I1.45)

- Coordenadora do PCT refere que em anos anteriores, eram feitos encontros para discutir as questões da tuberculose no Distrito (COO.I1.46)

- Coordenadora do PCT refere que a SUVIS tem recebido muitas ligações solicitando orientação para acompanhamento de casos, então está sendo pensada a retomada dessas reuniões bimestrais (COO.I1.47)

- Coordenadora do PCT refere que o propósito das reuniões, não será o TS, mas o acompanhamento da tuberculose (COO.I1.48)

- Coordenadora do PCT refere que quando os profissionais de saúde precisam aprender sobre a vigilância, eles entram em contato com a SUVIS e é marcado um horário para conhecer como todos trabalham na SUVIS com a vigilância (COO.I1.49)

- Coordenadora do PCT refere ter conhecimento dos casos a partir do controle das cestas básicas e o contato com os responsáveis pela vigilância nas unidades (COO.I1.50). 